\title{
Predictive Skill and Predictable Patterns of the U.S. Seasonal Precipitation in CFSv2 Reforecasts of 60 Years (1958-2017)
}

\author{
BOHUA HuANG AND CHUL-SU SHIN \\ Department of Atmospheric, Oceanic, and Earth Sciences, and Center for Ocean-Land-Atmosphere \\ Studies, George Mason University, Fairfax, Virginia \\ ARUN KUMAR \\ Climate Prediction Center, NOAA/NWS/National Centers for Environmental Prediction, College Park, Maryland
}

(Manuscript received 26 March 2019, in final form 1 September 2019)

\begin{abstract}
Analyzing a set of ensemble seasonal reforecasts for 1958-2017 using CFSv2, we evaluate the predictive skill of the U.S. seasonal mean precipitation and examine its sources of predictability. Our analysis is for each of the three periods of 1958-78, 1979-99, and 2000-17, corresponding to the positive phase of the Pacific decadal oscillation (PDO) during 1979-99 and negative ones before and after. The ensemble reforecasts at two-month lead reproduce the spatial distribution of winter precipitation trends throughout the 60 years and the continental-scale increase of summer precipitation since 2000 . The predicted signalto-noise $(\mathrm{S} / \mathrm{N})$ ratio also reveals greater predictability in the post-1979 period than during 1958-78. A maximized $\mathrm{S} / \mathrm{N}$ ratio EOF analysis is applied to the ensemble seasonal precipitation predictions. In winter and spring, the most predictable patterns feature a north-south dipole throughout United States. The summer and fall patterns are dominated by the anomalies in central and southern United States, respectively. In verification with observations, the winter-spring patterns are more skillful. ENSO influences on these predictable patterns are most dominant in winter and spring, but other oceanic factors also play an active role during summer and fall. The multidecadal change of the U.S. precipitation predictability is attributable to the low-frequency modulation of the ENSO predictability and the influences of other major climate modes. PDO can be a dominant factor associated with enhanced prediction skill in 1979-99 and reduced skill in 1958-78. Since the 2000s, the forcing from the SST anomalies in the tropical North Atlantic with opposite sign to those in the tropical Pacific becomes a significant factor for the U.S. summer precipitation prediction.
\end{abstract}

\section{Introduction}

Severe floods and droughts are among the most costly natural disasters in the United States (e.g., Cayan et al. 1999; Perry 2000; Cook et al. 2007). They pose serious risks to human lives and property and impact the food and water supplies. Furthermore, landsides (e.g., Biasutti et al. 2016), wildfires (e.g., Crockett and Westerling 2018), and heat waves (e.g., Oswald 2018) induced by droughts or floods cause major environmental damage and adverse economical and societal consequences. Since anomalous precipitation strongly influences the onset, intensity, duration, and demise of both floods and droughts, there have been considerable efforts toward understanding the mechanisms and predictability of

Corresponding author: Bohua Huang, bhuang@gmu.edu abnormal precipitation in the United States, ranging from extreme weather causing flash flooding to prolonged rainfall deficits that sustain multiyear droughts.

Many previous studies have identified ENSO as a major source of U.S. seasonal precipitation anomalies (e.g., Ropelewski and Halpert 1986; Barnston and Smith 1996; Dai and Wigley 2000; Hoerling and Kumar 2003; Quan et al. 2006; Seager and Hoerling 2014). For instance, the U.S. drought study establishes that La Niña events tend to cause major droughts in the southwest United States, northern Mexico, and the southern Great Plains (e.g., Mason and Goddard 2001; Mo and Lettenmaier 2018). Extended AMIP simulations forced with observed SST confirm the La NiñaU.S. drought paradigm (see, e.g., Feng et al. 2008; Herweijer et al. 2006; Schubert et al. 2016). In this scenario, the cold equatorial SST anomalies generate a 
northeastward-propagating atmospheric wave train with an anticyclonic anomaly extending to the North America (see, e.g., Seager et al. 2014). This atmospheric teleconnection pattern largely reverses sign during El Niño (e.g., Ropelewski and Halpert 1986; L'Heureux et al. 2015, 2017), although there is still notable asymmetry between the two (e.g., Chiodi and Harrison 2015; Chen et al. 2017).

Beyond ENSO, other SST anomalies in the Pacific also play active roles. Using 70-yr (1930-2000) AMIP ensemble simulations, Schubert et al. (2004) link the Pacific decadal SST fluctuations (e.g., Zhang et al. 1997) with low-frequency precipitation variations of 6 years or longer in the Great Plains, especially during the multiyear Dust Bowl (1932-39). Several studies further note that the SST anomalies in the northwestern tropical Pacific are effective in forcing atmospheric planetary waves propagating into North America. Hoerling and Kumar (2003) found that, after the strong 1997/98 El Niño, remnant warm SST anomalies in the western Pacific and Indian Oceans induced the multiyear U.S. drought from 1998 to 2002. Examining a set of multimodel AMIP ensemble simulations for 1950-99, Quan et al. (2006) found that U.S. fall temperature anomalies can be skillfully predicted by the SST variability in the subtropical western Pacific Ocean and the South China Sea. Seager et al. (2015) showed that the 2012/13 and 2013/14 winter droughts in California were related to a persistent warm-west/cool-east SST dipole in the tropical Pacific. Hartmann (2015) further demonstrated that, in the winter of 2013/14, persistent warm SST anomalies extending from the North Pacific into the northwestern tropical Pacific generated an anomalous ridge in the northeast Pacific with a downstream trough over central North America. In addition to the dominant role of the tropical and subtropical SST anomalies, Ting and Wang (1997) found that the SST anomalies in the North Pacific can modulate the atmospheric jet stream to influence the U.S. summer precipitation.

Many studies demonstrated the roles played by the Atlantic multidecadal variability (AMV) (e.g., Enfield et al. 2001; Schubert et al. 2009; Findell and Delworth 2010; Kushnir et al. 2010). Interestingly, AMV also influences the U.S. precipitation mainly through its subtropical branch during summer. Kushnir et al. (2010) showed that a positive AMV reduces U.S. summer precipitation because its warm tropical branch weakens the subtropical anticyclone in the Atlantic Ocean, which reduces the northward moisture transport at its western end into North America. Indeed, Wang et al. (2008) found that the fluctuation of the Atlantic warm pool, located in the western tropical North Atlantic, is significantly correlated with the summer precipitation over the central United States. Nigam et al. (2011) argued that AMV might be more influential to multiyear droughts in the Great Plains than Pacific SST anomalies.

The interference of the atmospheric responses induced by these SST patterns may be as important as the individual ones in causing and modulating the U.S. precipitation conditions (e.g., Wang et al. 2014). $\mathrm{Hu}$ and Huang (2009) found that a La Niña contemporary to a negative phase of the Pacific decadal oscillation (PDO) is more likely to cause a stronger drought in the Great Plains whereas an El Niño combined with a positive PDO phase enhances a wet condition. Mo et al. (2009) noted that AMV tends to enhance U.S. drought if its tropical Atlantic branch has the opposite sign to the ENSO state. Several studies based on U.S. CLIVAR Drought Working Group idealized climate model simulations (e.g., Weaver et al. 2009) also showed that, although the direct influence of the AMV on U.S. drought is small, it can modulate the remote ENSO effect on U.S. rainfall and drought especially when the SST anomalies in the tropical Pacific and in the North Atlantic are in opposite phase. Therefore, the combination of a cold tropical Pacific with a warm tropical North Atlantic forms the strongest oceanic forcing to U.S. drought (e.g., Schubert et al. 2008).

Although the AMIP simulations with perfect SST information identify the sources of the oceanic forcing to the U.S. precipitation anomalies and provide its potential predictability, they cannot determine how much of the potential is realizable. Some studies estimate the seasonal predictability in the AGCM framework. For instance, Goddard and Mason (2002) conducted AGCM seasonal runs with prescribed persistent SST anomalies. On the other hand, Quan et al. (2006) developed linear regression models from large ensemble AMIP runs between the leading patterns of the SST anomalies and U.S. precipitation or temperature anomalies at oneseason lag, which showed that nearly all the AGCM skill in the U.S. precipitation can be explained by the tropical SST patterns associated with ENSO. These assessments, however, usually involve statistical assumptions and simplifications. Moreover, an AMIP run tends to exaggerate and distort the atmospheric response in certain areas due to its lack of air-sea feedback (e.g., Zhu and Shukla 2013).

The natural next step is to investigate the extent of the potential predictability that can be realized in initialized seasonal climate predictions. There have been major progresses of the dynamical seasonal prediction during the past 25 years (e.g., Barnston et al. 1994; Ji et al. 1994; Stockdale et al. 1998, 2011; Saha et al. 2006, 2014; Kirtman et al. 2014). Current seasonal forecast systems can predict certain oceanic and atmospheric anomalies at seasonal lead times (e.g., Jin et al. 2008; 
Kirtman et al. 2014; Huang et al. 2017a). Jia et al. (2015) evaluated the seasonal prediction skill of the precipitation and 2-m air temperature over global land domain from a set of seasonal reforecasts for the period of 1980-2012 using two versions of the Geophysical Fluid Dynamics Laboratory (GFDL) coupled forecast systems with the purpose of examining the effect of model resolution, while exploring the sources of the prediction skills. Becker and van den Dool (2016) assessed the probabilistic skills of the North American Multimodel Ensemble (NMME) seasonal reforecasts (1982-2010) for ENSO and Northern Hemisphere (NH) SST, tropical precipitation and 2-m air temperature over the $\mathrm{NH}$ land. There have also been studies of the seasonal reforecasts focused on the prediction skill of the U.S. precipitation and its connection to the predictable signals in other variables. Recently, Chen et al. (2017) examined the composite prediction patterns of the U.S. precipitation and temperature by the NMME reforecasts during the El Niño and La Niña events in 1982-2010. They found that the general characteristics of the ENSO-induced precipitation anomalies can be predicted reasonably well with both deterministic and probabilistic measures.

A potential limitation of these previous studies is that the datasets of current seasonal reforecasts generally cover relatively short time spans. Chen et al. (2017) found that their NMME reforecast composite for 1982-2010 bear closer resemblance to the observed composite derived from a longer period (1950-2010) than from its matching period. They attribute this paradoxical result as a manifestation of inadequate sampling in observations for the latter period. With the given number of the ENSO events in 1982-2010, NMME achieves sufficient sampling for a stable reforecast composite through its large number of multimodel ensemble members while the corresponding sampling from observations, equivalent to an ensemble size of one, is insufficient. In addition to the sampling issue, more importantly, the short span of the reforecasts does not provide adequate record to evaluate the effect of the decadal and multidecadal variability on the seasonal predictability (e.g., Ding et al. 2019). A similar limitation may also affect the sufficiency of the statistical postprocessing to improve the skill and reliability of the ensemble forecasting systems. For instance, most hybrid statistical-dynamical seasonal forecast systems of North American temperature and precipitation (e.g., Strazzo et al. 2019) are calibrated with observations of the past 30 years or so due to the limited span of reforecast datasets.

In this study, we evaluate the prediction skill of the U.S. seasonal precipitation and examine its sources of predictability using a set of ensemble seasonal reforecasts from the NCEP Climate Forecast System, version 2 (CFSv2), covering 1958-2017. Conducted at the Center for Ocean-Land-Atmosphere Studies (COLA), the 60-yr CFSv2 reforecasts not only provide more adequate sampling of the observed interannual signals (e.g., historical ENSO events) but also allow us to examine the influences of the decadal-multidecadal climate variability and the long-term trends of climate change on the seasonal prediction and predictability of the U.S. precipitation. We first identify the spatial patterns of the predictable signals in the United States from the reforecasts without presumption, then evaluate their skill and identify the possible sources of predictability. This approach is different from Chen et al.'s (2017) and Strazzo et al.'s (2019) a priori focus on the ENSO-induced U.S. precipitation. We also use a method different from Jia et al. (2015) to identify the predictable patterns and concentrate on the contiguous United States (CONUS).

The rest of the paper is structured as the following. Section 2 describes the version of the CFSv2 reforecast, the observational datasets for verification, and the analysis methodology. Section 3 examines some basic statistical characteristics of the reforecast CONUS precipitation. Section 4 analyzes the most predictable patterns of the CONUS precipitation in different seasons and evaluates their skills. Section 5 further identifies the potential sources of these predictable patterns. Section 6 gives a summary and a discussion.

\section{CFSv2 60-yr reforecast dataset and analysis method}

\section{a. CFSv2 60-yr reforecast}

CFSv2 is a global coupled general circulation model that has been used for operational seasonal prediction at NCEP since April 2011 (Saha et al. 2014). Its atmospheric component is the Global Forecast System (GFS) with a spectral horizontal resolution of T126 (105-km grid spacing) and 64 vertical levels in a hybrid sigmapressure coordinate. The oceanic component is the GFDL Modular Ocean Model version 4 (MOM4) (Griffies et al. 2004), which is configured with 40 vertical levels in a $z$ coordinate and a horizontal tripolar grid with a resolution of approximately $0.5^{\circ}$ latitude $\times 0.5^{\circ}$ longitude poleward of $30^{\circ}$ latitudes, increasing to $0.25^{\circ}$ latitude within $\left.10^{\circ} \mathrm{S}-10^{\circ} \mathrm{N}\right)$. The sea ice component is a 3-layer dynamical sea ice model (Winton 2000) and the land component is the Noah land surface model (Ek et al. 2003). The land (sea ice) model is directly coupled to the atmospheric (ocean) model on its native Gaussian 
(tripolar) grid with surface fluxes transferring through their interface on every time step of the model integration. The atmospheric and ocean-sea ice components exchange surface momentum, heat, and freshwater fluxes, as well as SST and surface information on sea ice every $30 \mathrm{~min}$. More details of the CFSv 2 configuration and coupling procedure, as well as the major subscale physical parameterizations of the component models, can be found in Saha et al. (2010, 2014).

The version of the CFSv2 used in this study is slightly different from the one for the NCEP operational seasonal prediction and the CFS Reanalysis (CFSR) and Reforecast (CFSRR) (Saha et al. 2014). Specifically, we have corrected a coding error in the original CFSv2 that misidentifies the sea ice covered areas in the coupler, resulting in discrepancies in the surface fluxes passing from the atmospheric to the oceanic component over the northern North Atlantic. The correction of this error restores consistency of air-sea surface flux exchange over the global ocean domain and improves the sea ice coverage and SST simulation in the northern oceans (Huang et al. 2015). Based on a series of decadal test runs, we found that the original setting of the albedo parameters causes a gradual reduction of ice thickness even after the correction of the coding error. As a result, the sea ice is unrealistically thin after a few years' integration and the ice coverage becomes seasonal in most places. Therefore, we have increased the dry sea ice albedo from 0.60 to 0.66 in this set of seasonal reforecasts and reduced the temperature range of transition from dry to wet sea ice albedo. Our adjustment of the sea ice albedo parameters leads to realistic ice thickness simulation, permanent ice distribution and improved annual cycle of total ice volume in the northern ocean, as demonstrated in Huang et al. (2015).

Using this version of CFSv2, we produced a set of ensemble reforecasts with 12-month duration initialized at the beginning of January, April, July, and October, respectively, for 1958-2016 and January and April of 2017 (Huang et al. 2017a). Our initialization of the coupled prediction is also different from CFSRR. For the whole period, the ocean initial states are from the instantaneous restart files of the ECMWF Ocean Reanalysis System 4 (ORA-S4) with a set of five-member ensemble assimilation runs (Balmaseda et al. 2013), which are interpolated linearly to the MOM4 grid. Our previous studies (Huang et al. 2015) have shown that the CFSv2 runs initialized by the interpolated monthly fields of the ECMWF ocean reanalysis (a predecessor to ORA-S4) do not generate extra climate drift or initial shock, compared to those initialized with CFSR. In this study, we also do not see a major increase in model bias with the ORA-S4 instantaneous initial states. This is possibly because the NEMO ocean model (Madec 2008) used to produce the ECMWF analysis has a horizontal resolution and vertical levels largely compatible to those of MOM4 used in CFSv2. Our studies (e.g., Zhu et al. 2012; Huang et al. 2017a; Shin et al. 2019) have also shown that the CFSv2 initialized with the ECMWF monthly ocean reanalysis are comparable and, in some cases, slightly better seasonal forecast skills of ENSO and Asian monsoon than those from some other ocean reanalysis products, including CFSR.

The initial conditions for other component models were assembled from several different data sources before and after 1979. Starting in 1979, the atmosphere, land and sea ice initial states were taken from the restart files of the CFS Reanalysis (CFSR) (Saha et al. 2010). For 1958-78, the atmospheric initial states are interpolated from the ERA-40 atmospheric reanalysis (Uppala et al. 2005). The land initial states are interpolated from the Global Land Data Assimilation System, version 2.0, analysis produced by the National Aeronautics and Space Administration (Rui and Beaudoing 2015). We also use a specified annual cycle of sea ice states for 1958-78. An ensemble reforecast of 20 members is generated by matching each of the five ocean initial states at 0000 UTC first of the initial month with the atmospheric and land initial states at 0000 UTC of the first four days while the sea ice initial state is fixed at 0000 UTC first for all ensemble members. More details of the initialization procedure are given in Huang et al. (2017a), which also presented an evaluation of the ENSO prediction skill for the period of 1958-2014.

In this study, the monthly anomalies of all predicted variables are derived as departures from the monthly climatology for each subset of reforecasts initialized in the same calendar month. Furthermore, we define separate monthly climatologies for each of the three periods of 1958-78, 1979-99, and 2000-17 to take into account the influence of multidecadal variations and climate change. The time-dependent $\mathrm{CO}_{2}$ concentrations are prescribed based on historical data for 1958-2009 and a future extrapolation of the concentration values is given with a constant growth rate of $2 \mathrm{ppmv} \mathrm{yr}^{-1}$ since 2010 (Huang et al. 2015). On the other hand, the three periods roughly correspond to the different phases of the PDO/interdecadal Pacific oscillation (IPO; Deser et al. 2004), associated with the two major climate shifts in the late 1970s (Trenberth and Hurrell 1994) and early 2000s (Barnston and Lyon 2016), and the three drywet-dry periods of the U.S. precipitation (Dai 2013). Our analysis is focused on the seasonal precipitations in CONUS for winter [December-February (DJF)], spring [March-May (MAM)], summer [June-August (JJA)], and fall [September-November (SON)] predicted 
at 2-month lead. The 2-month lead refers to the first two months of the model integration from its initial state before the predicted seasonal mean is calculated using the model output from months 3 to 5. For example, the DJF anomalies are derived from the reforecasts initialized in previous October.

For model verification, the Climate Prediction Center (CPC) daily unified gauge-based analysis of precipitation at $0.25^{\circ}$ latitude $\times 0.25^{\circ}$ longitude (Chen et al. 2008 ) is used as the observations. The observed SST used for verification is the global monthly Extended Reconstructed SST, version 5 (ERSSTv5; Huang et al. 2017b), for $1958-2017$ on a $2^{\circ}$ latitude $\times 2^{\circ}$ longitude grid. The mean sea level pressure (MSLP) and 200-hPa geopotential height data are from the ERA-40 and ERA-Interim reanalyses for 1958-78 and 1979-2017, respectively. Monthly anomalies of the observational datasets for the 1958-78, 1979-99, and 2000-17 periods are also calculated with respect to the monthly climatologies for each of the periods, respectively.

In addition, we have compared the precipitation of our reforecasts with that from a set of ensemble AMIP simulations using GFS (atmospheric component of CFSv2) forced with the observed SST from January 1957 to December 2018, to be referred to as the GFS simulations hereafter. The GFS simulations have a total of 101 members with slightly different atmospheric initial states (Hu et al. 2017). These GFS runs can be considered as idealized predictions from uninitialized atmosphere-land states but with "perfect" SST skill at any lead time. For comparison, we have also used the 10-member initialized seasonal ensemble reforecast from the Community Climate System Model, version 4 (CCSM4), for 1982-2017. The CCSM4 reforecast is chosen because it is the only NMME Phase-II dataset extending to 2017 and with a total record equally spanning the last two periods of our reforecasts.

\section{b. Maximum signal-to-noise EOF analysis}

In addition to a general evaluation of the model precipitation characteristics and prediction skill, we use the empirical orthogonal function (EOF) analysis with maximized signal-to-noise ratio (MSN EOF) to identify the most predictable patterns of the U.S. precipitation from the CFSv2 ensemble reforecasts. The MSN EOF is originally designed to extract the leading patterns of the forced response from an ensemble of simulations under a common forcing such as the prescribed SST (e.g., Venzke et al. 1999; Huang 2004). For an ensemble simulation with a moderate size of the ensemble members, its ensemble mean is composed of both signal and residual internal noise. As a result, the conventional EOF modes of the ensemble mean may still contain a substantial amount of noise variance and not accurately represent the dominant patterns of the signal. On the other hand, the MSN EOF analysis takes into account the noise characteristics estimated from the departures from the ensemble mean in deriving its leading modes so that they maximize the ratios between the variances of signal and noise. Compared to the conventional EOF modes, the MSN EOF modes estimate the leading patterns of the signals more accurately. The reader is referred to Venzke et al. (1999) for a detailed description of the formulation and procedure of the MSN EOF analysis.

Applied to the time sequence of the ensemble reforecast fields with a given lead time from initialization, the leading MSN EOF modes can be explained as the time-spatial patterns of the most predictable signals of the ensemble mean of reforecasts. The MSN EOF approach has been used effectively in identifying the predictable patterns from ensemble reforecasts by previous studies (e.g., Hu and Huang 2007; Liang et al. 2009; Zhu et al. 2015; Zhang et al. 2018a; Shin et al. 2019). In our study, only the first MSN EOF modes, that is, the most predictable patterns, are discussed. We further measure the representativeness of the MSN EOF pattern by projecting the pattern to each of the ensemble members and comparing the time series of the MSN EOF mode [i.e., MSN principal component (PC)] with these projected time series. One should also note that the derived predictable patterns are properties of the forecast system because the MSN EOF analysis depends only on the reforecasts. Whether these modes connect to reality (i.e., have predictive skill) should be evaluated by their verification against observations. For this purpose, we regress the first MSN PCs with the observations and examine the resemblance of the resulting regressional patterns with the corresponding MSN EOF patterns. This approach is adopted because the MSN PCs may still represent the predictable temporal variations in observations even when the MSN EOF patterns are distorted by model systematic bias.

\section{General statistics of U.S. precipitation in seasonal reforecasts}

In this section, we describe some gross statistical features of the U.S. precipitation in the observations and the 60 -yr reforecast dataset. Figure 1 shows the spatial distribution of the precipitation standard deviation in CONUS during winter (DJF) for observations and the reforecasts respectively in 1958-78, 1979-99, and 200016. Observationally, high precipitation variability is located in the southeastern United States centered near 
Standard Deviation of US DJF precip. [mm/day]
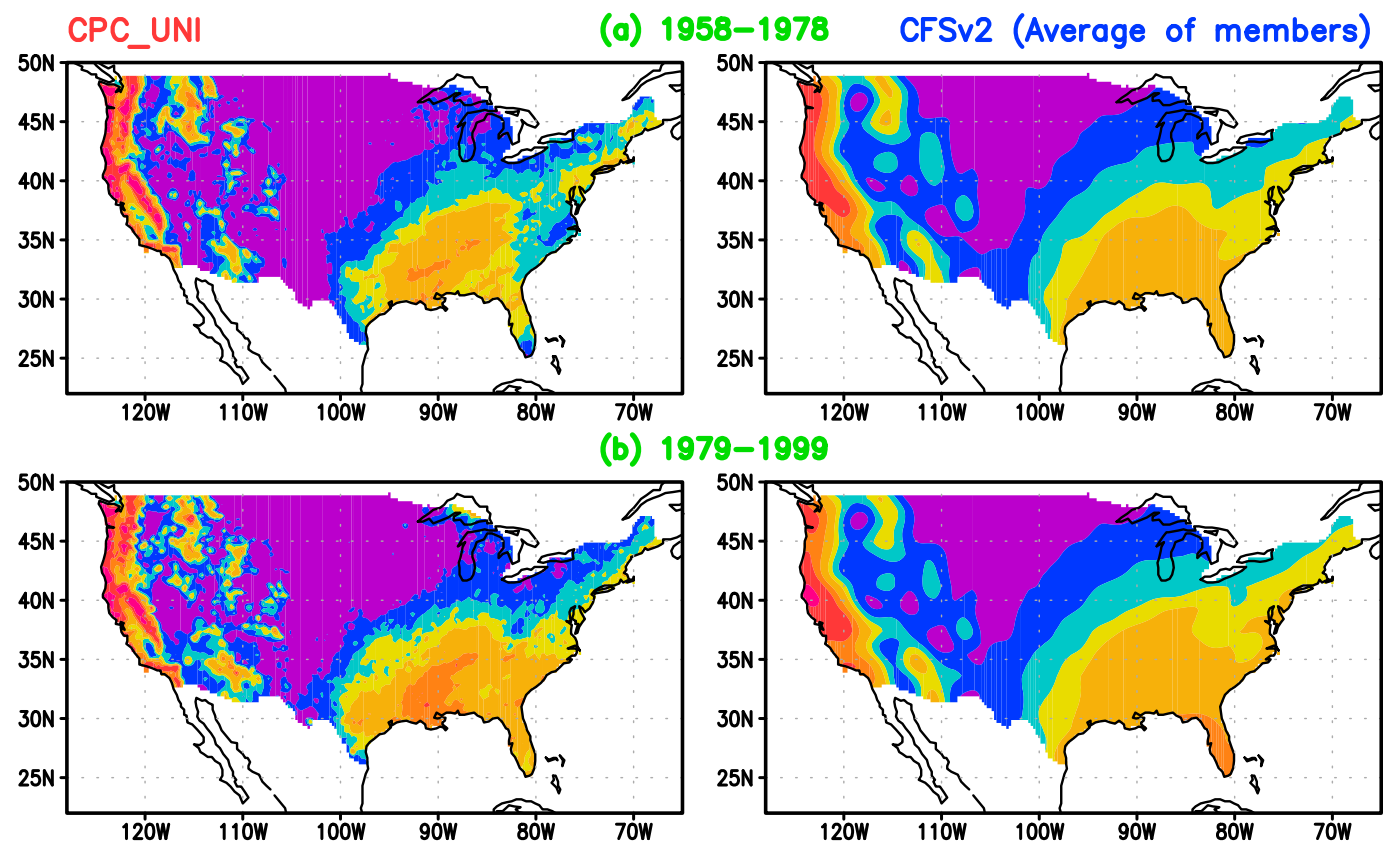

(c) 2000-2016

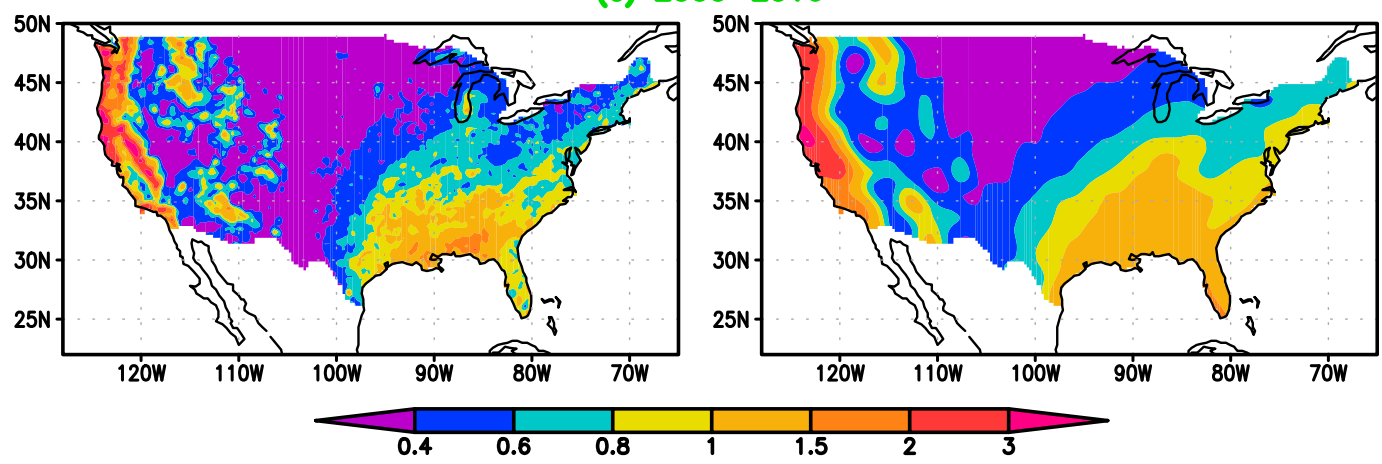

FIG. 1. The standard deviation of the winter (DJF) precipitation for (a) 1958-78, (b) 1979-99, and (c) 2000-16 from (left) observations and (right) the reforecasts. The standard deviation of the reforecasts is the average of all individual ensemble members. The color bar for the shading is located at the bottom. The unit is mm day ${ }^{-1}$.

the Gulf of Mexico coast and in the western United States extending from the Pacific coast, including most of the Pacific Northwest, with a broad area of low variability in between $\left(<0.4 \mathrm{~mm} \mathrm{day}^{-1}\right.$, shaded with purple color) in the central United States and a part of the Midwest (left panels, Fig. 1). In general, the areas of high standard deviation are also associated with those of large mean precipitation in this season (not shown). The distribution of the DJF precipitation variability bears certain resemblance to the annual mean pattern shown in Seager et al. (2014) and is well simulated by the reforecasts, though with somewhat reduced magnitudes of the regional peaks (right panels, Fig. 1). Among the three periods, the 1979-99 episode showed enhanced variations in the southeastern United States in observations (left panel, Fig. 1b) but not in the reforecasts (right panel, Fig. 1b).

The observed precipitation standard deviation in summer (JJA) is characterized by a strong east-west contrast (left panels, Fig. 2), with the region of small fluctuation (shaded with purple color) shifted from the central United States in winter to the west in summer. In addition to the large fluctuations in the southeast near the coast, there is a distinctive center over the Great Plains, with its maximum above $1.0 \mathrm{~mm} \mathrm{day}^{-1}$ located near Kansas and Missouri, which is consistent with previous studies (e.g., Ting and Wang 1997). The reforecasts also reproduce these general features realistically (right panels, Fig. 2). In the observations, and to a lesser extent in the reforecasts, the fluctuations 


\section{Standard Deviation of US JJA precip. [mm/day]}

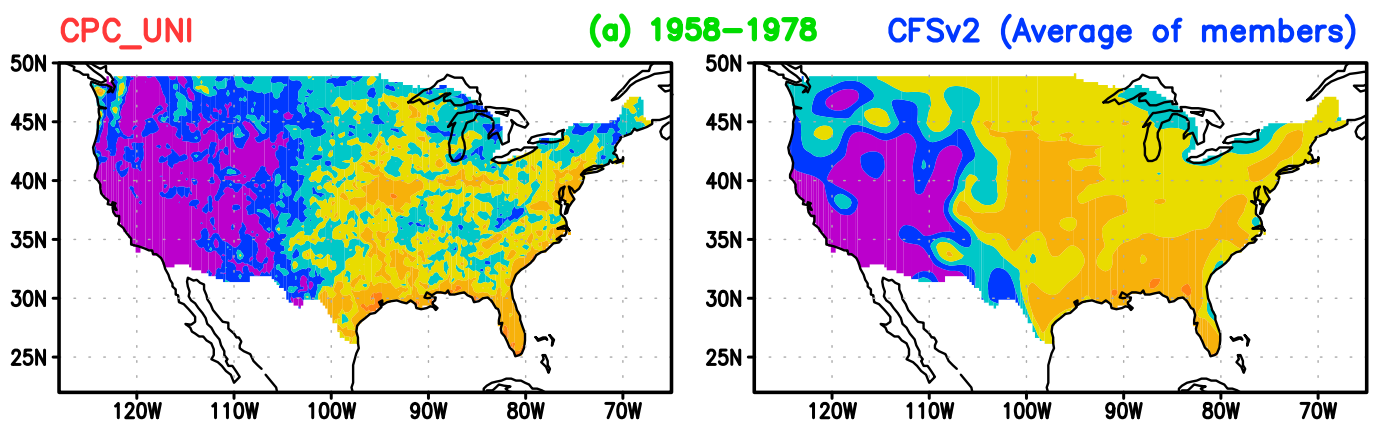

(b) $1979-1999$
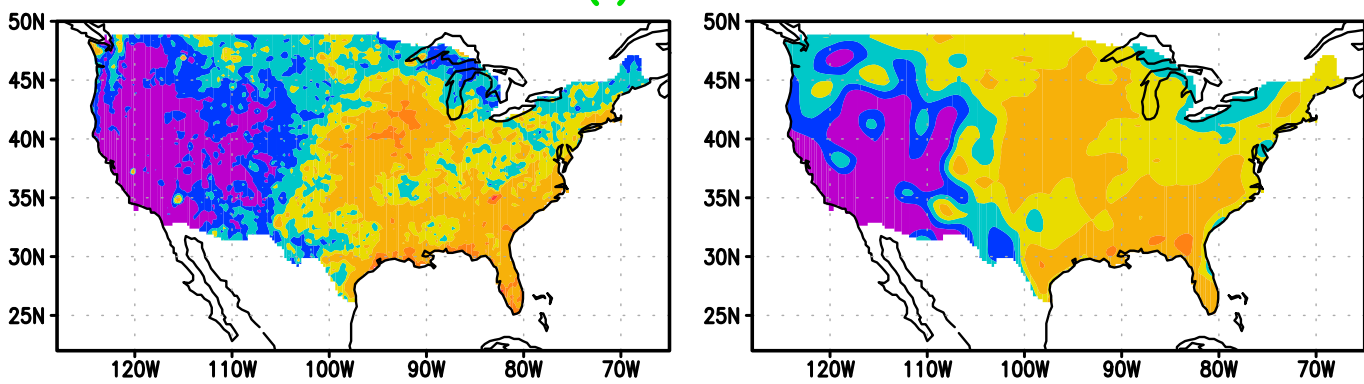

(c) 2000-2017

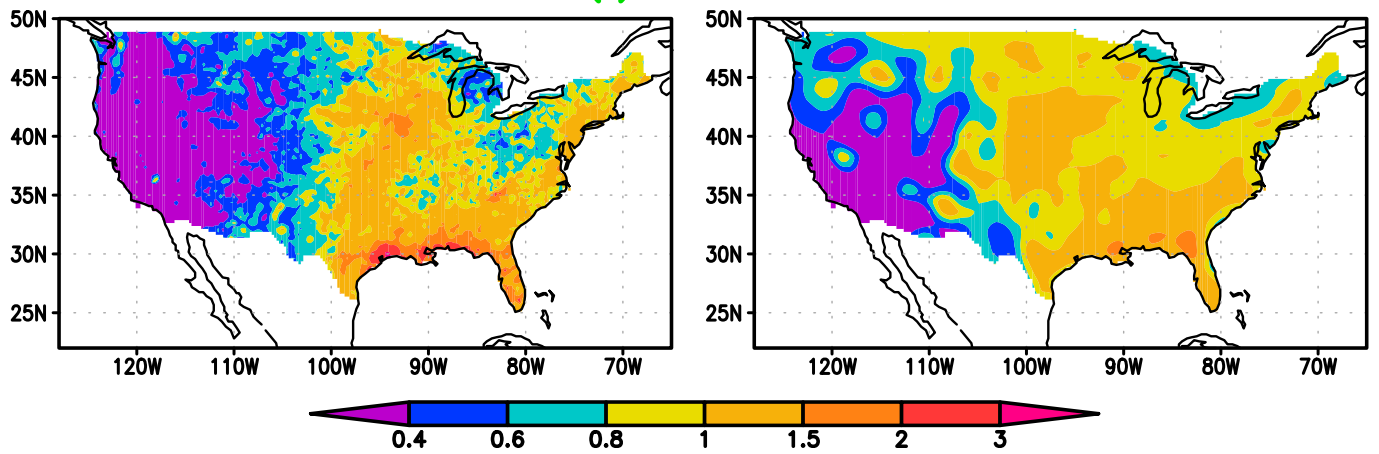

FIG. 2. The standard deviation of summer (JJA) precipitation for (a) 1958-78, (b) 1979-99, and (c) 2000-17 from (left) observations and (right) the reforecasts. The standard deviation of the reforecasts is the average of all individual ensemble members. The color bar for the shading is located at the bottom. The unit is mm day ${ }^{-1}$.

intensify in both the southeast and the Great Plains during 1979-99 than the earlier and later periods although the interannual variation near the coast of the Gulf of Mexico in 2000-17 is greater than that in 197999. The reforecasts also simulate reasonably well the patterns of the precipitation standard deviations in the two transitional seasons (MAM and SON) with an underestimate of the regional maximum in magnitudes (figures not shown). Therefore, the reforecasts reproduce the seasonality of the precipitation variance distributions realistically.

Figure 3 shows the spatial distribution of the linear trends of the DJF precipitation in each of the three periods for the observations and for the ensemble mean reforecasts. The linear trends are derived from the seasonal mean data for each of the three periods separately. Observationally, winter precipitation increases during all three periods in the eastern and northeast states, as well as in the Pacific Northwest (left panels, Fig. 3), suggesting a persistent tendency throughout the whole period. This persistent pattern is reproduced by the reforecasts to a large extent (right panels, Fig. 3), although the magnitudes are generally weaker during the first two periods, especially in 197999 (comparing the left and right panels, Fig. 3b). To a certain extent, the model also reproduces the observed drying tendency in the southwestern region. Compared with the positive trends, the negative trends have a more variable spatial distribution with time, which extended from the western Texas toward Colorado in 1958-78 
Linear Trend of US DJF precip. [0.1 $\mathrm{mm} /$ day $/$ decade]

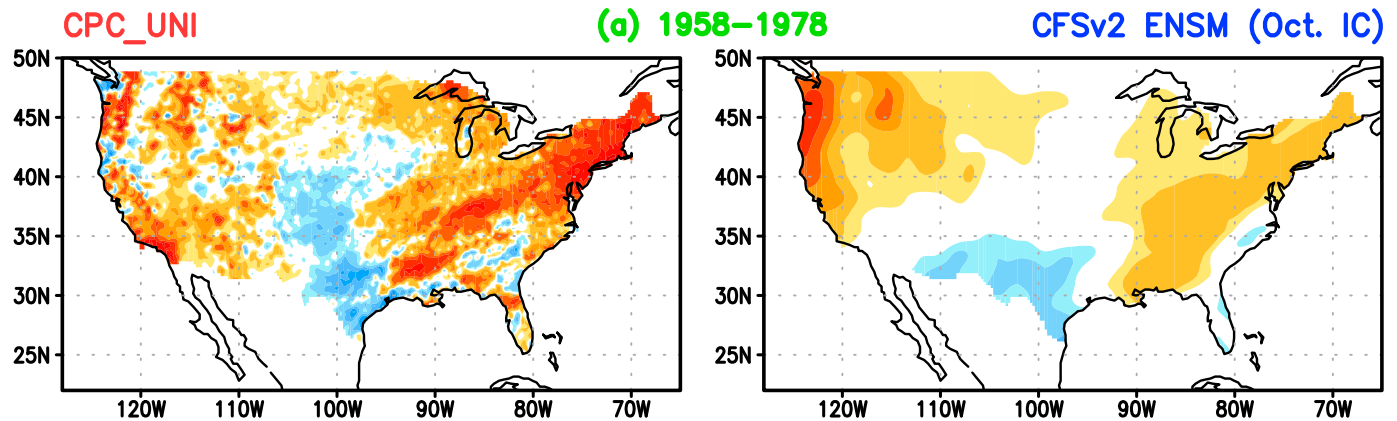

(b) 1979-1999
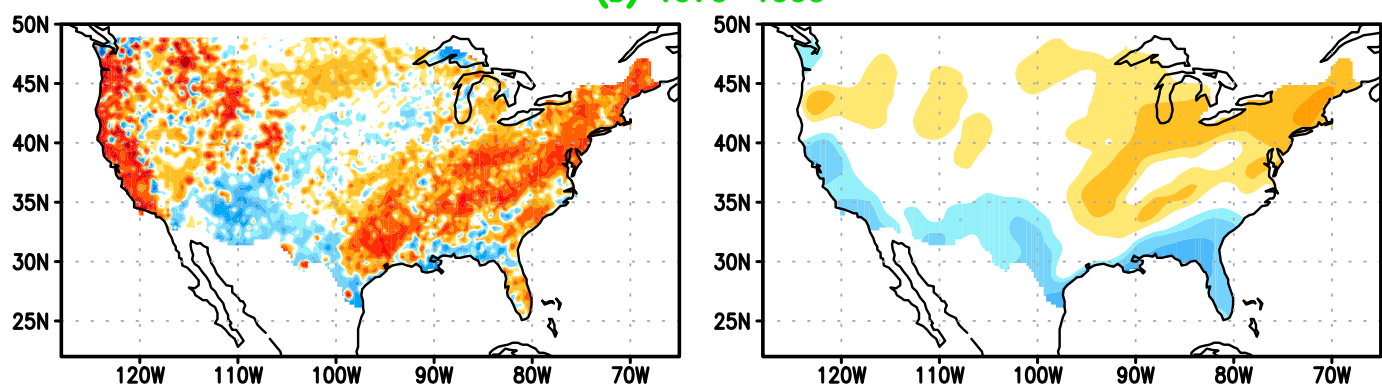

(c) $2000-2016$

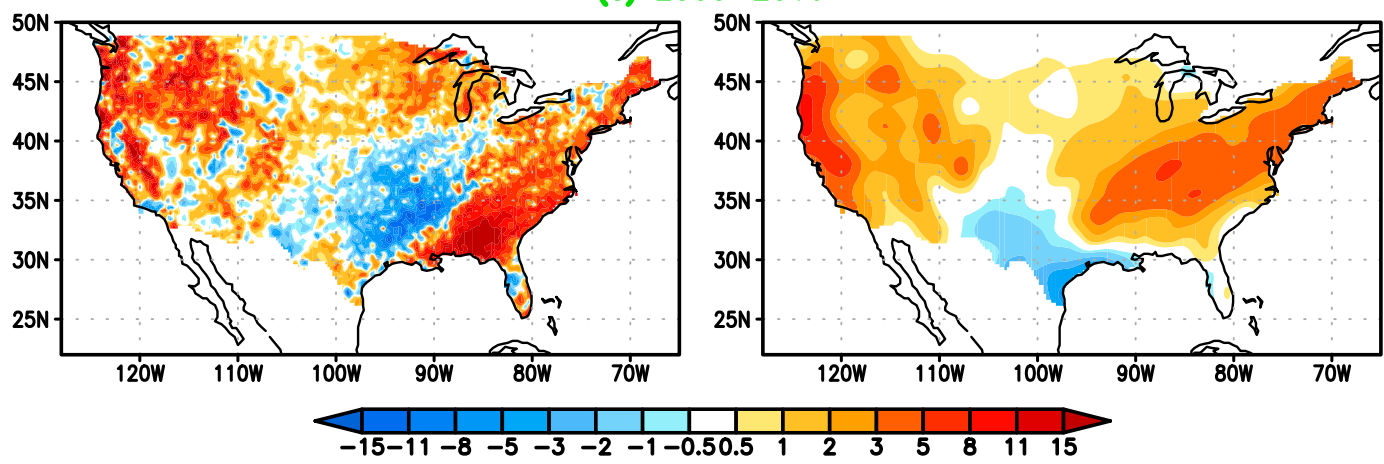

FIG. 3. Spatial distribution for the linear trend of the seasonally averaged DJF precipitation anomalies for (left) the observations and (right) the ensemble mean reforecasts for (a) 1958-78, (b) 1979-99, and (c) 2000-16. The shading scale is shown at the bottom of the figure. The unit is $0.1 \mathrm{~mm}_{\text {day }}{ }^{-1}$ decade $^{-1}$.

(left panel, Fig. 3a) but shifted to a more east-west band stretching from Arizona to the coastal region of the Gulf of Mexico, showing a notable north-south contrast between the increasing and decreasing precipitations (left panel, Fig. 3b). During 2000-16, the region of the negative trends migrated to the area of eastern Texas, Oklahoma, and Arkansas, more inland from the Gulf Coast (left panel, Fig. 3c). The reforecasts simulate the general location of the negative trends in the southwest (right panels, Fig. 3) and reproduces the zonal dry band, as well as the north-south contrast, during 1979-99 (right panel, Fig. 3b) but did not reproduce the inland migration of the drying zones, resulting in the east-west contrast with the negative (west) and positive (east) trends since the 2000s (right panel, Fig. 3c).
The reforecasts are less successful in reproducing the spatial distribution of the observed trends in JJA for the two early periods and the model trends were significantly weaker (Figs. 4a,b). This is also the case for the MAM and SON seasons (not shown). During 200017 , however, the reforecasts reproduce substantial positive trends in the observations over CONUS in MAM (not shown) and JJA (Fig. 4c).

Overall, our results show that the reforecasts reproduce the long-term trends in the winter season when persistent positive tendencies occurred in the southeastern and eastern United States and the Pacific Northwest throughout the 60 years, while negative tendencies appeared in the southwestern areas. The model also reproduces the positive precipitation 


\section{Linear Trend of US JJA precip. [0.1 $\mathrm{mm} /$ day $/$ decade]}

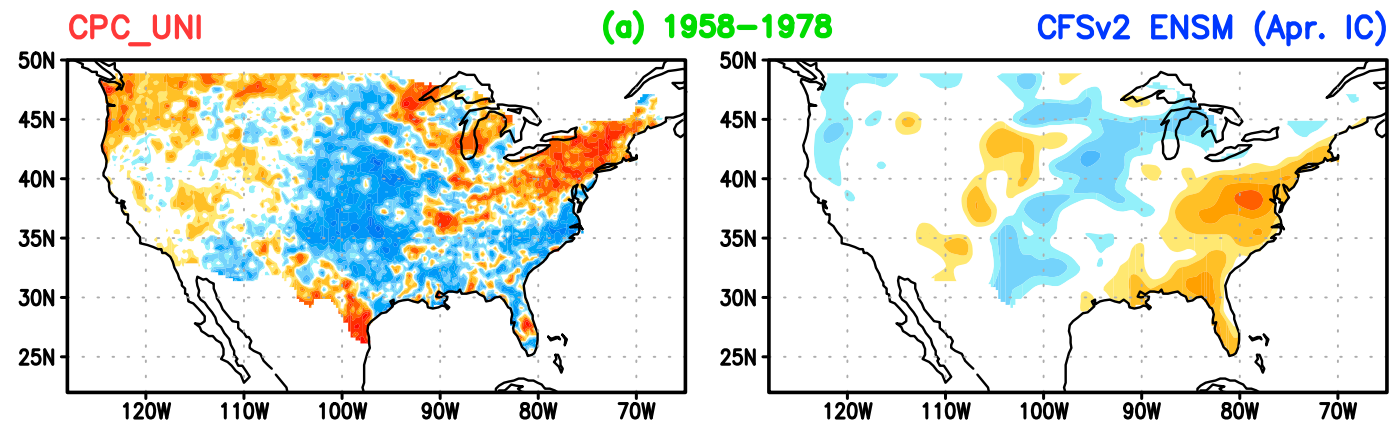

(b) 1979-1999
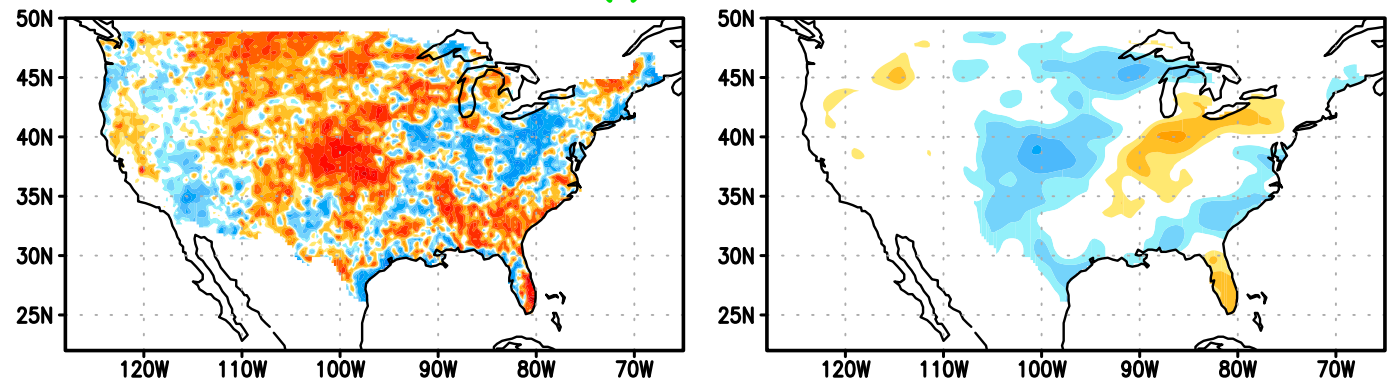

(c) 2000-2017

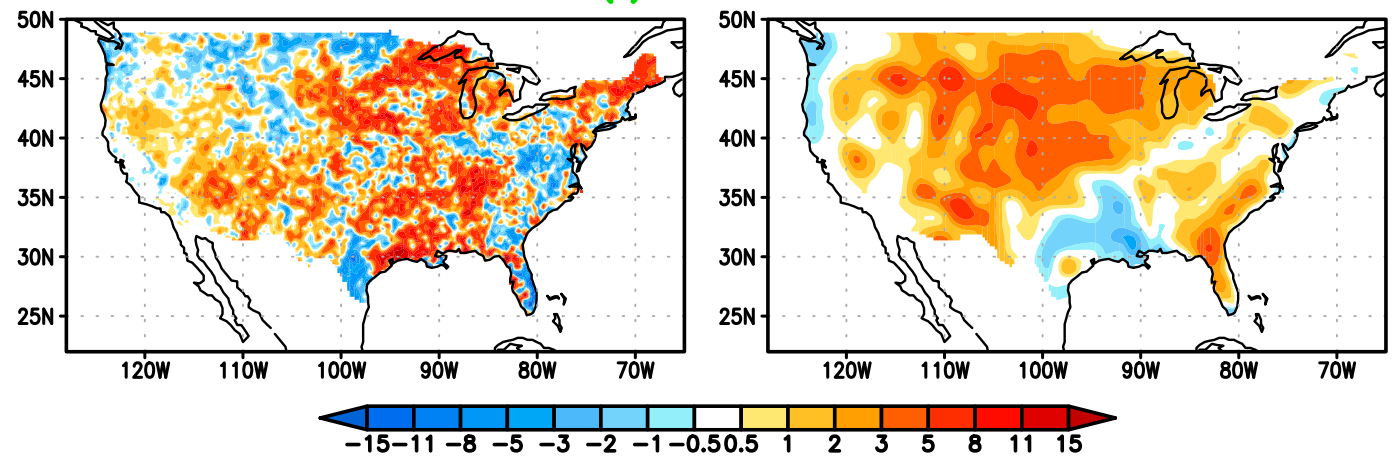

FIG. 4. Spatial distribution for the linear trend of the seasonally averaged JJA precipitation anomalies for (left) the observations and (right) the ensemble mean reforecasts for (a) 1958-78, (b) 1979-99, and (c) 2000-17. The shading scale is shown at the bottom of the figure. The unit is $0.1 \mathrm{~mm}_{\text {day }}{ }^{-1}$ decade $^{-1}$.

tendency since the 2000s in MAM and JJA. In general, the long-term trends in the observed seasonal precipitation could be due to the trends in SST, greenhouse gases, and other external forcings, as well as due to the atmospheric internal variability. For the model ensemble mean, the trends are mainly due to the former two. In the reforecasts, it also measures the model's capability of maintaining the long-term shift of the basic climate state in the duration of the seasonal predictions (e.g., Barnston and Lyon 2016).

It should be noted that the trend patterns of the reforecasts described here are different from the AMIPsimulated annual mean precipitation trend for 19012009 by Seager et al. (2014, their Fig. 1e), which is characterized by the north-south contrast somewhat similar to our DJF pattern in 1979-99 (right panel, Fig. 3b). Our observed trends are also different from the observed pattern of century-long trend in Peterson et al. (2013, their Fig. 3b), which features enhanced precipitations in the central and northeast United States, as well as the Pacific Northwest, but reduced precipitations in the western United States from Arizona and New Mexico to Montana and in the southeast surrounding the Florida Panhandle. One reason of these differences may be the way we calculate the precipitation anomalies for the three periods with respect to their own climatologies separately, which might have partially removed some of the long-term trends shown in the other studies. Moreover, our calculation might also have interpreted parts of the multidecadal variability during 1958-2017 
as trends within some of the periods, especially when the signs of the trends change from one period to the other.

Figure 5 shows the correlation skill of the seasonal mean precipitations predicted by the ensemble mean reforecasts, verified against the CPC analysis. Before the correlation analysis, the long-term trends as described above have been removed from the seasonal mean precipitation anomalies for both the reforecasts and the observations, and the detrended seasonal anomalies will be used in further analysis hereafter. In general, regions of positive correlations passing the $95 \%$ significance test as shown in Fig. 5 are quite spotty. During winter and spring, skillful predictions are mostly in the southwest from 1958 to 1999 (left and middle panels, Figs. 5a and 5b). In DJF, the skill is also relatively high in the southeast and east for 1979-99 (middle panel, Fig. 5a) but generally reduced in 2000-16 throughout CONUS (right panel, Fig. 5a). In MAM, however, significant skills appear in the northeast throughout 1979-2017 (middle and right panels, Fig. 5b). During summer and fall, there is little skill in the predictions for 1958-78 (left panels, Figs. 5c and 5d). During 197999, however, a substantial area of skillful predictions emerges in the northwest in summer (middle panel, Fig. 5c) and, to a lesser extent, in fall (middle panel, Fig. 5d). During 2000-17, positive correlations are shifted to the central and south United States in summer (right panel, Fig. 5c) and become more significant in fall (right panel, Fig. 5d).

\section{Seasonal and interdecadal change of the signal-noise ratio and predictable patterns of the U.S. precipitation}

In this section, we first show the spatial distributions of the signal-to-noise $(\mathrm{S} / \mathrm{N})$ ratio estimated from the ensemble mean standard deviation and that from the ensemble departures for the four seasons during the three periods (Fig. 6). The $\mathrm{S} / \mathrm{N}$ ratio is generally larger in winter-spring than in summer-fall and also shows clear seasonal dependence in geographical distribution. In DJF, larger $\mathrm{S} / \mathrm{N}$ values are located to the south of $35^{\circ} \mathrm{N}$ and north of $45^{\circ} \mathrm{N}$, with a band of minimum around $40^{\circ} \mathrm{N}$ (Fig. 6a). In MAM, S/N values in the southwest United States are enhanced and expand northward (Fig. 6b). In JJA (Fig. 6c) and SON (Fig. 6d), however, the S/N centers are shifted to the central and centralwest United States, with the SON patterns more concentrated to the south. Comparing Figs. 5 and 6, one may find a rough correspondence in the geographical locations between the higher values of the S/R (Fig. 6) and correlation skill (Fig. 5) in winter and spring (two upper rows). This is consistent with the theoretical results (see Kumar 2009; Kumar et al. 2014a) that there is a one-on-one correspondence between the two quantities in a perfect model scenario.

Among the three periods, the $\mathrm{S} / \mathrm{N}$ ratio is generally smaller in the first period than in the other two, which suggests apparent greater predictability in the post-1979 period than during 1958-78. Moreover, although the forecast skills in DJF (Fig. 5a) and MAM (Fig. 5b) are lower during 2000-17 (right column) than during 197999 (middle column), their $\mathrm{S} / \mathrm{N}$ ratios (Figs. 6a,b) are more similar between these two periods. The lower forecast skills in the U.S. winter-spring precipitation after 2000 are likely associated with the reduced ENSO forecast skills during the same period, as reported by many previous studies (e.g., Barnston et al. 2012; Huang et al. 2017a). Hu et al. (2019) suggest that the lower ENSO predictive skill since 2000 is due to reduced ENSO predictability. On the other hand, the lessened reduction of the $\mathrm{S} / \mathrm{N}$ ratio of the U.S. precipitation after 2000 may imply the existence of other sources of predictability, which has yet to be more adequately represented in the model to compensate for the lost forecast skill of the U.S. precipitation due to the reduced ENSO predictability.

In summer and fall, however, the correspondence between the forecast skill and the $\mathrm{S} / \mathrm{N}$ ratio is not obvious (two lower rows, Figs. 5 and 6). In fact, both quantities are small in 1958-78 (left panels, Figs. 5c,d and $6 \mathrm{c}, \mathrm{d})$ and the discrepancies are large between them in 1979-99 (middle panels, Figs. 5c,d and 6c,d). In 200017 , the two variables seem more consistent, with higher values appearing in the central United States for both (right panels, Figs. 5c,d and 6c,d). It is also noticeable that the $\mathrm{S} / \mathrm{N}$ ratios are slightly enhanced during these two seasons from the period of 1979-99 to 2000-17.

Since the $\mathrm{S} / \mathrm{N}$ ratio largely dictates the seasonal predictability (Jha et al. 2019), it is critical to assess whether this decomposition of the model total variance is realistic. Since the $\mathrm{S} / \mathrm{N}$ ratio cannot be estimated directly from observations, we compare the $\mathrm{S} / \mathrm{N}$ ratio of CFSv2 with those derived from other model simulations, with the proposition that consistency among models may testify representativeness to nature. Figure 7 shows that the $\mathrm{S} / \mathrm{N}$ ratio of precipitation from a 20 -member ensemble GFS simulation is qualitatively similar to that of CFSv2 (Fig. 6). The GFS multidecadal change among the three periods is also largely consistent with that of CFSv2, with S/N ratios stronger in 1979-99 but weaker in 1958-78. There are some differences in details between CFSv2 and GFS. For instance, compared to CFSv2, the GFS runs have higher $\mathrm{S} / \mathrm{N}$ ratio in the Great Lake area in 1979-99 but show a stronger zonal contrast in 1958-78 and 2000-17 during the winter season 
Correlation of rainfall anomalies on 2-month lead

(a) DJF (Oct. IC)

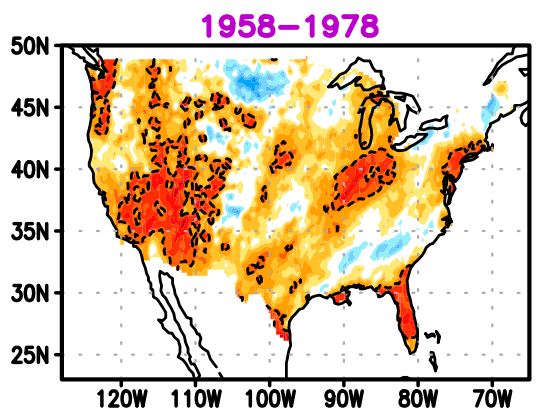

(b) MAM (Jan. IC)

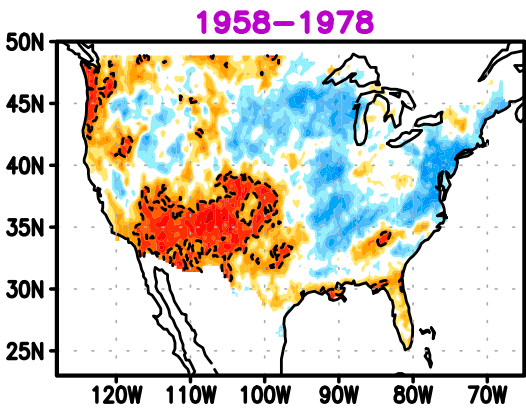

(c) JJA (Apr. IC)

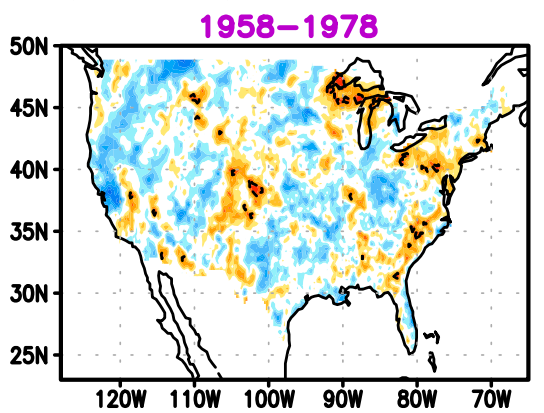

(d) SON (Jul. IC)

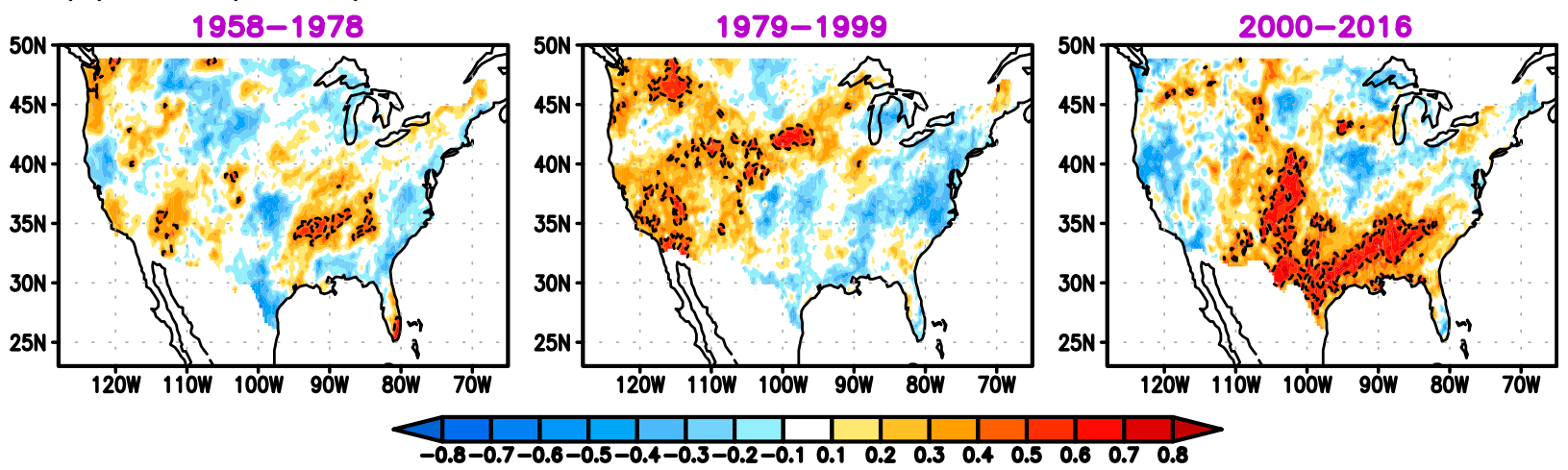

FIG. 5. Spatial distributions for the correlation skill of the seasonal mean precipitation from the ensemble mean for (a) DJF, (b) MAM, (c) JJA, and (d) SON. (left) 1958-78, (middle) 1979-99, and (right) 2000-17. The shading scale is shown at the bottom of the figure. The contours outline the areas passing the $95 \%$ significance test.
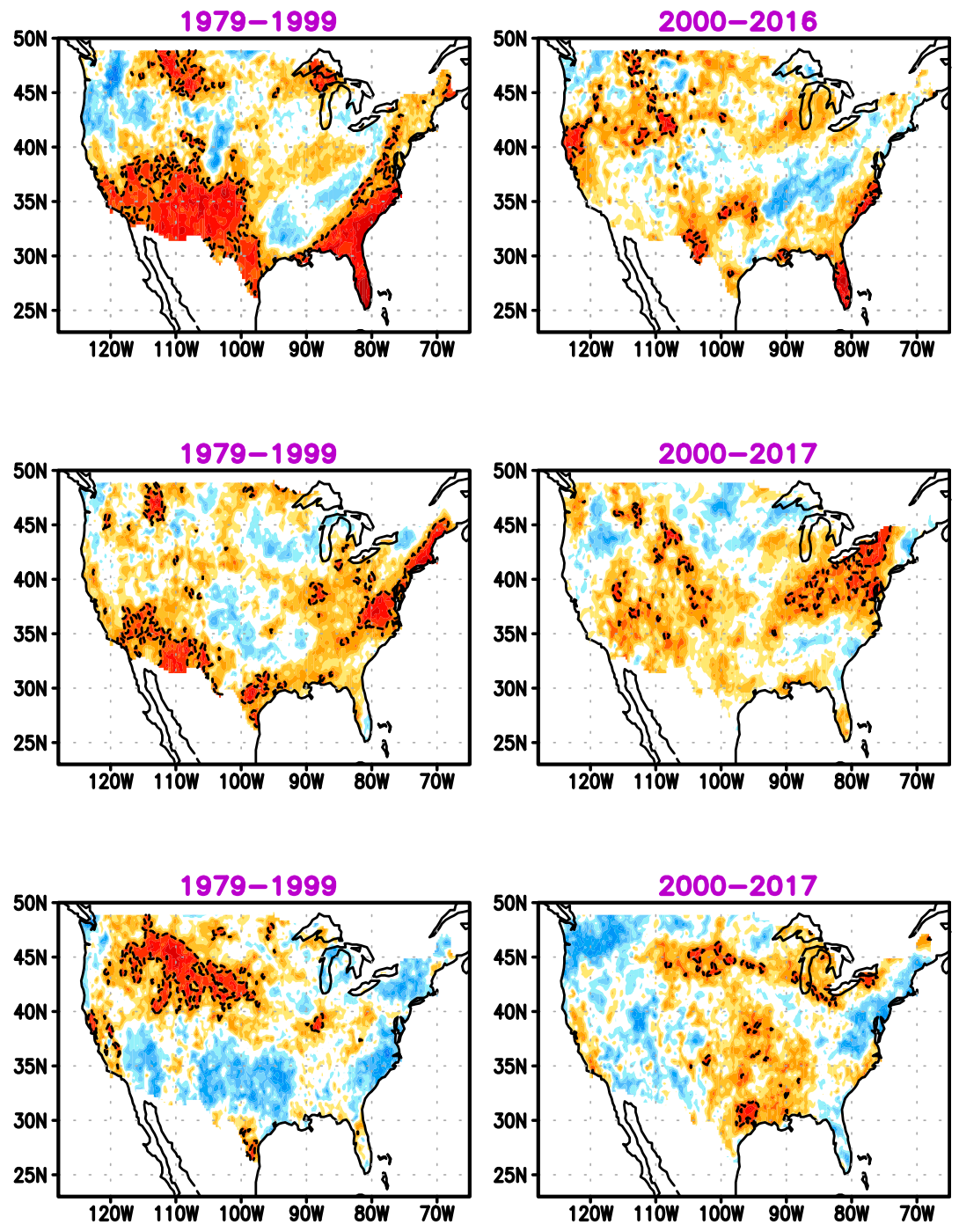
Signal/Noise Ratio of CFSv2 predicted rainfall on 2-month lead

(a) DJF (Oct. IC)
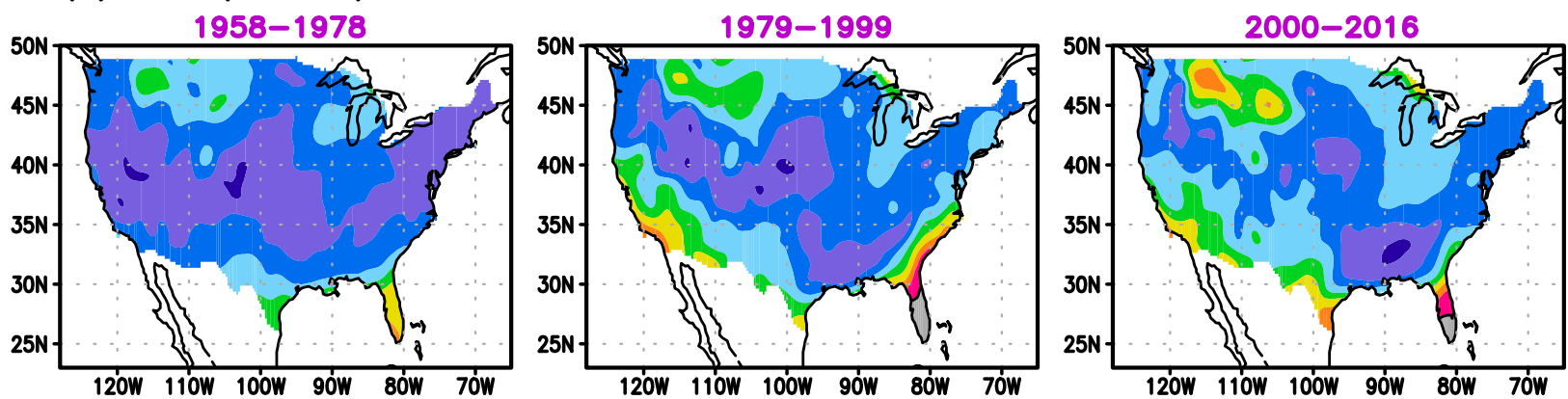

(b) MAM (Jan. IC)
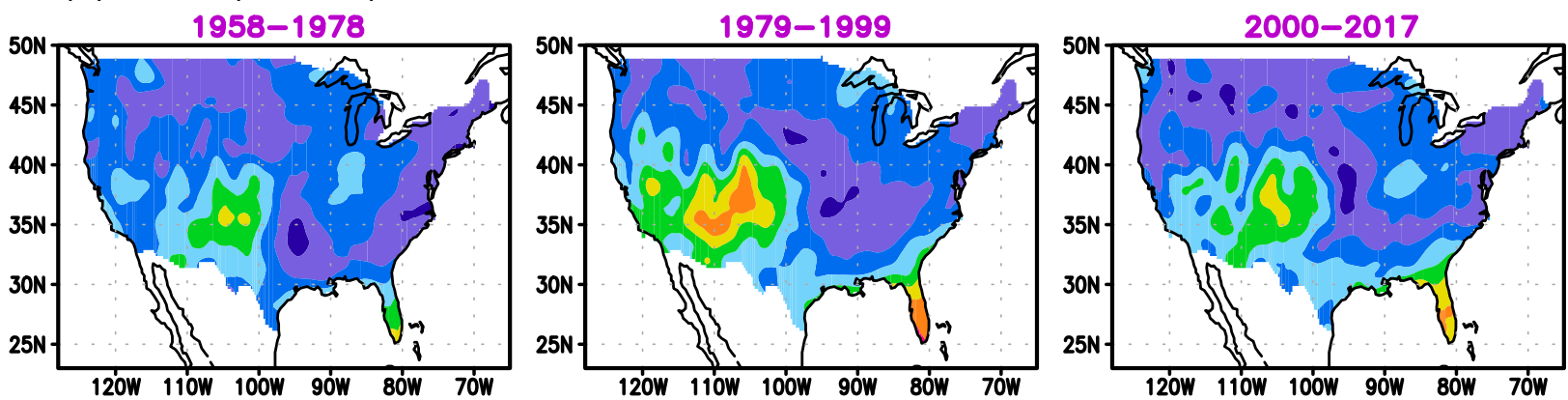

(c) JJA (Apr. IC)
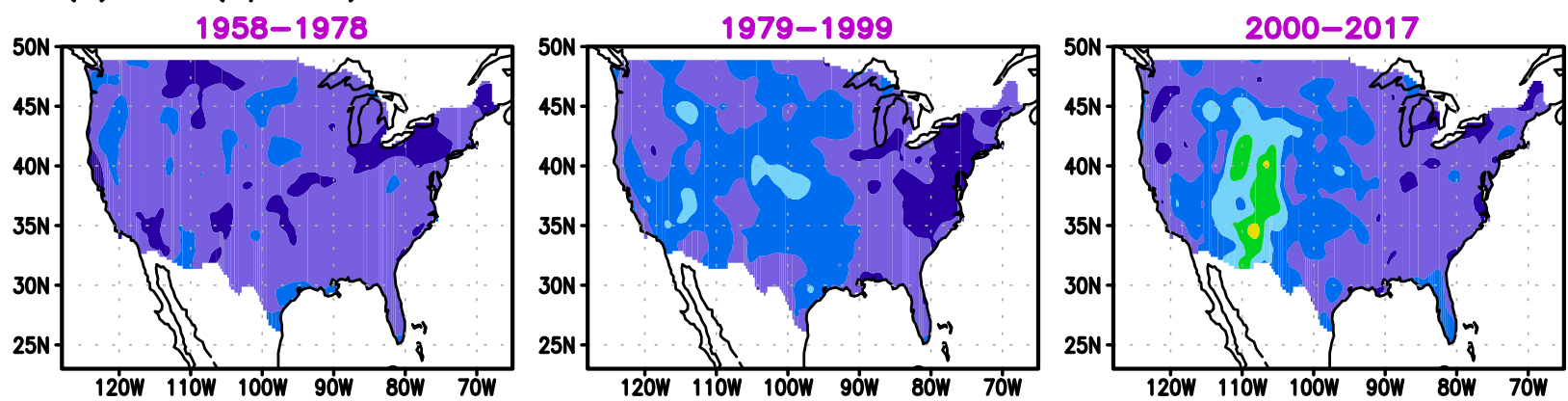

(d) SON (Jul. IC)
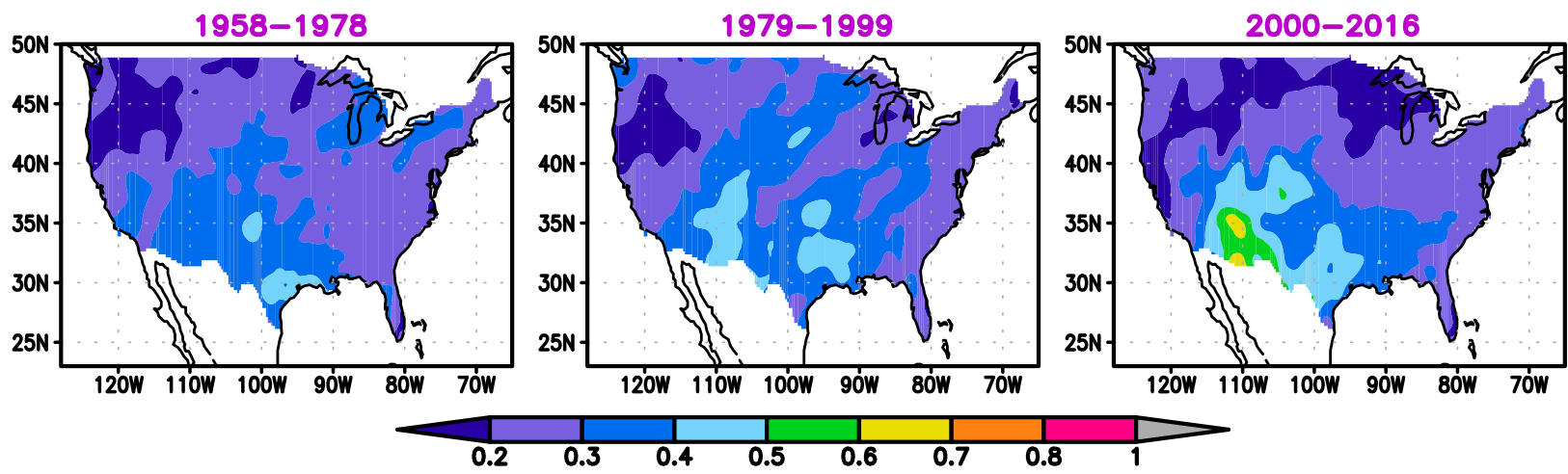

FIG. 6. The signal/noise ratio estimated from the ratio between the standard deviation of the ensemble mean and the ensemble departures from the CFSv2 2-month reforecasts for (a) DJF, (b) MAM, (c) JJA, and (d) SON. (left) 1958-78, (middle) 1979-99, and (right) 2000-17. The shading scale is shown at the bottom of the figure. 
Signal/Noise Ratio of CFSv2 AMIP rainfall (20 members)

(a) DJF
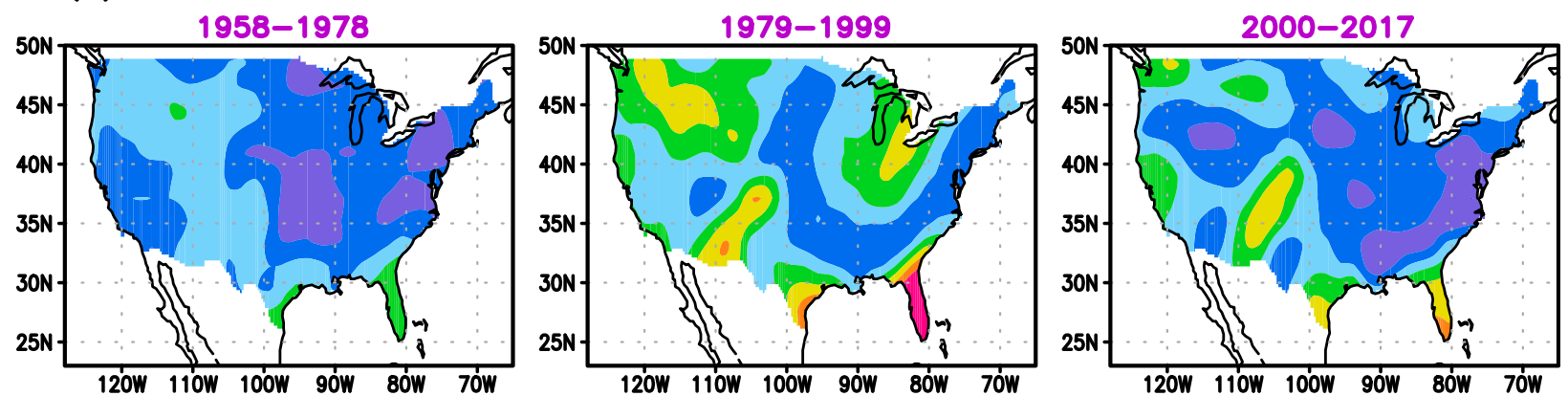

(b) MAM
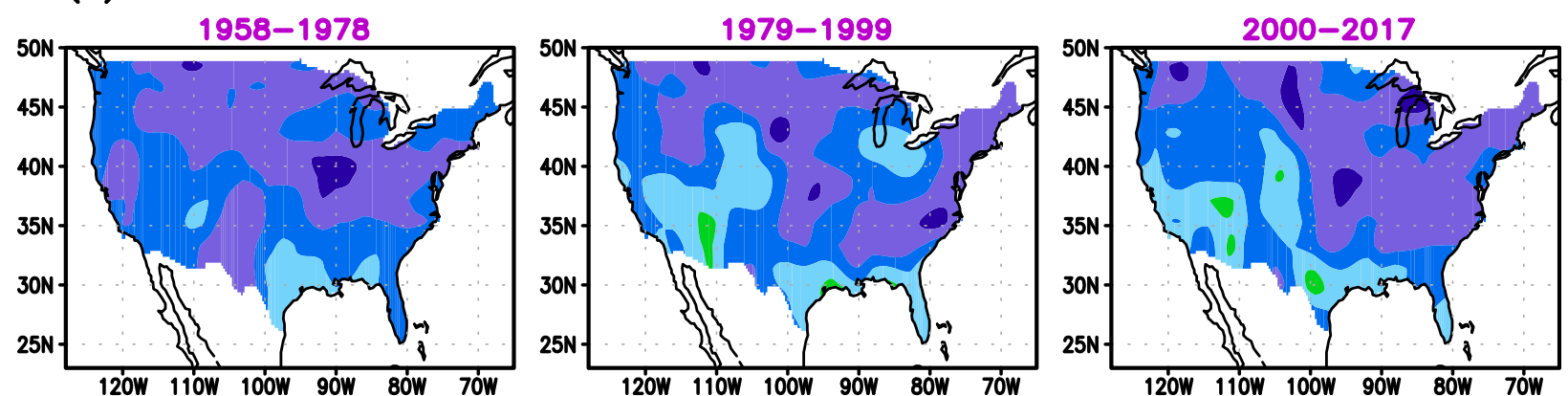

(c) JJA
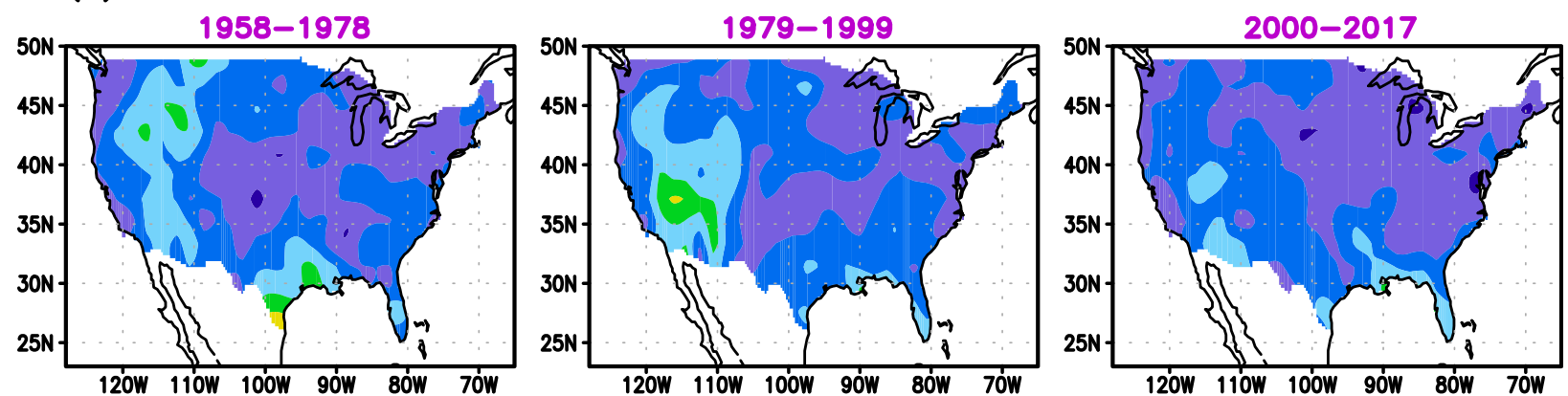

(d) SON
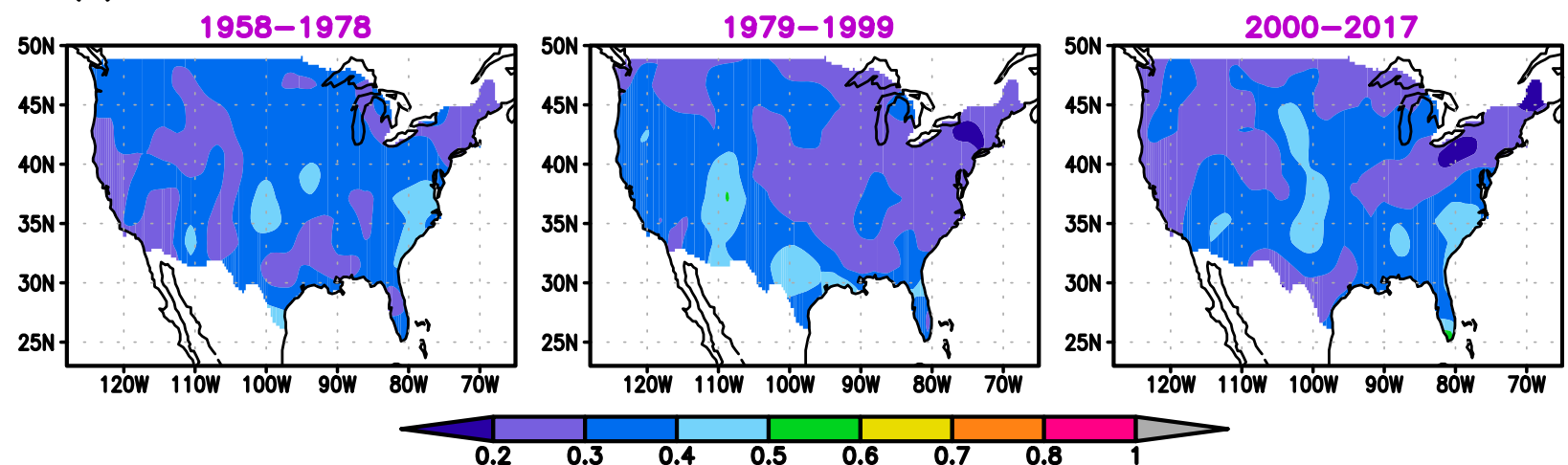

FIG. 7. The signal/noise ratio estimated from the ratio between the standard deviation of the ensemble mean and the ensemble departures from the 20-member GFS simulations for (a) DJF, (b) MAM, (c) JJA, and (d) SON. (left) 1958-78, (middle) 1979-99, and (right) 2000-17. The shading scale is shown at the bottom of the figure. 
(Fig. 7a). Compared with GFS, the S/N ratios of CFSv2 in 1979-99 and 2000-17 are more consistent with those derived from the CCSM4 seasonal reforecasts for 198299 and 2000-17 in DJF (Fig. 8a), MAM (Fig. 8b), and SON (Fig. 8d) except for the southwestern United States in DJF. Like CFSv2, the S/N ratios of the CCSM4 reforecast also tend to enhance from the early to later periods in JJA and SON.

Overall, the above comparison shows considerable model consistency and, based on this comparison, we argue that the $\mathrm{S} / \mathrm{N}$ ratio of the CFSv2 reforecast is realistic. The larger discrepancies of CCSM4 with CFSv2 (GFS) in JJA may be attributable to uncertainty associated with the former's smaller ensemble size. We have also calculated the $\mathrm{S} / \mathrm{N}$ ratio of the ensemble GFS runs using all 101 members and found that its $\mathrm{S} / \mathrm{N}$ patterns (not shown) are almost identical to those shown in Fig. 7 but the magnitude is somewhat reduced. This suggests that, even with 20 ensemble members, the residual noise may still have nonnegligible quantitative effect if we consider the ensemble means. An MSN EOF analysis is further applied to mitigate this effect.

Next, we examine the leading patterns of the most predictable U.S. precipitation in these three periods, as derived from the MSN EOF analysis on a seasonal basis. We will show that the first MSN EOF modes derived from each of the four seasons reflect well the basic characteristics of the $\mathrm{S} / \mathrm{N}$ ratio distributions. For reasons that will become clearer later, we start the description from the fall (SON) season.

Figure 9 shows the first MSN EOFs and MSN PCs for the three periods, as well as the ensemble member projections to the former and regression patterns of the observations to the latter. The spatial patterns of the MSN EOF modes (i.e., the most predictable patterns) show similar spatial distributions for the three periods (right panels, Figs. 9a-c), which feature precipitation anomalies centered at the coastal region of Texas and expand inland, especially northward, to CONUS to the south of $40^{\circ} \mathrm{N}$. Farther north, major precipitation anomalies appear in the Pacific Northwest with the largest anomalies along the coastal region. A unique feature for $1958-78$ is that substantial anomalies opposite to the south also appear in the northeast (right panel, Fig. 9a).

The peaks of the MSN PCs (Fig. 9d) largely appear in major ENSO years, including the El Niño years in 1965, 1972, 1982, 1986, 1997, 2009, and 2015 and the La Niña years in 1964, 1971, 1974, 1989, and 2010. The spread of the projection time series associated with the ensemble members (shading in Fig. 9d) is large in all three periods indicating substantial contribution from internal variability. To demonstrate whether the level of noise changes between the ENSO and non-ENSO years, we have plotted the scatter diagrams between the predicted ensemble mean Niño-3.4 index and the ensemble spread of the projected time series. It is found that the noise level does not change significantly with the magnitude of the Niño-3.4 index, that is, the noise level does not change between the ENSO and non-ENSO years (not shown). This is consistent with the previous studies (e.g., Hu et al. 2019) that the noise of the predicted SST anomalies in the Pacific also does not change between the ENSO and non-ENSO years.

Over the whole domain, the observed regression pattern to the MSN PC in 2000-16 (left panel, Fig. 9c) shows the most qualitative resemblance to its corresponding reforecast pattern (right panel, Fig. 9c). The reforecast patterns for the other two periods, however, only show similarity to the observations in the western coastal domain associated with the northsouth contrast.

The DJF predictable patterns (right panels, Figs. 10a-c) show a general north-south dipole structure throughout the continent during all three periods. Superimposed on this dipole, there are enhanced precipitation anomalies in the southeast and southwest, as well as the opposite anomalies in the northeast and in northwest covering Oregon and Washington State and a separate center near Montana. Compared to SON, the observed regression patterns (left panels, Figs. 10a-c) bear closer resemblance to their corresponding MSN EOF patterns in all three periods. In fact, the main discrepancy between the model and observations occurred in 2000-16 when the signs of the observed precipitation anomalies are largely opposite to those of the reforecasts near the western coast (Fig. 10c). This may be contributed by the fact that the observed precipitation anomalies in the winter of 2015/16 strong El Niño events were opposite to the mean ENSO response over the U.S. southwest (Chen and Kumar 2018).

The peaks of the MSN PCs (Fig. 10d) are more tightly linked with the ENSO events. For instance, the El Niño winters of 1991/92 and 2002/03 are prominent peaks in the DJF MSN PCs while the SON time series only show mild positive values in 1991 and 2002. The enhanced effect of ENSO can be explained by the fact that DJF is the season with largest ENSO SST anomalies, and further, tropical-extratropical teleconnections are also most well defined. It is also interesting to see that the projections of the ensemble members onto the DJF MSN EOF modes form tighter envelope around the MSN PCs, suggesting that the predictable patterns are more detectable in the individual ensemble members. This situation is also demonstrated by the better similarity between the DJF MSN EOF patterns and the 
Signal/Noise Ratio of CCSM4 rainfall (10 members)

(a) DJF
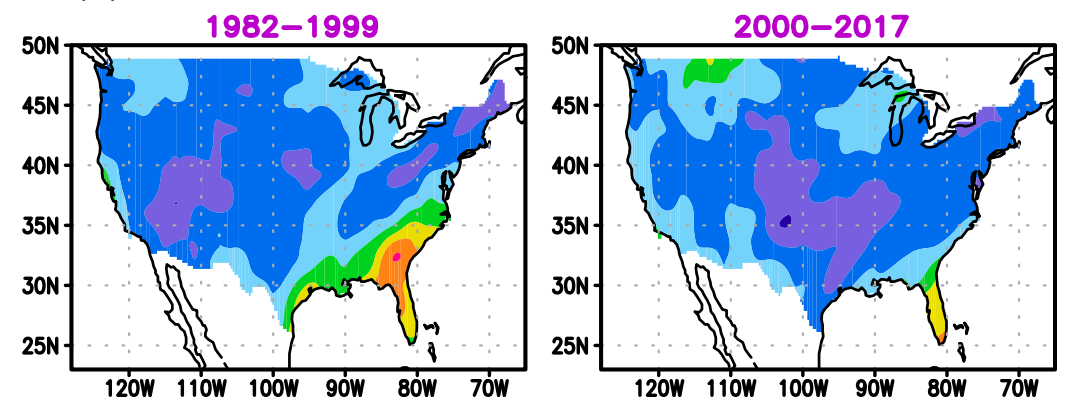

(b) MAM
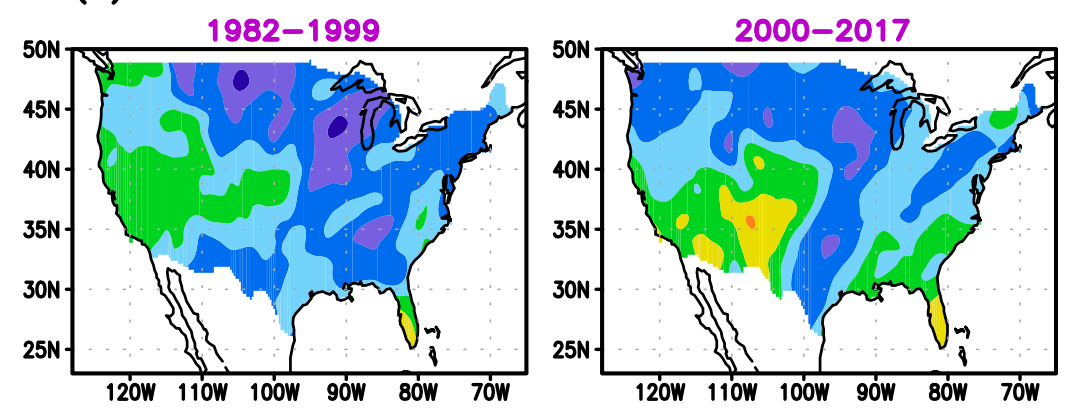

(c) JJA
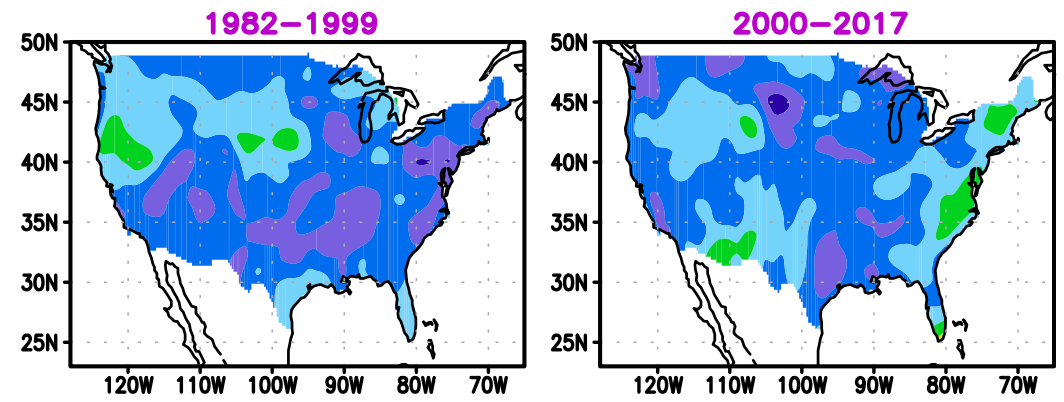

(d) SON

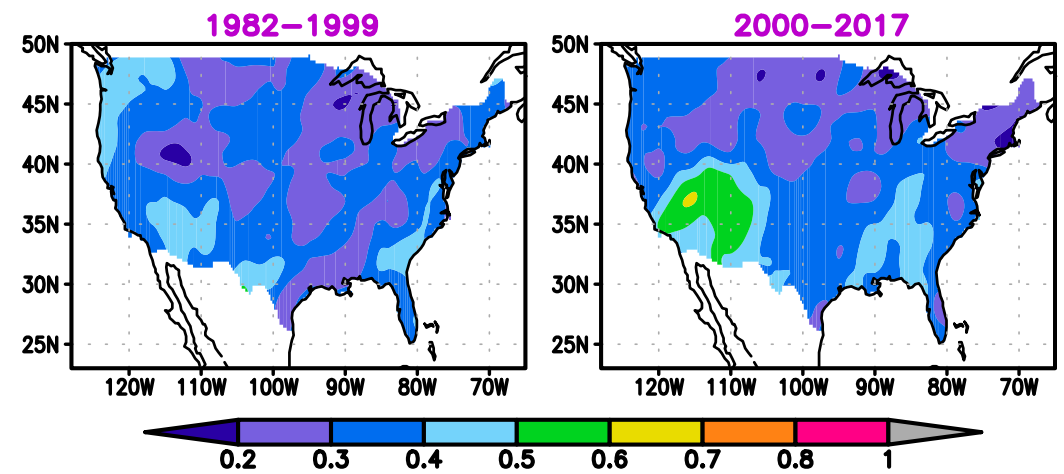

FIG. 8 . The signal/noise ratio estimated from the ratio between the standard deviation of the ensemble mean and the ensemble departures from the 10-member CCSM4 2-month reforecasts of precipitations for (a) DJF, (b) MAM, (c) JJA, and (d) SON. (left) 1982-99 and (right) 2000-17. The shading scale is shown at the bottom of the figure. 


\section{The most predictable mode of SON precip. [mm/day] (detrended)}

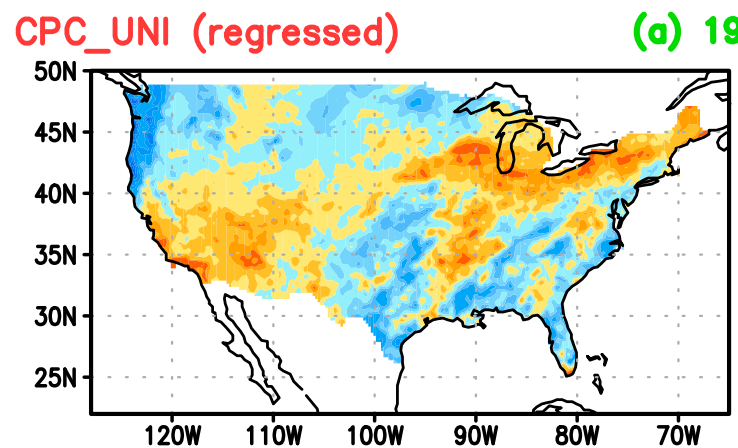

$33.4 \%$ CFSv2 (July IC)

(b) 1979-1999
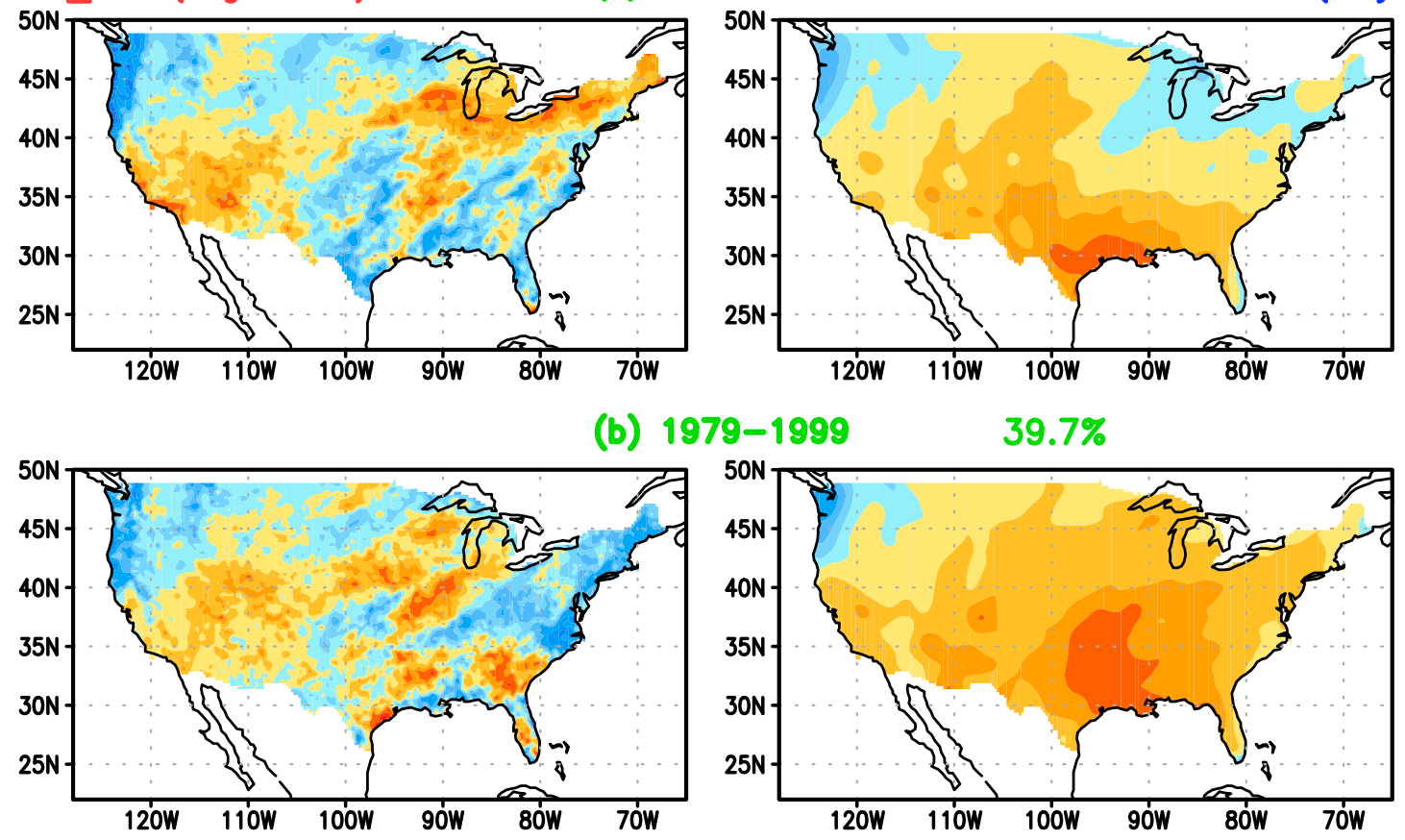

(c) 2000-2016

$47.7 \%$
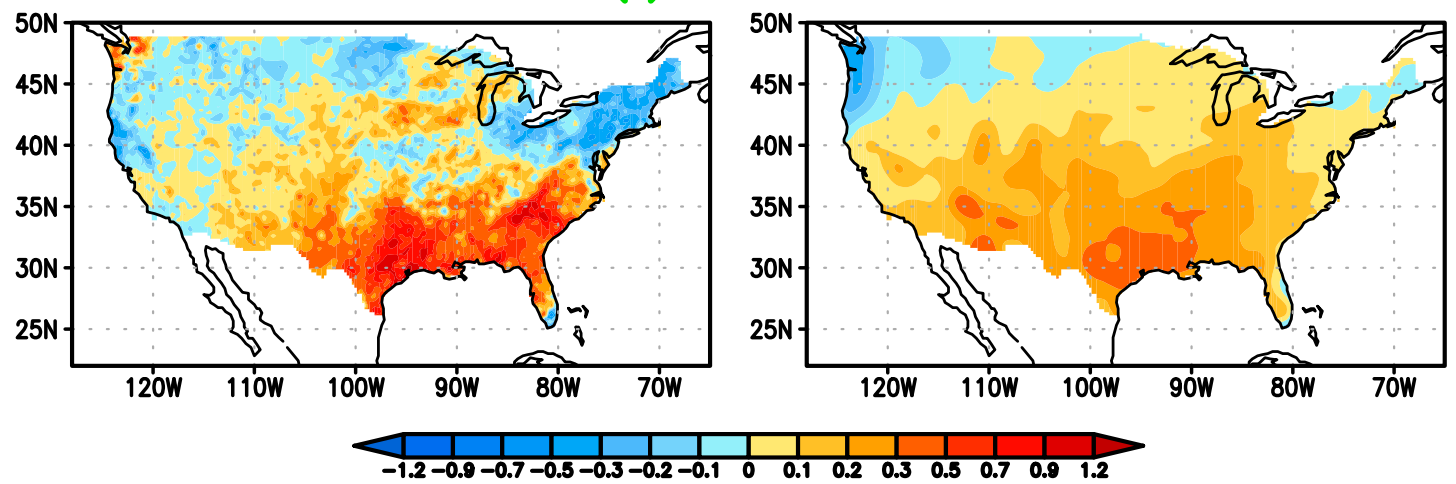

(d) PC Time Series
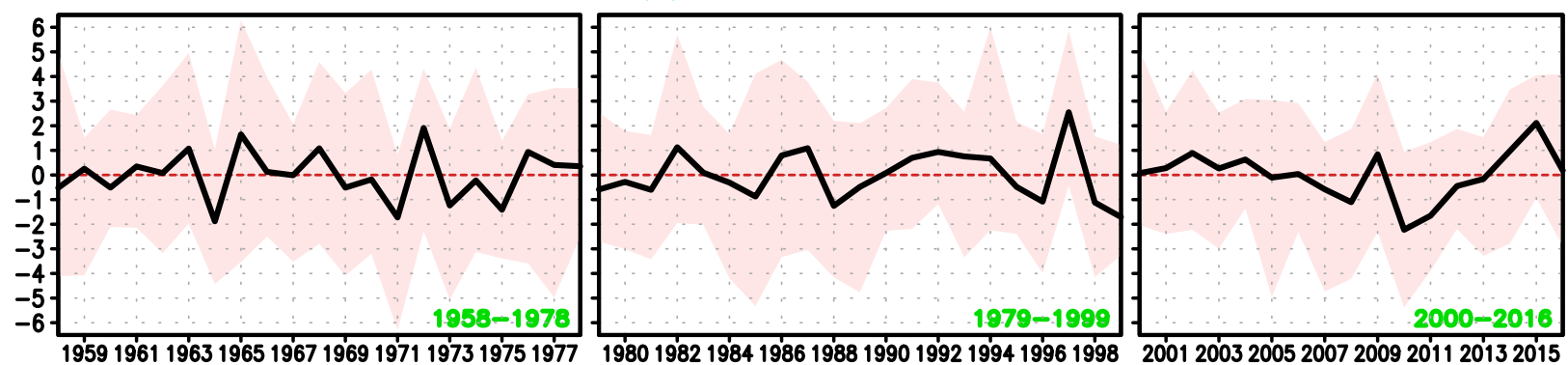

FIG. 9. [(a)-(c), right panels] The spatial patterns of the first MSN EOF modes for the SON U.S. precipitation in (a) 1958-78, (b) 197999, and (c) 2000-16. The corresponding MSN PCs are shown in (d) for the three periods in the order from left to right. The MSN PCs are normalized while the MSN EOF patterns have unit $\mathrm{mm}_{\text {day }}{ }^{-1}$. The percentage of the total variance of the ensemble mean precipitation anomalies explained by the first MSN EOF mode is given at the top of the right panels in (a)-(c). The month of initialization is given on the top right of the figure. [(a)-(c), left panels] The spatial distribution for the regressional coefficients of the observed seasonal precipitation anomalies with the corresponding MSN PCs. The color bar at the bottom of (c) shows the shading scale for the spatial patterns. The shading in (d) shows the envelope of the projections of all ensemble members onto the MSN EOF spatial patterns. 
The most predictable mode of DJF precip. [mm/day] (detrended) CPC_UNI (regressed) $\quad$ (a) 1958-1978 54.4\% CFSv2 (Oct. IC)
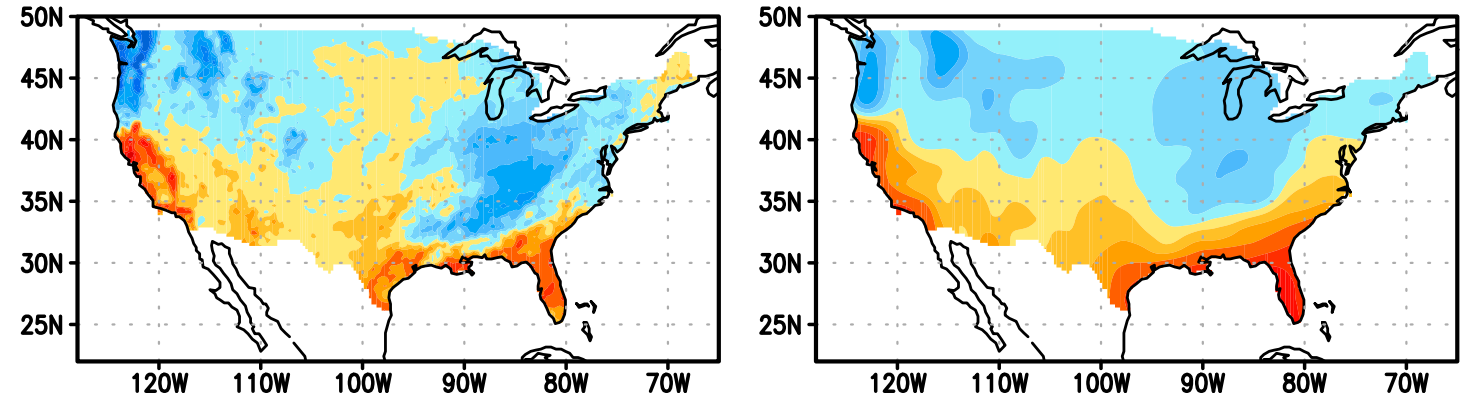

(b) 1979-1999

$68.3 \%$
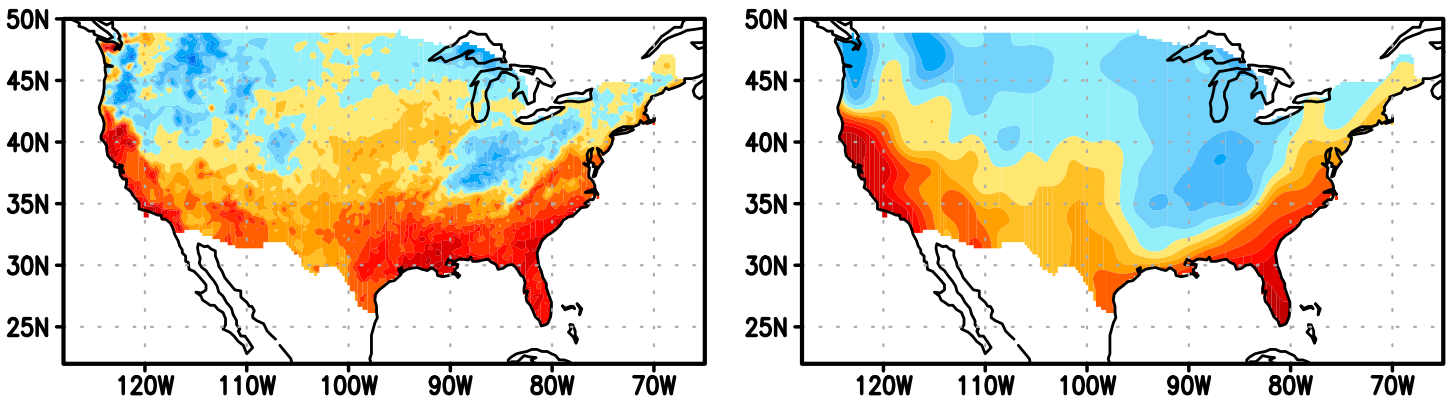

(c) 2000-2016

$76.5 \%$

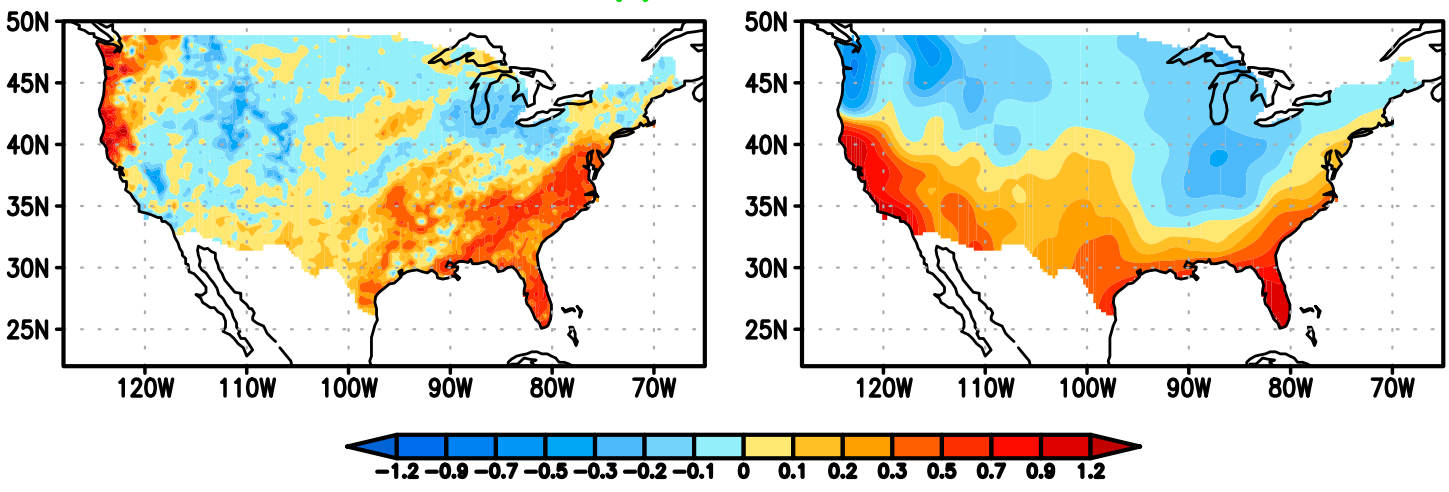

(d) PC Time Series
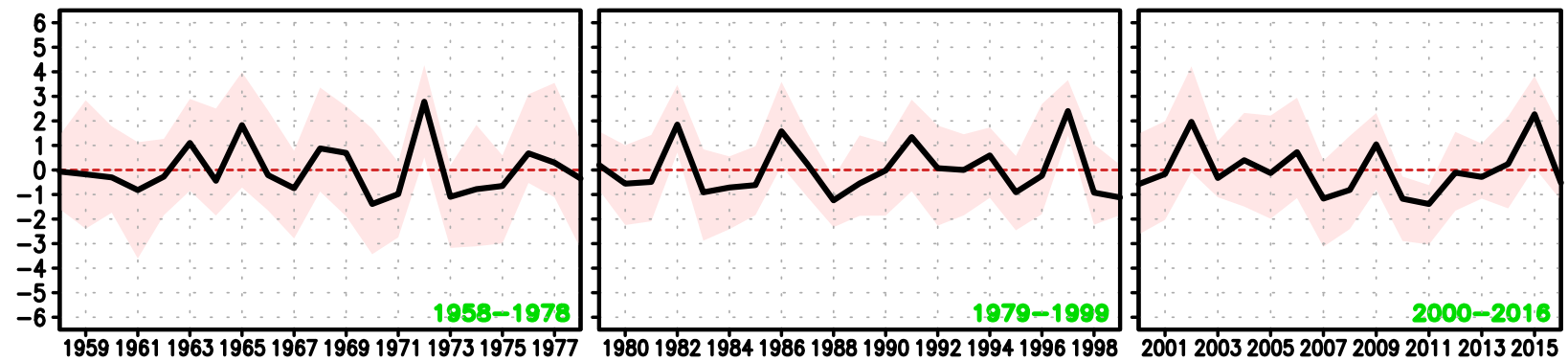

FIG. 10. [(a)-(c), right panels] The spatial patterns of the first MSN EOF modes for the DJF U.S. precipitation in (a) 1958-78, (b) 197999, and (c) 2000-16. The corresponding MSN PCs are shown in (d) for the three periods in the order from left to right. The MSN PCs are normalized while the MSN EOF patterns have unit $\mathrm{mm} \mathrm{day}^{-1}$. The percentage of the total variance of the ensemble mean precipitation anomalies explained by the first MSN EOF mode is given at the top of the right panels in (a)-(c). The month of initialization is given on the top right of the figure. [(a)-(c), left panels] The spatial distribution for the regressional coefficients of the observed seasonal precipitation anomalies with the corresponding MSN PCs. The color bar at bottom of (c) shows the shading scale for the spatial patterns. The shading in (d) shows the envelope of the projections of all ensemble members onto the MSN EOF spatial patterns. 
corresponding observed regression patterns since the latter may be considered equivalently as a single ensemble member. Another interesting point to note is that variations in the spatial pattern in the ensemble mean (Figs. 10a-c, right panels) are much less than in observations (Figs. 10a-c, left panels) since the latter is equivalent to a single realization with stronger influence of internal variability.

The first MSN EOF patterns in spring (MAM) (right panels, Figs. 11a-c) share the characteristics with their DJF counterparts in the general north-south dipole structure and with resemblance to observations (left panels, Figs. 11a-c). The unique feature of the MAM patterns is the northward expansion of the anomalies in the southwest, especially near the Great Plains, which was also seen in the $\mathrm{S} / \mathrm{N}$ ratio distributions (Fig. 6b). This is possibly associated with the initiation of the seasonal enhancement of the northward transport of moisture. Similar to DJF, the MAM MSN PCs also show significant ENSO connection and tight ensemble envelope. Large precipitation anomalies in Texas and Great Plains during the spring months of ENSO onset and decay and the associated atmospheric anomalies were discussed in Lee et al. (2014).

On the other hand, the first JJA MSN EOF modes (Fig. 12) show very different features from those of the other three seasons. The predictable spatial patterns in JJA (right panels, Figs. 12a-c) are characterized by the continental-scale precipitation anomalies centered at the Great Plains and the Midwest for all three periods. These summer precipitation centers have long been recognized (e.g., Ting and Wang 1997) and are physically associated with the interannual variability of the Great Plains low-level jet (GPLLJ) (e.g., Harding and Snyder 2015), the ENSO influence (e.g., Barlow et al. 2001), and the meridional moisture transport by the fluctuations of the North Atlantic subtropical high (e.g., Li et al. 2018). The observed regression patterns (right panels, Figs. 12a-c) generally do not show a substantial resemblance to the model predictable patterns, except for maybe the 2000-17 when somewhat enhanced variability in the central United States was observed (left panel, Fig. 12c). The MSN PCs (Fig. 12d) show major positive years $(1969,1972,1983,1993,1997,2000$, and 2015) and major negative years (1963, 1964, 1971, 1977, 1981, 1988-91, 2010, and 2013) that are partially, but not exclusively associated with warm and cold ENSO events, respectively. It is also noticeable that the envelope of the ensemble member projections is significantly wider in JJA than in other seasons. Within the JJA season, the spread is also notably larger in 1958-78 and, correspondingly, the explained variance is smallest in this period.
In summary, the above analysis shows a substantial seasonal dependence of the predictable patterns in the U.S. precipitation. The predictability and prediction skill of the U.S. precipitation are generally higher in DJF and MAM. The most predictable patterns in these seasons feature a characteristic north-south dipole structure with enhancements in the east and west regions. The co-occurrence of the MSN-EOF peaks and the major ENSO events suggests a significant influence of the latter in these seasons. This is consistent with the ENSO composites of the NMME predictions (Chen et al. 2017). The SON modes show a somewhat different spatial pattern and weaker ENSO influence. The JJA patterns, on the other hand, are more distinctive from the other seasons and suggest lower predictability and prediction skill. The analysis also demonstrates substantial multidecadal change in the model's predictive skill and predictability, with apparent greater predictability in the post-1979 periods, especially 1979-99, than during 1958-78.

\section{Oceanic forcing to the seasonal predictability of U.S. precipitation}

In this section, we further investigate the connections between the predictable patterns of the U.S. seasonal precipitation and the global SST anomalies in the reforecasts and observations on a seasonal basis. In the left panel of Fig. 13a, the lead-lag correlations are generally high $(>0.6)$ between the SON MSN PC1 and the model monthly mean Niño-3.4 index stratified by calendar month throughout the forecast duration from $\operatorname{July}(0)$ to June $(+1)$. Hereafter, the number $(-1,0,+1)$ in the parentheses next to a calendar month indicates the previous, present, and next year, respectively. The correlations peak in SON to $0.8-0.9$ for all three periods and then decrease gradually to 0.6 for 1958-78 (red curve) and 1979-99 (blue curve) but still above 0.8 for 2000-16 (green curve). As a comparison, we also show the lead-lag correlations of the SON MSN PC1 with the observed Niño-3.4 index for a broader range from October $(-1)$ to September(+1). It can be seen that the MSN PC1 in SON is highly correlated (above $0.8)$ with the Niño-3.4 index from June $(0)$ to $\mathrm{May}(+1)$ in the periods of 1979-99 (blue curve) and 2000-16 (green curve) and decreases quickly before and after this episode. For 1958-78, the high correlation (red curve) is from June(0) to December(0), decreasing earlier than the other two periods, and than its model counterpart (red curve, left panel, Fig. 13a). For both the model and observations, the duration of the sustained high correlation and phase lock to the calendar months correspond to the lifespan of a typical ENSO 
The most predictable mode of MAM precip. [mm/day] (detrended)
CPC_UNI (regressed)
(a) 1958-1978
$49.1 \%$
CFSv2 (Jan. IC)
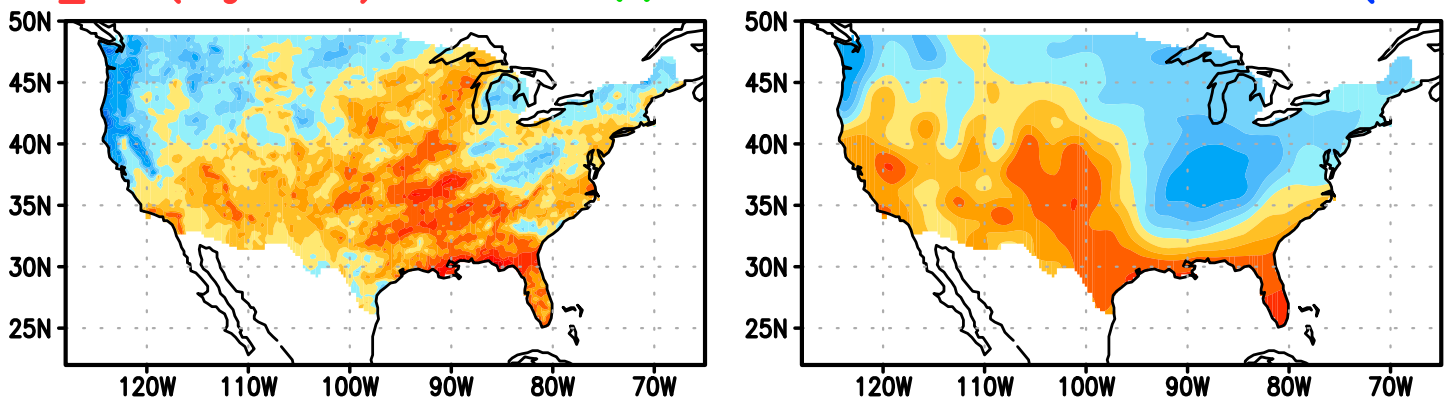

(b) 1979-1999

$57.7 \%$
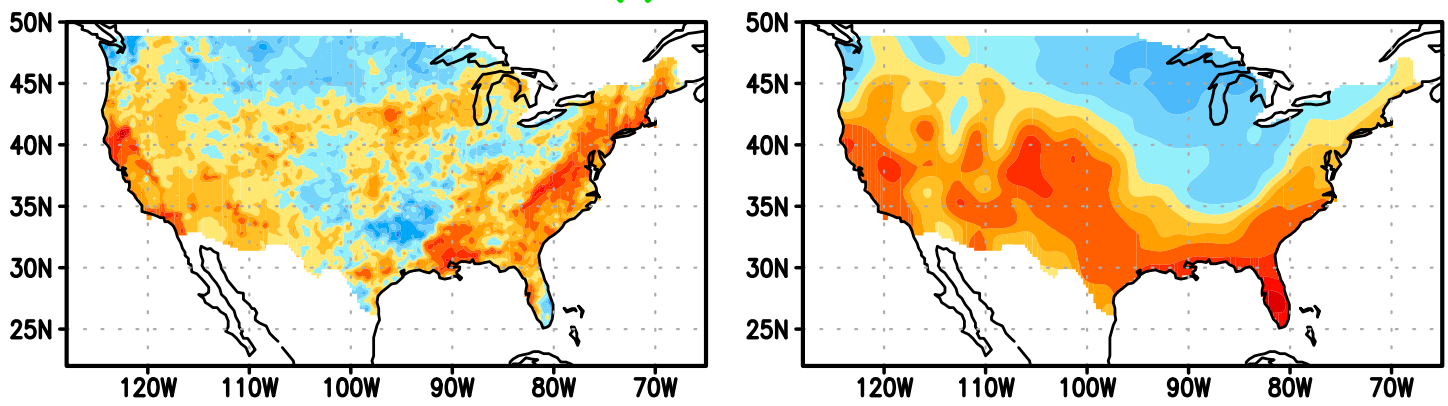

(c) 2000-2017

$54.5 \%$

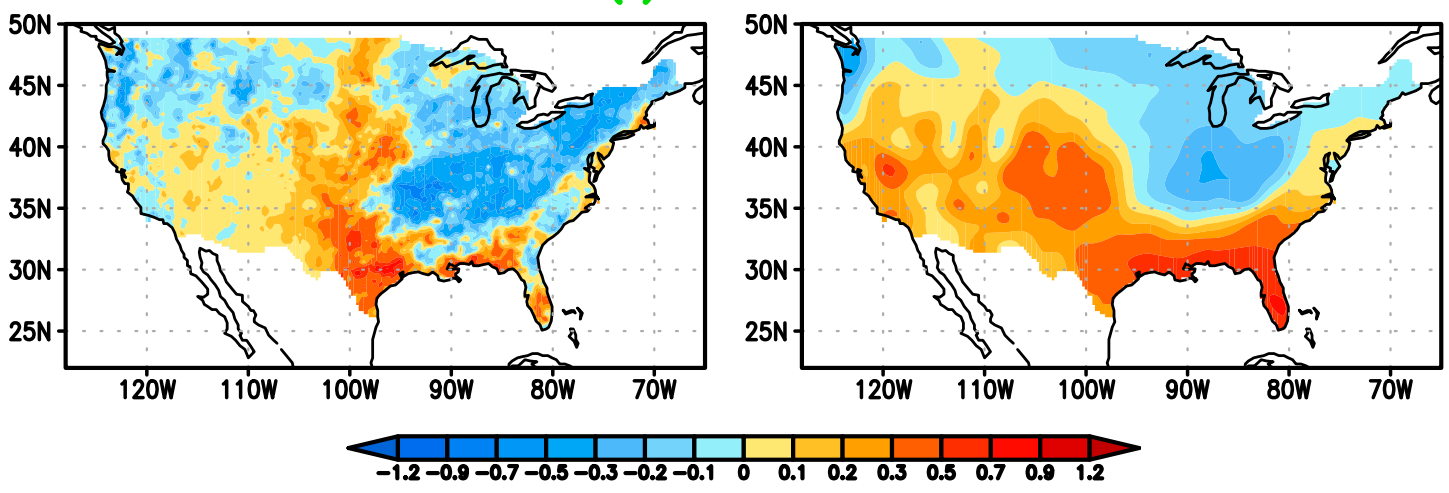

(d) PC Time Series
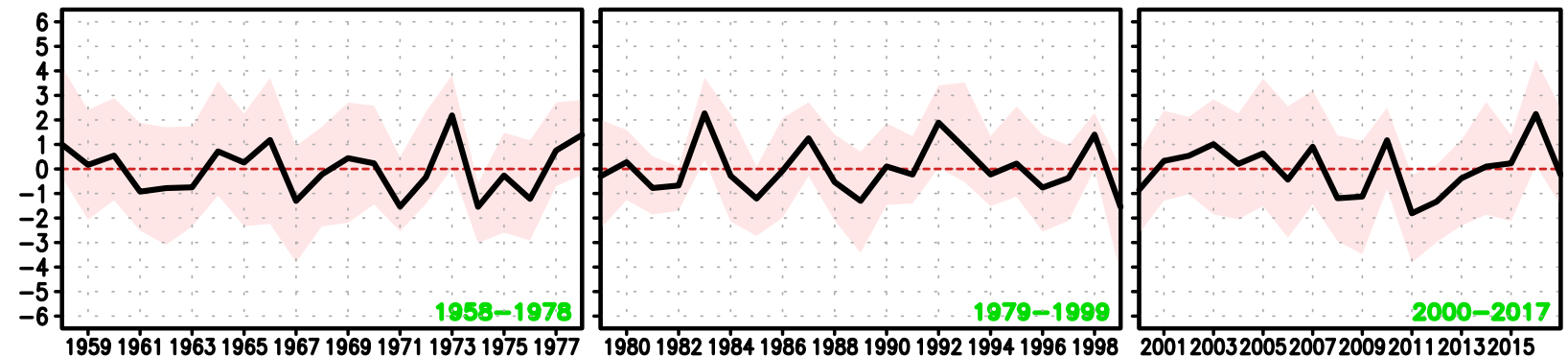

FIG. 11. [(a)-(c), right panels] The spatial patterns of the first MSN EOF modes for the MAM U.S. precipitation in (a) 1958-78, (b) 1979-99, and (c) 2000-17. The corresponding MSN PCs are shown in (d) for the three periods in the order from left to right. The MSN PCs are normalized while the MSN EOF patterns have unit $\mathrm{mm} \mathrm{day}^{-1}$. The percentage of the total variance of the ensemble mean precipitation anomalies explained by the first MSN EOF mode is given at the top of the right panels in (a)-(c). The month of initialization is given on the top right of the figure. [(a)-(c), left panels] The spatial distribution for the regressional coefficients of the observed seasonal precipitation anomalies with the corresponding MSN PCs. The color bar at bottom of (c) shows the shading scale for the spatial patterns. The shading in (d) shows the envelope of the projections of all ensemble members onto the MSN EOF spatial patterns. 


\section{The most predictable mode of JJA precip. [mm/day] (detrended)}
CPC_UNI (regressed)
(a) 1958-1978
$19.8 \%$
CFSv2 (Apr. IC)
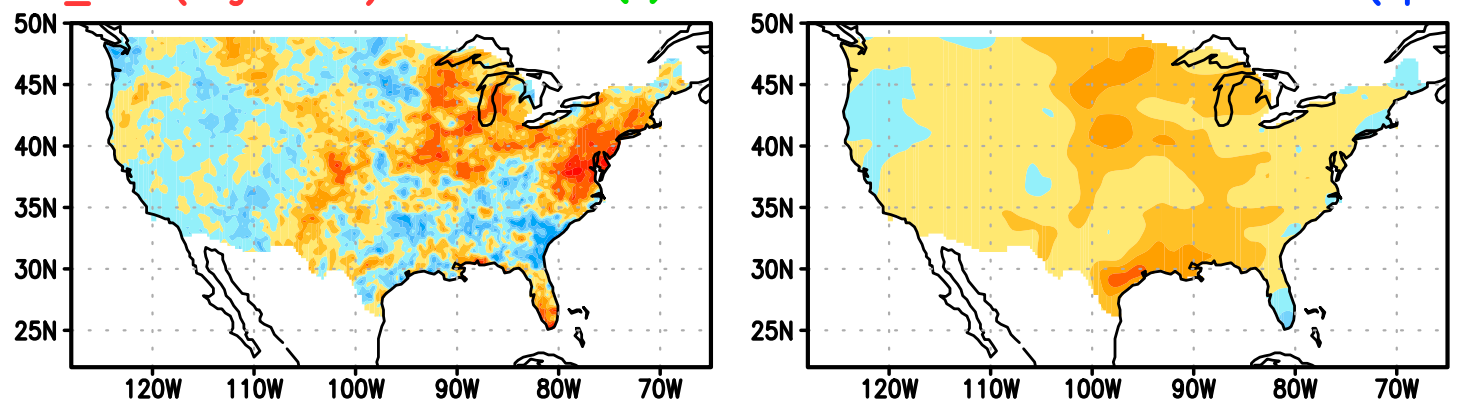

(b) $1979-1999$

$35.5 \%$
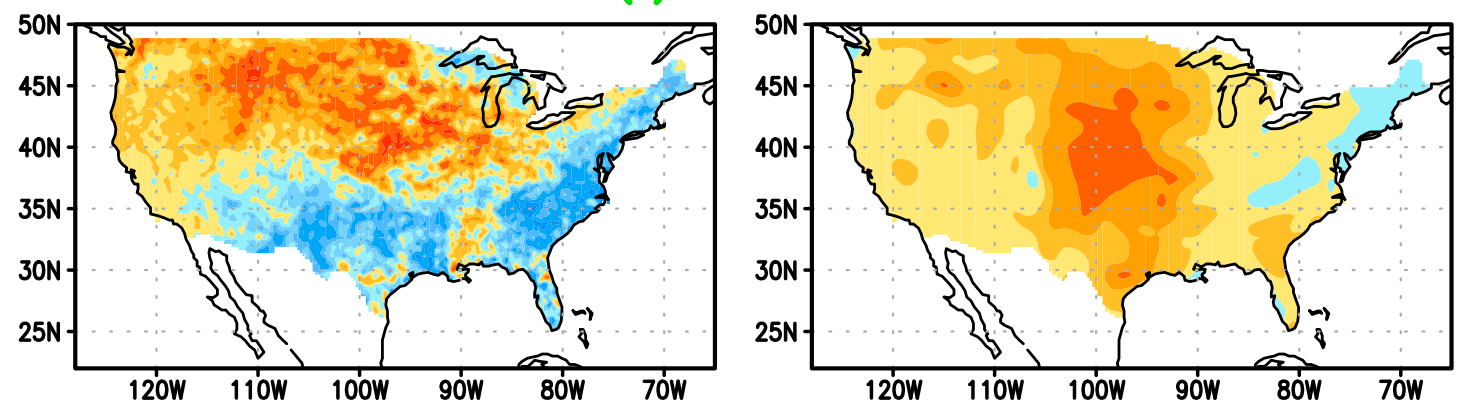

(c) 2000-2017

$30.5 \%$
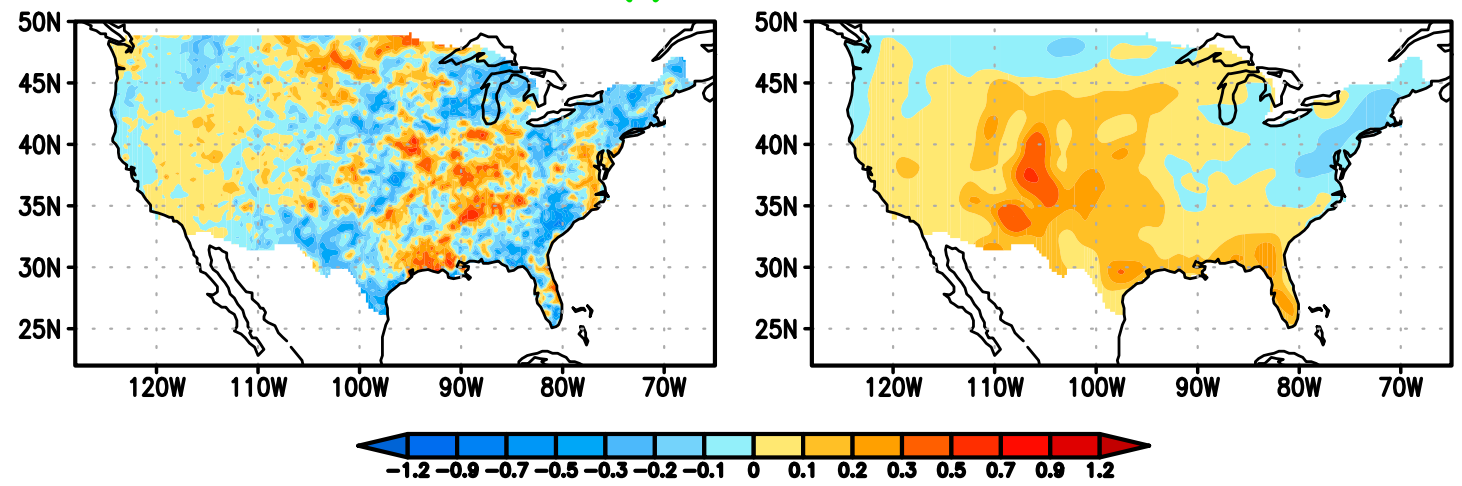

(d) PC Time Series
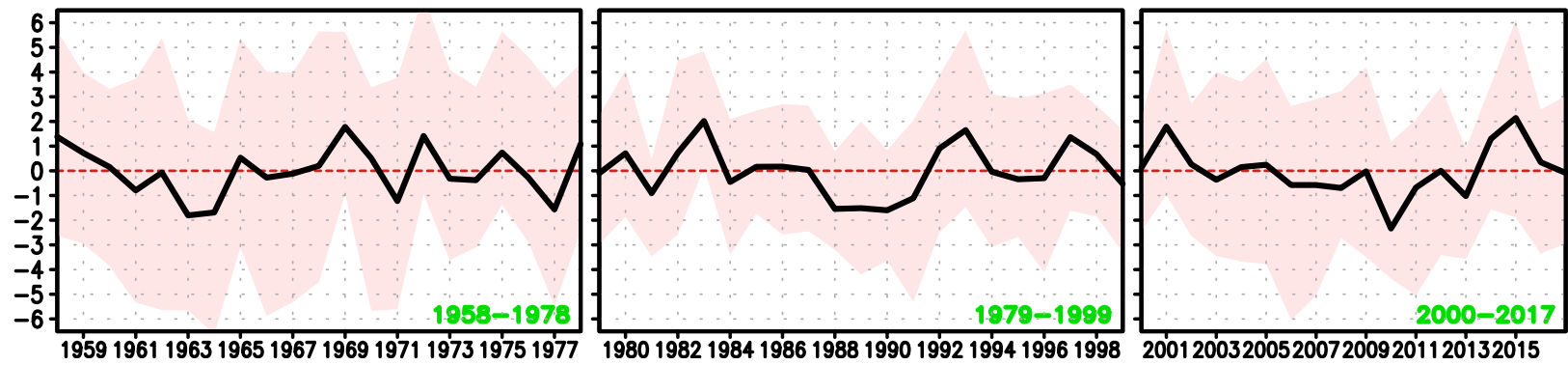

FIG. 12. [(a)-(c), right panels] The spatial patterns of the first MSN EOF modes for the JJA U.S. precipitation in (a) 1958-78, (b) 197999, and (c) 2000-17. The corresponding MSN PCs are shown in (d) for the three periods in the order from left to right. The MSN PCs are normalized while the MSN EOF patterns have unit $\mathrm{mm} \mathrm{day}^{-1}$. The percentage of the total variance of the ensemble mean precipitation anomalies explained by the first MSN EOF mode is given at the top of the right panels in (a)-(c). The month of initialization is given on the top right of the figure. [(a)-(c), left panels] The spatial distribution for the regressional coefficients of the observed seasonal precipitation anomalies with the corresponding MSN PCs. The color bar at bottom of (c) shows the shading scale for the spatial patterns. The shading in (d) shows the envelope of the projections of all ensemble members onto the MSN EOF spatial patterns. 
CFSv2

(a) Lead/lag correlation between NIN03.4 and PC1

OBS.
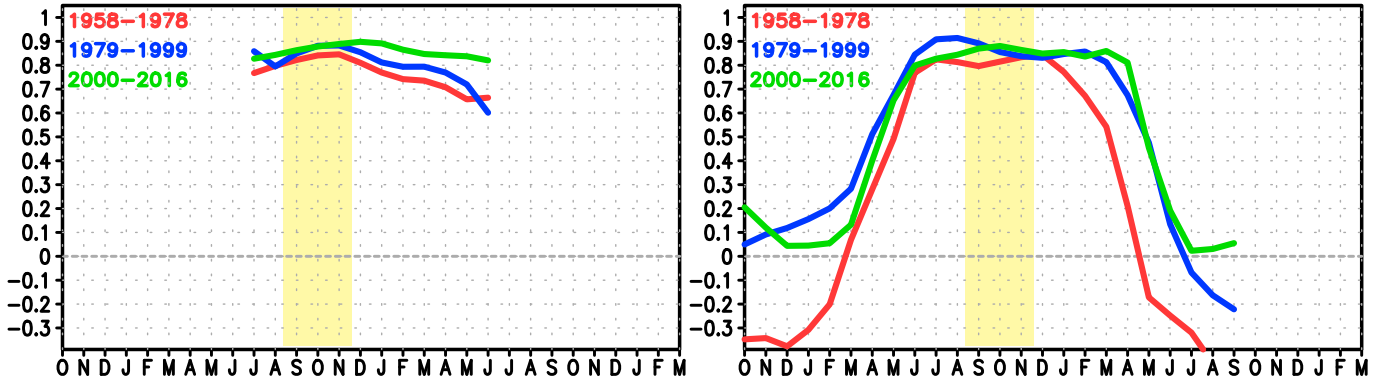

Anomaly Correlation between SSTA (SON) and PC1

CFSv2

(b) 1958-1978

OBS.
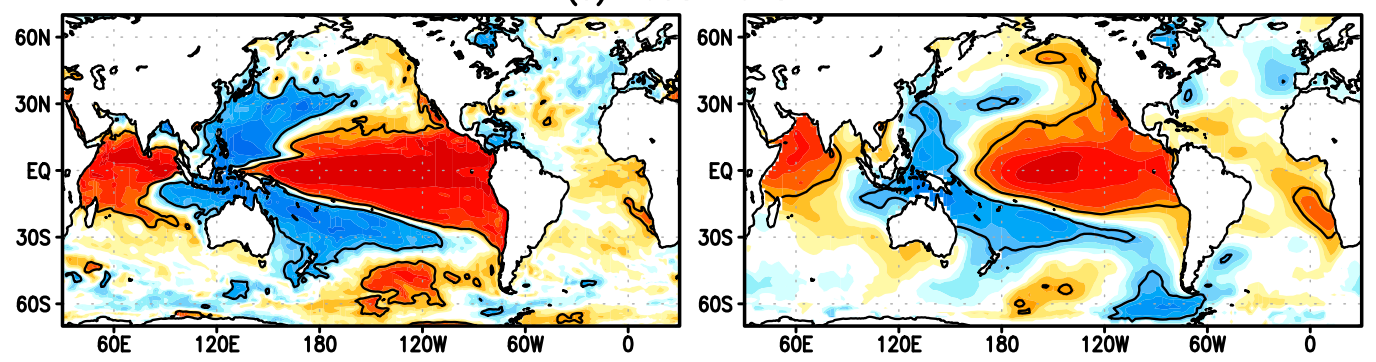

(c) 1979-1999
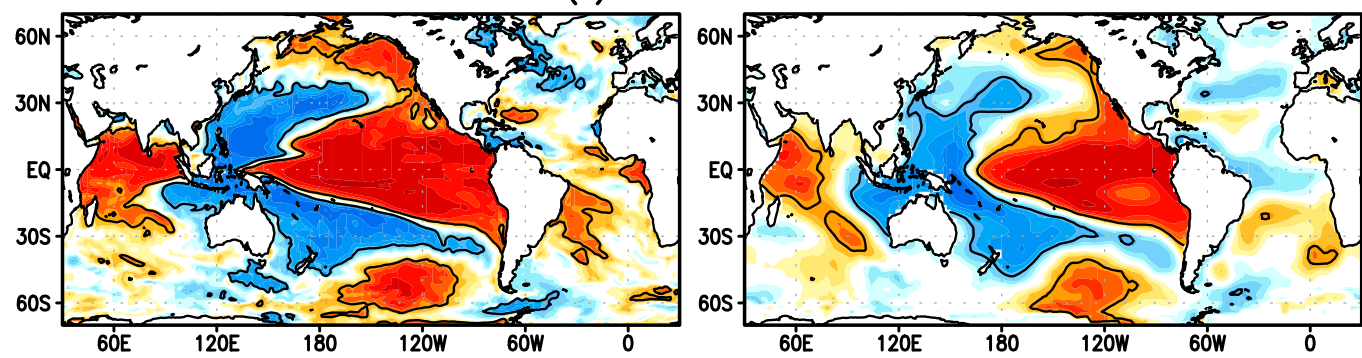

(d) 2000-2016

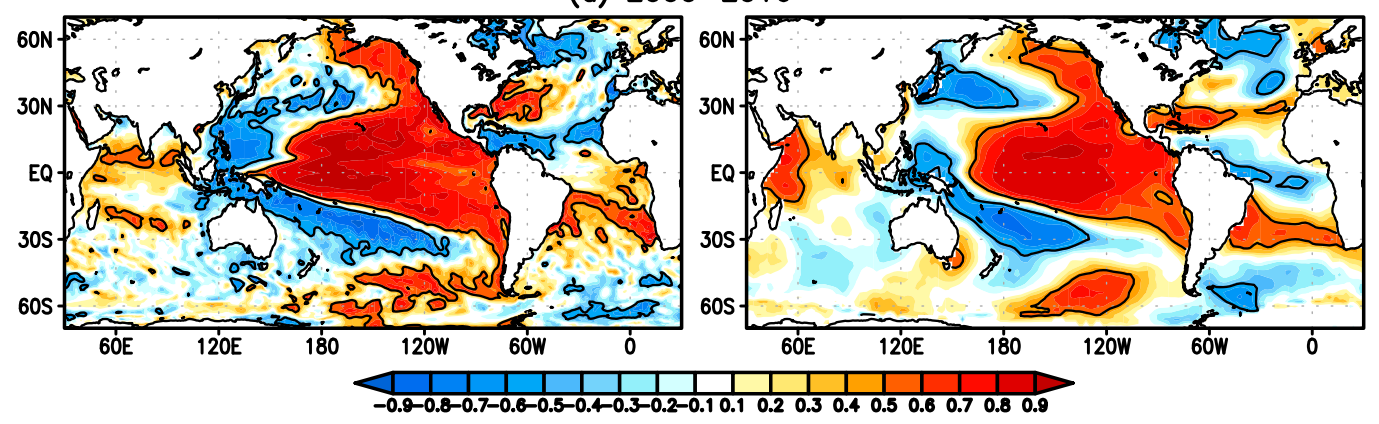

FIG. 13. (a) (left) The correlation coefficients of the SON MSN PC1 with the model Niño-3.4 index of specific calendar months from $\operatorname{July}(0)$ to June $(+1)$. (right) Its correlation with the observed Niño-3.4 index from October $(-1)$ to September $(+1)$. Here, the number $(-1,0,+1)$ in the parentheses indicates the previous, present, and next year, respectively. The red, blue, and green curves correspond to the correlations in 1958-78, 1979-99, and 2000-16. (b)-(d) The spatial distributions of the correlation coefficients of the seasonal mean SST anomalies for SON [vertical shading in (a)] with MSN PC1 for the (left) ensemble mean reforecasts and (right) observations for (b) 1958-78, (c) 1979-99, and (d) 2000-16. The contours in (b)-(d) correspond to the $95 \%$ statistical significance level. The color bar for (b)-(d) is shown at the bottom of the figure. 
event and the shorter duration with the observed Niño3.4 in 1958-78 reflects the early termination of the observed ENSO events during this period, a phenomenon that is not well captured by the reforecasts (e.g., Huang et al. 2017a).

Since the seasonal mean precipitation anomalies are more likely due to the contemporary, instead of previous SST forcing, Figs. 13b-d show the global distributions of the correlations between the SON MSN PC1 and the mean SST anomalies of the same season from the ensemble mean reforecasts (left panels) and the observations (right panels) for 1958-78 (Fig. 13b), 1979-99 (Fig. 13c), and 2000-16 (Fig. 13d). The general patterns of the correlation are quite similar among the three periods. There is also high resemblance between the model reforecasts and the observations although the former generally show higher correlations due to ensemble averaging. In the Pacific, warm SST anomalies associated with positive MSN PC1 are located in the central-to-eastern tropical Pacific and extend northward to the North Pacific near the North American coast. The cold SST anomalies form a V-shape pattern centered near the Maritime Continent and extending eastward and poleward into extratropical ocean in both hemispheres. This warm and cold SST distribution is clearly ENSO-like. Moreover, the tropical SST anomalies seem to show broader meridional widths in the central and eastern Pacific, which are the characteristic of the Pacific decadal SST fluctuations described in Zhang et al. (1997) and Deser et al. (2004). The cold SST anomalies near the western Pacific extend into the eastern equatorial Indian Ocean near the Sumatra coast, which, together with the warm SST anomalies in the western Indian Ocean, form the Indian Ocean dipole (IOD) pattern that peaks in SON (Saji et al. 1999). This suggests a tight connection between the Pacific and Indian Ocean (e.g., Huang and Kinter 2002), especially during the earlier two periods. In comparison, the Atlantic SST anomalies are not significantly correlated with the MSN PC1 except for 2000-16, when a negative AMV pattern seems to prevail during the positive phases of the latter (Fig. 13d). The Atlantic influence is relatively weak in SON because the SST anomalies in the northern tropical Atlantic in response to ENSO are strongest in April-June (e.g., Enfield and Mayer 1997).

Similar lead-lag Niño-MSN PC correlations can be seen for the DJF (Fig. 14a) and MAM (Fig. 15a) cases. The fact that the high correlations for these two seasons occur in exactly the same lead-lag months confirms the central role of the ENSO forcing. The contemporary correlation maps of the SST anomalies and the MSN PCs (Figs. 14b-d and 15b-d) also show somewhat similar features to those described for SON. On the other hand, the SST anomalies are more centered in the central and eastern equatorial Pacific and seem to show narrower meridional span than their SON counterparts, suggesting a stronger ENSO influence in these two seasons. Other distinctive features of the DJF and MAM correlation patterns include stronger positive correlations in the tropical Atlantic Ocean (especially in the reforecasts), the expansion of the positive correlations from the west to the whole basin of the tropical Indian Ocean (Huang and Kinter 2002; Zhu et al. 2015; Shin et al. 2019), the stronger South Pacific dipole (Guan et al. 2014), and the South Atlantic dipole (Huang 2004). One should note that these features are generally associated with the ENSO global teleconnection, which are strongest in these two seasons (Kumar et al. 2014b). Therefore, whether these SST anomalies provide additional oceanic forcing to the U.S. seasonal precipitation need further investigation.

The lead-lag correlations of the JJA MSN PC1 with Niño-3.4 (Fig. 16a) show quite different characteristics from the other three seasons. Furthermore, there is a clear distinction between the periods of 1958-78 (red curve) and 1979-99 (blue curve) and the last period (2000-17, green curve) for both the reforecasts and the observations. In the first two periods, the model correlations (left panel, Fig. 16a) peak in April at 0.4 in 1958-78 (red curve) and in June at 0.7 in 1979-99 (blue curve) before decaying quickly in the next few months. In 2000-17 (green curve), however, the model correlation increases from 0.2 in April quickly to above 0.7 in June and maintains near this level until the coming April, which seems more consistent with the time span of a typical ENSO event. Similar patterns emerge in the correlations of the JJA MSN PC1 with the observed Niño-3.4, except that the peaking correlations for the 1958-78 and 1979-99 periods occur in February and the sustained higher-level correlations for 2000-17 start in March. One of the complicating factors for explaining the correlation patterns is that, statistically, the JJA season can be influenced by the decaying ENSO anomalies associated with the terminating events in some years but by the growing ENSO anomalies associated with the emerging anomalous events in some other years (Kumar and Hoerling 2003). For the two periods with relatively high correlations, we speculate that the 1979-99 period is dominated by the former situation while the most recent period by the latter. The later times of the peaking correlation in the reforecasts may possibly be due to the influences of the initial shock, which seems to be stronger during the seasonal transition from spring to summer than other seasonal 
CFSv2

(a) Lead/lag correlation between NINO3.4 and PC1

OBS.
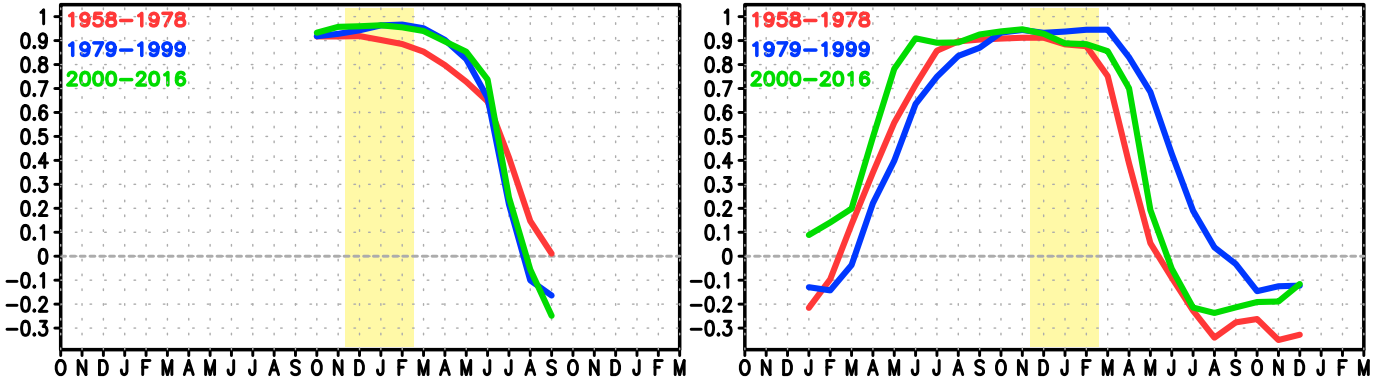

Anomaly Correlation between SSTA (DJF) and PC1

CFSv2

(b) 1958-1978

OBS.
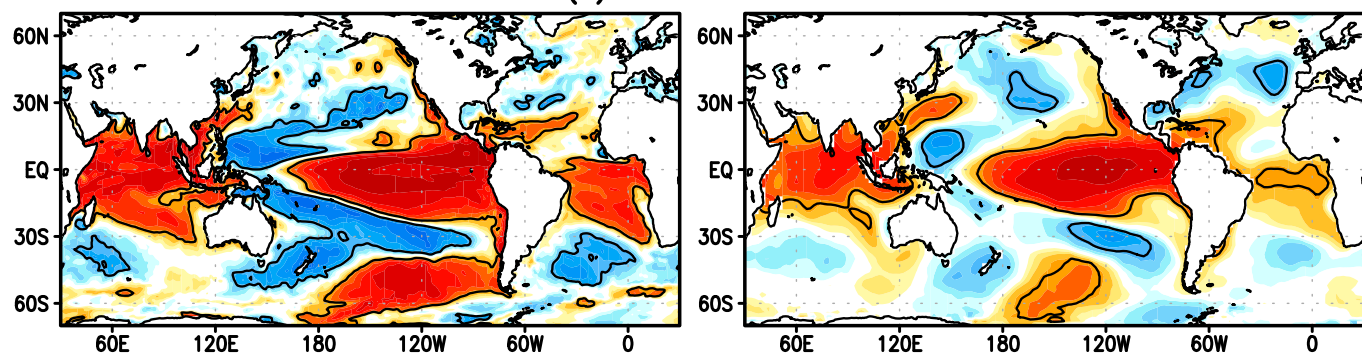

(c) 1979-1999
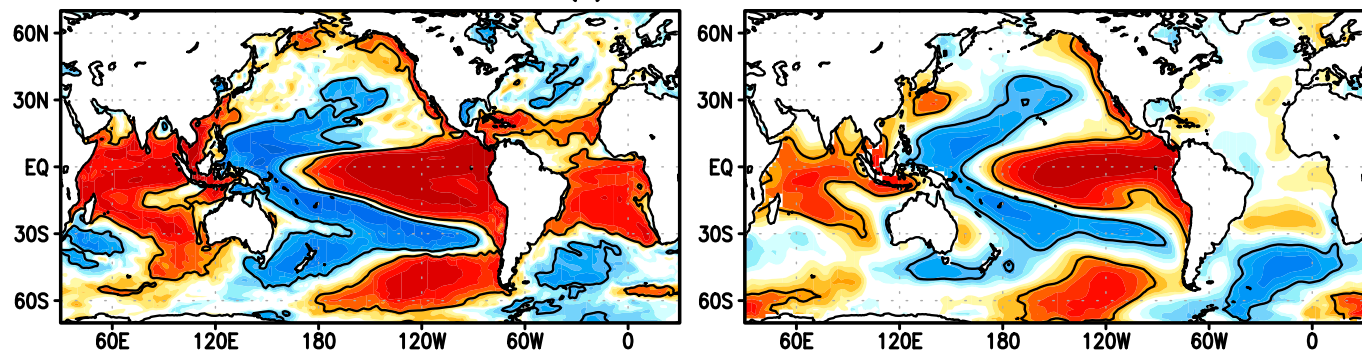

(d) 2000-2016

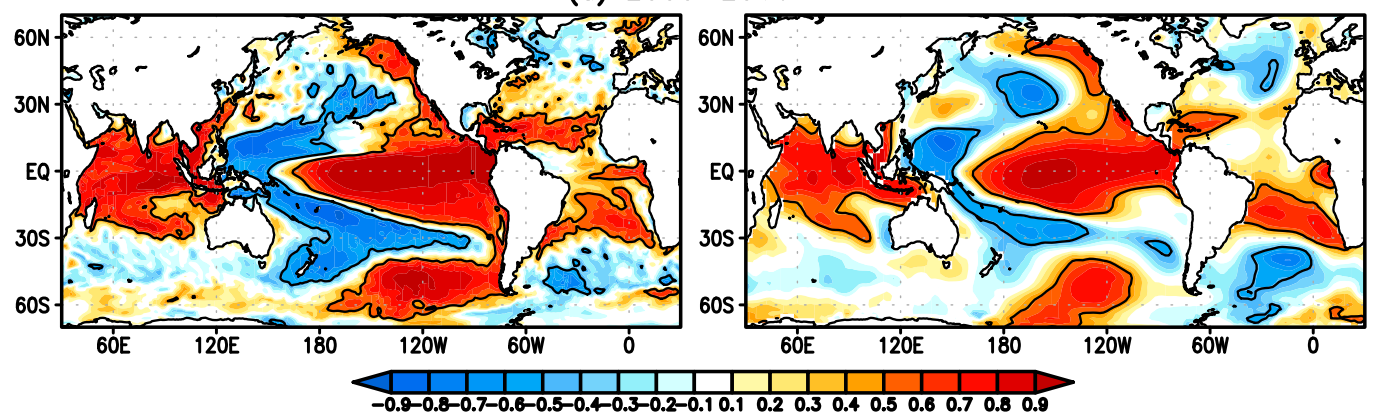

FIG. 14. (a) (left) The correlation coefficients of the DJF MSN PC1 with the model Niño-3.4 index of specific calendar months from October $(0)$ to September $(+1)$. (right) Its correlation with the observed Niño-3.4 index from January $(0)$ to December $(+1)$. Here, the number $(-1,0,+1)$ in the parentheses indicates the previous, present, and next year, respectively. The red, blue, and green curves correspond to the correlations in 1958-78, 1979-99, and 2000-16. (b)-(d) The spatial distributions of the correlation coefficients of the seasonal mean SST anomalies for DJF [vertical shading in (a)] with MSN PC1 for the (left) ensemble mean reforecasts and (right) observations for (b) 1958-78, (c) 1979-99, and (d) 2000-16. The contours in (b)-(d) correspond to the $95 \%$ statistical significance level. The color bar for (b)-(d) is shown at the bottom of the figure. 
CFSv2

(a) Lead/lag correlation between NINO3.4 and PC1

OBS.
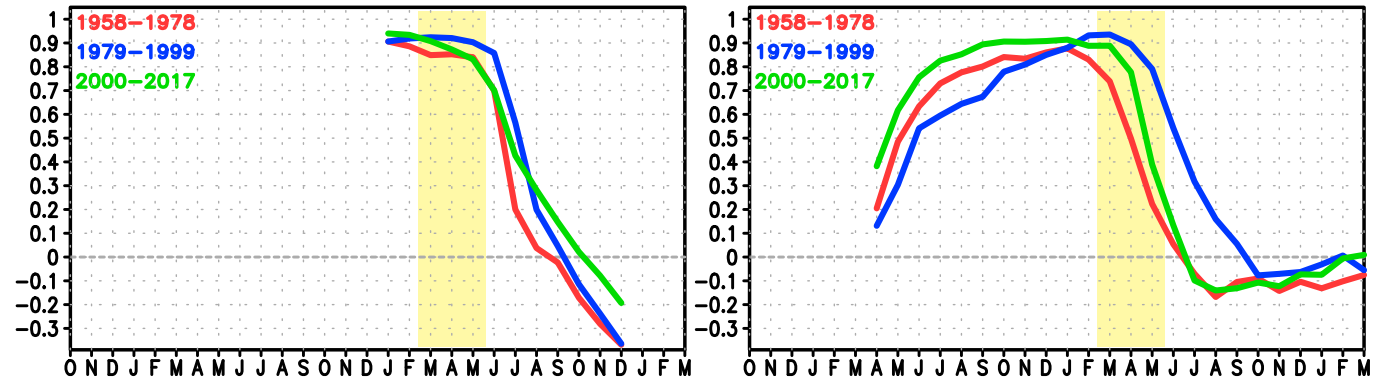

Anomaly Correlation between SSTA (MAM) and PC1

CFSv2

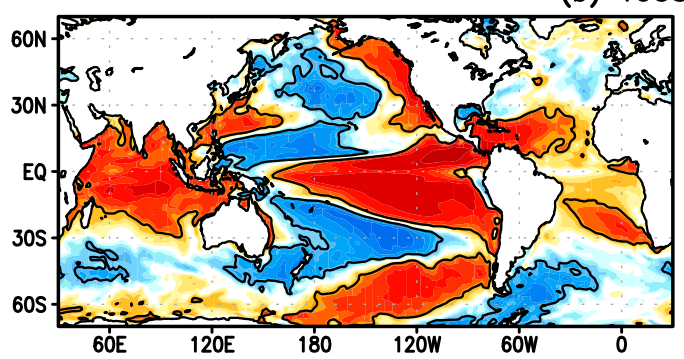

(c) $1979-1999$
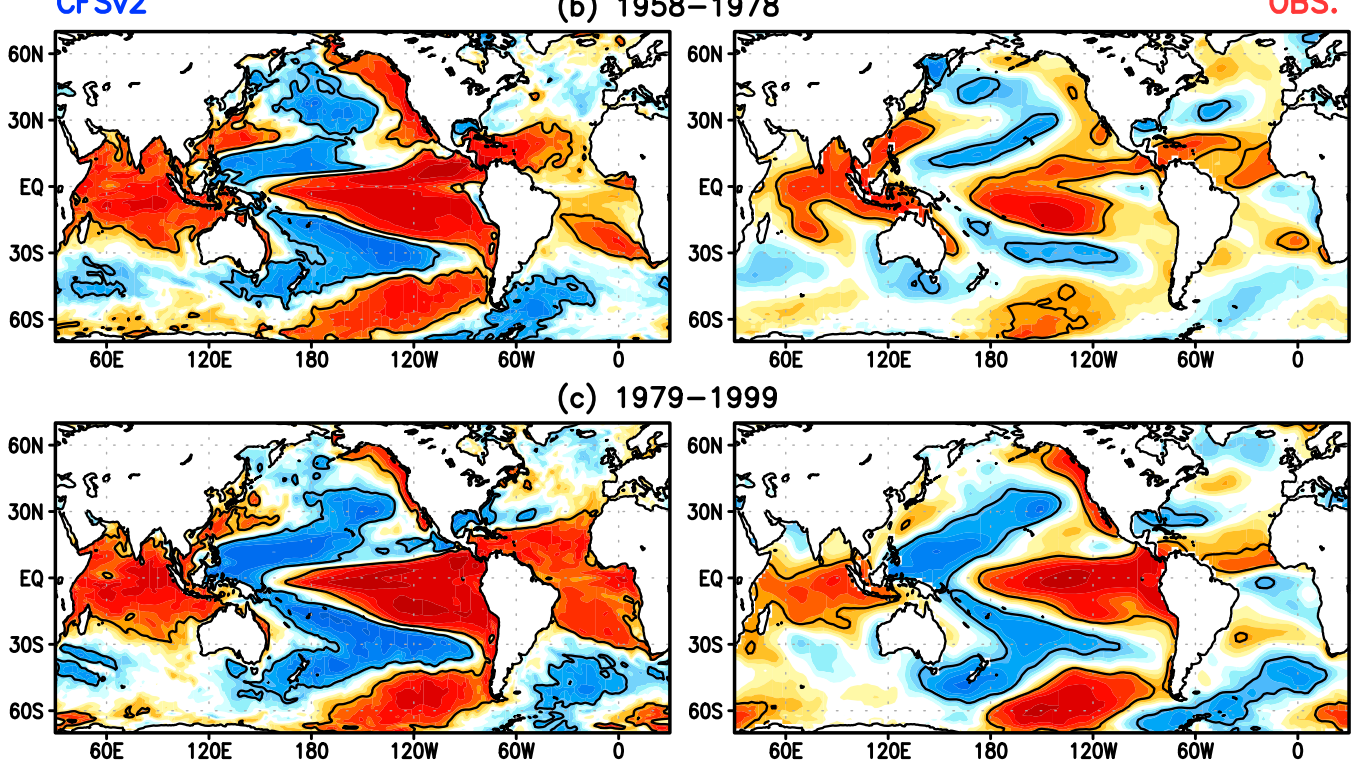

(d) 2000-2017

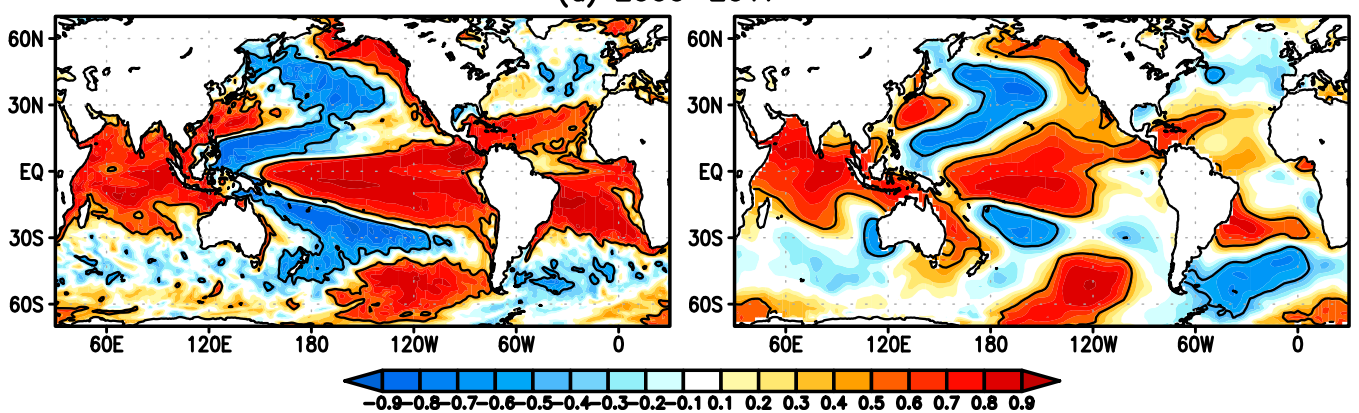

FIG. 15. (a) (left) The correlation coefficients of the MAM MSN PC1 with the model Niño-3.4 index of specific calendar months from January(0) to December(0). (right) Its correlation with the observed Niño-3.4 index from April $(-1)$ to $\operatorname{March}(+1)$. Here, the number $(-1,0,+1)$ in the parentheses indicates the previous, present, and next year, respectively. The red, blue, and green curves correspond to the correlations in 1958-78, 1979-99, and 2000-17. The vertical shading indicates the season the MSN PC1 represents. (b)-(d) The spatial distributions of the correlation coefficients of the seasonal mean SST anomalies for MAM [vertical shading in (a)] with MSN PC1 for the (left) ensemble mean reforecasts and (right) observations for (b) 1958-78, (c) 1979-99, and (d) 2000-17. The contours in (b)-(d) correspond to the $95 \%$ statistical significance level. The color bar for (b)-(d) is shown at the bottom of the figure. 
CFSv2

(a) Lead/lag correlation between NINO3.4 and PC1

OBS.
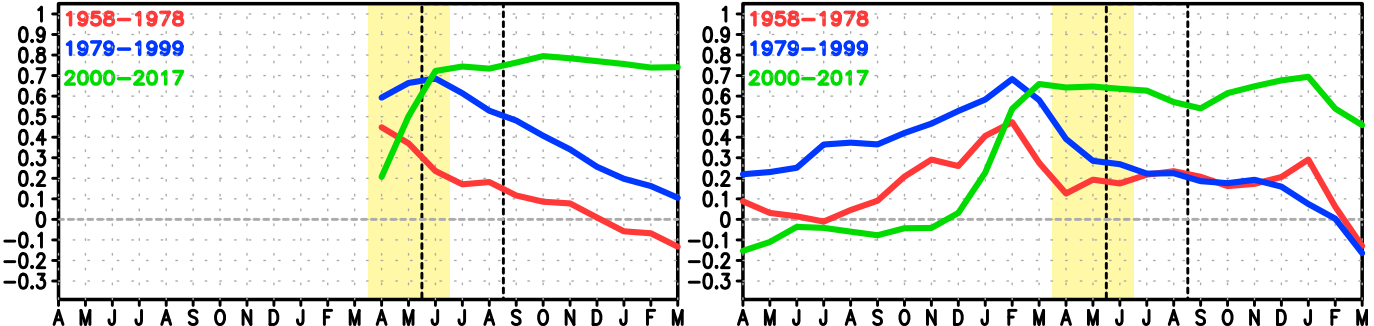

CFSv2

Anomaly Correlation between SSTA and PC1
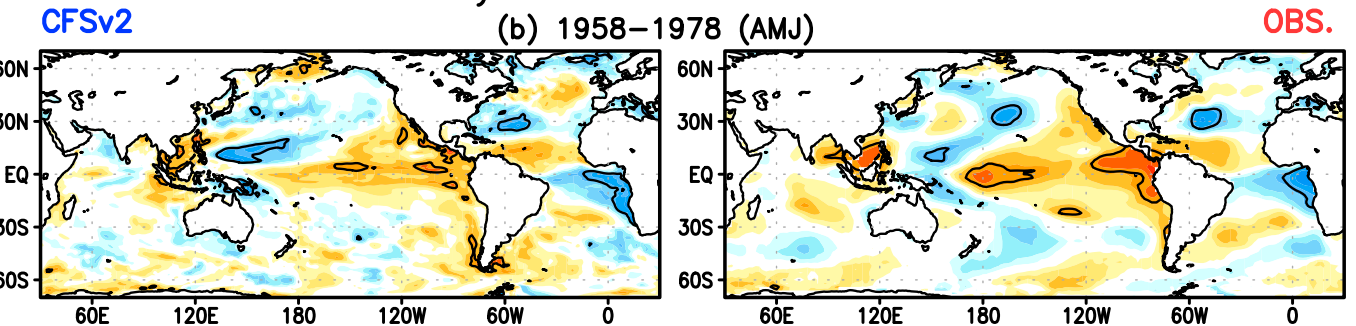

(c) 1979-1999 (AMJ)
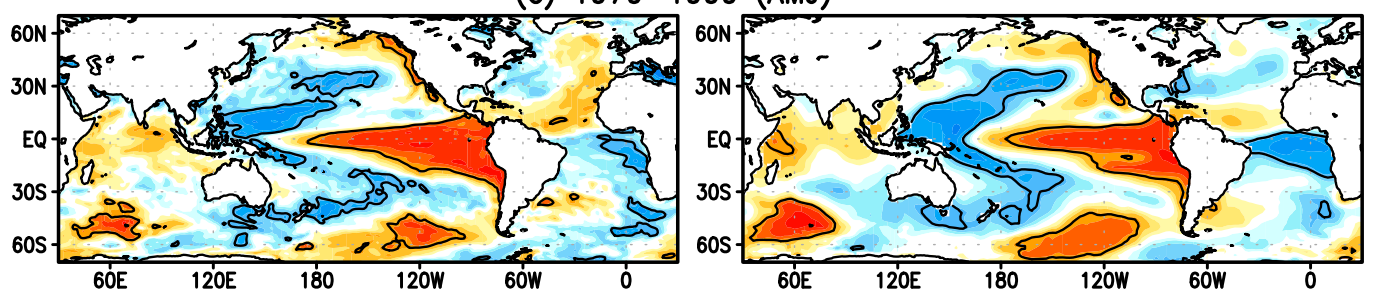

(d) 2000-2017 (AMJ)
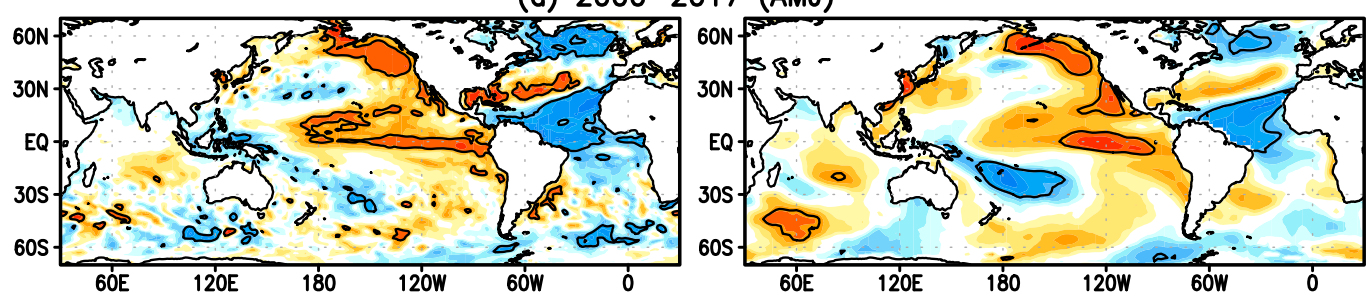

(e) 2000-2017 (JJA)

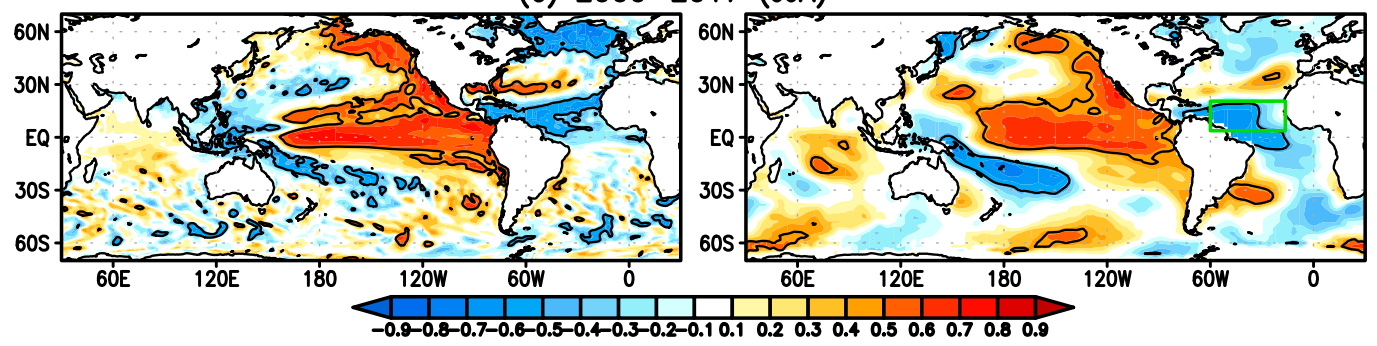

FIG. 16. (a) (left) The correlation coefficients of the JJA MSN PC1 with the model Niño-3.4 index of specific calendar months from April(0) to $\operatorname{March}(+1)$. (right) Its correlation with the observed Niño-3.4 index from April $(-1)$ to $\operatorname{March}(+1)$. Here, the number $(-1,0,+1)$ in the parentheses indicates the previous, present, and next year, respectively. The red, blue, and green curves correspond to the correlations in 1958-78, 1979-99, and 2000-17. (b)-(d) The spatial distributions of the correlation coefficients of the seasonal mean SST anomalies for AMJ [marked by the yellow shading in (a)] with MSN PC1 for the (left) ensemble mean reforecasts and (right) observations for (b) 1958-78, (c) 1979-99, and (d) 2000-17. (e) The correlation for JJA [marked by the space between the two vertical dashed lines in (a)]. The green box in the right panel of (e) outlines the averaging area for the TNA index. The contours in (b)-(e) correspond to the $95 \%$ statistical significance level. The color bar for (b)-(e) is shown at the bottom of the figure. 
transition (e.g., winter-spring transition) (e.g., Shukla et al. 2018).

Given these different correlation patterns, we have further examined the spatial distribution of the correlations between the JJA MSN PC1 with the SST anomalies averaged in April-June (AMJ) for all three periods (Figs. 16b-d) and JJA for 2000-17 (Fig. 16e). It is reassuring that the spatial patterns of the correlation are similar between the reforecasts and the observations. Furthermore, the correlation patterns for 1958-78 (Fig. 16b) and 1979-99 (Fig. 16c) are similar while the magnitudes are weaker and statistically insignificant during the former period. In general, the distributions of the SST anomalies in the Pacific during AMJ are similar to those from the other seasons although the correlations are confined in the tropics. This seems to confirm that they represent the residual ENSO influences at the terminating stage of the anomalous events. The 1958-78 correlations are weaker than the 1979-99 ones because the ENSO events in the former period generally terminated earlier (e.g., Huang et al. 2017a).

The correlation patterns seem more complicated during 2000-17. In AMJ (Fig. 16d), the SST anomalies in the central and eastern tropical Pacific are generally broader with two symmetric maxima on both sides off the equator associated with the Rossby waves reflected from the eastern boundary characterizing the decaying ENSO events. In addition, the significant SST anomalies near the North America coast also make this pattern similar to the Pacific decadal variability as described by Zhang et al. (1997), suggesting a stronger influence of the lower-frequency SST fluctuations, such as the PDO. Interestingly, the decadal-like pattern is enhanced in the coming JJA (Fig. 16e) as the offequatorial SST anomalies become less obvious. Another interesting fact for 2000-17 is the significant negative correlation in the tropical Atlantic Ocean to the north of the equator during 2000-17. Overall, the correlation pattern in the North Atlantic is negative to the AMV, or the summer horseshoe pattern, although the extratropical nodes are not statistically significant. One possibility is that the AMJ condition in the tropical Atlantic is linked to the La Niña state in the previous winter, while a weak contemporary warming occurs in the tropical Pacific due to an El Niño onset. Such transitioning from La Niña to El Niño (or El Niño to La Niña) does occur quite frequently in nature as shown, for example, in Lee et al. (2018, their Fig. 2). The opposite correlations between the tropical Pacific and the tropical North Atlantic have been identified as a major forcing factor of the U.S. precipitation in summer (e.g., Schubert et al. 2008; Mo et al. 2009).
To quantify the roles played by the SST anomalies in the tropical North Atlantic (TNA), we define a TNA index as the SST anomalies averaged in $5^{\circ}-25^{\circ} \mathrm{N}, 15^{\circ}$ $60^{\circ} \mathrm{W}$ (the green box in the right panel of Fig. 16e). Figure 17 shows its lead-lag correlations with the MSN PCs in different seasons for both the reforecasts and observations, in the same way as with the Niño-3.4 index. The patterns of correlation with the reforecast (left panels) and observed (right panels) TNA show some similarity. We will concentrate on the former because the latter has larger uncertainty. For the DJF (left panel, Fig. 17b) and MAM (left panel, Fig. 17c) predictions (initialized in October and January, respectively), the MSN PC correlations with TNA are initially small but increase in the spring season quickly to above 0.6. Its peaking correlation has the same sign as its correlation with Niño-3.4. This relationship, held for all three periods, suggests that TNA SST could be a response to ENSO and may not add predictability to the U.S. precipitation in winter-spring. For the JJA prediction (left panel, Fig. 17d), the MSN PC-TNA correlations are still positive but smaller in 1958-78 (red curve) and 1979-99 (blue curve). During 2000-17, however, the MSN PC1 for JJA is negatively correlated with TNA at around -0.6 from April to July (green curve, left panel, Fig. 17d) while its correlation with Niño-3.4 is weakly positive during these months (green curve, left panel, Fig. 16a). Therefore, since the 2000s, TNA has shown a different influence on the U.S. summer precipitation. This change can also be seen, to a lesser extent, in SON (left panel, Fig. 17a).

We have also examined the correlations of the MSN PC1 in different seasons with the MSLP and 200-hPa geopotential height anomalies that characterize the lower- and upper-level patterns of the atmospheric circulation. The ENSO influence through the atmospheric planetary waves is detectable from DJF to MAM. Figure 18 shows the correlation patterns of the DJF MSN PC1 with the seasonal MSLP anomalies for the reforecasts (left panels) and the observations (right panels) during the three periods. The qualitative similarity between the model and the observed patterns, especially in the Pacific, are remarkable.

In the tropics, the pattern of the Southern Oscillation dominates the MSLP anomalies with negative correlations in the central-to-eastern Pacific and positive correlations in the western Pacific and Indian Ocean. The extratropical patterns of the MSLP anomalies reflect the atmospheric teleconnections similar to the PacificNorth American (PNA; Straus and Shukla 2002) and Pacific-South American (PSA; Guan et al. 2014) patterns. These anomalous MSLP patterns are closely linked to the SST anomalies as shown in Figs. 14b-d and 
CFSv2

(a) SON (Jul. IC)

OBS.
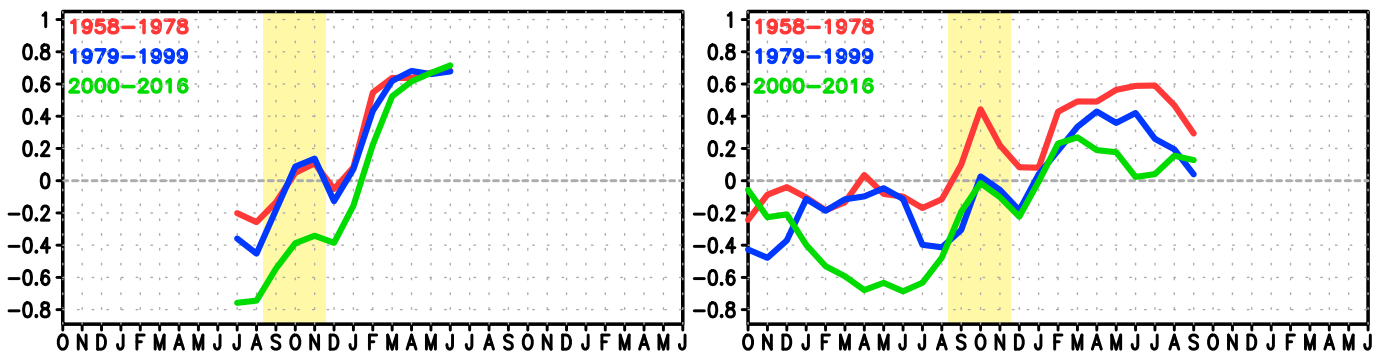

(b) DJF (Oct. IC)
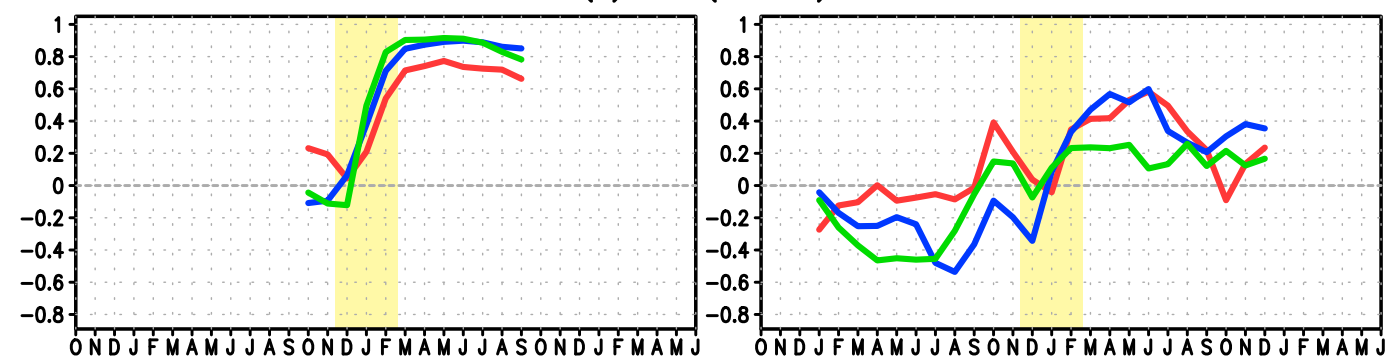

(c) MAM (Jan. IC)
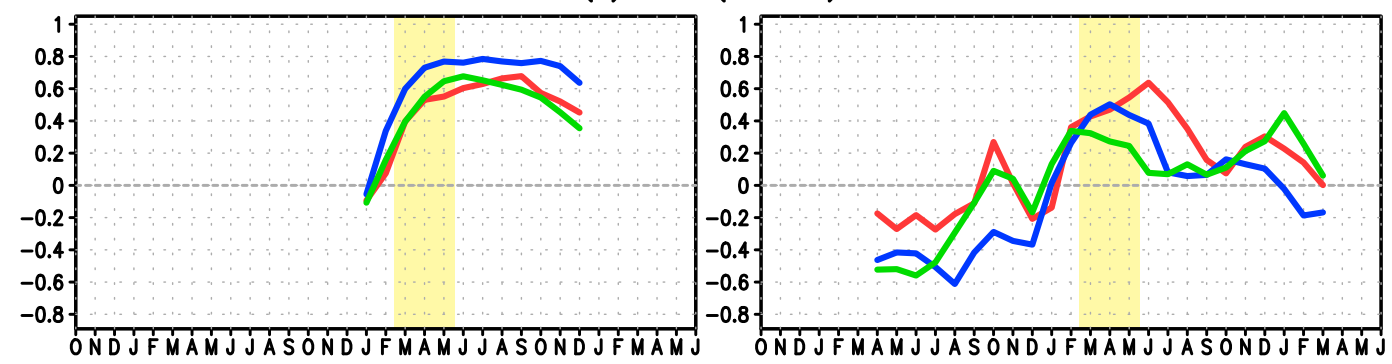

(d) JJA (Apr. IC)
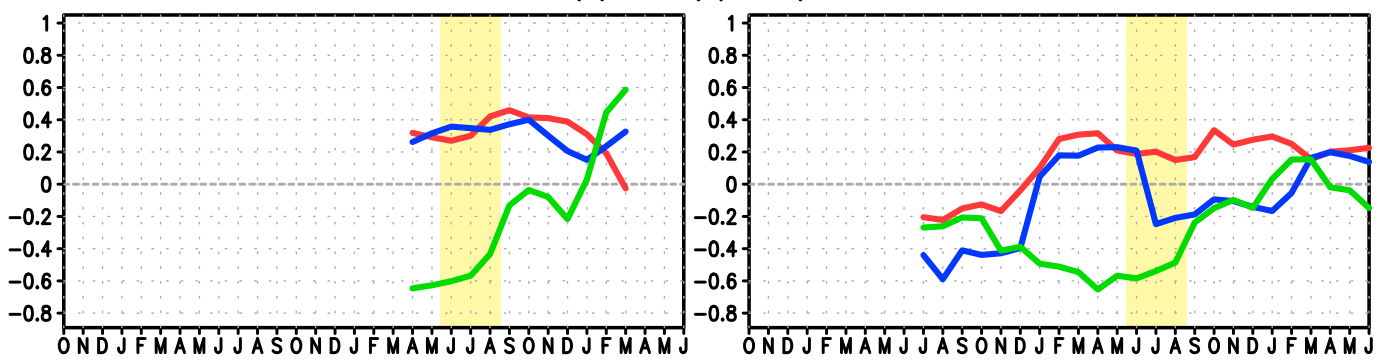

FIG. 17. (left) The lead-lag correlation coefficients between the reforecast monthly TNA index and the MSN PC1 for (a) SON, (b) DJF, (c) MAM, and (d) JJA during the period of 12-month forecast. (right) The MSN PC1 correlations with the observed monthly TNA index for a period of 24 months bracketing the corresponding season. The red, blue, and green curves correspond to the correlations in 1958-78, 1979-99, and 2000-17.

generated by the SST-induced tropical heating. Especially, the PNA pattern associated with ENSO is distinguished from the one by the atmospheric internal variability in spatial structures (Straus and Shukla 2002 and influences on the U.S. precipitation (Cook et al. 2018). Lopez and Kirtman (2019) also demonstrated this point using interactive ensemble simulations. The PNA and PSA patterns are also identifiable on the correlations of the DJF MSN PC1 with the 200-hPa geopotential height anomalies (not shown). In the tropics, a global band of positive correlations emerges as a typical ENSO response in the upper-level atmosphere (Yulaeva and Wallace 1994). Physically, the most relevant signals to the U.S. precipitation are the MSLP 

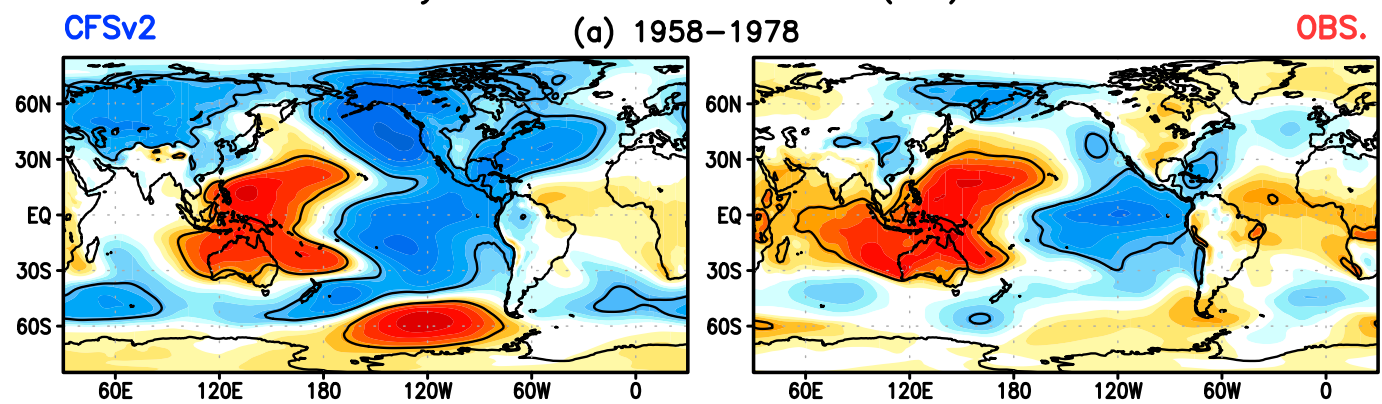

(b) 1979-1999
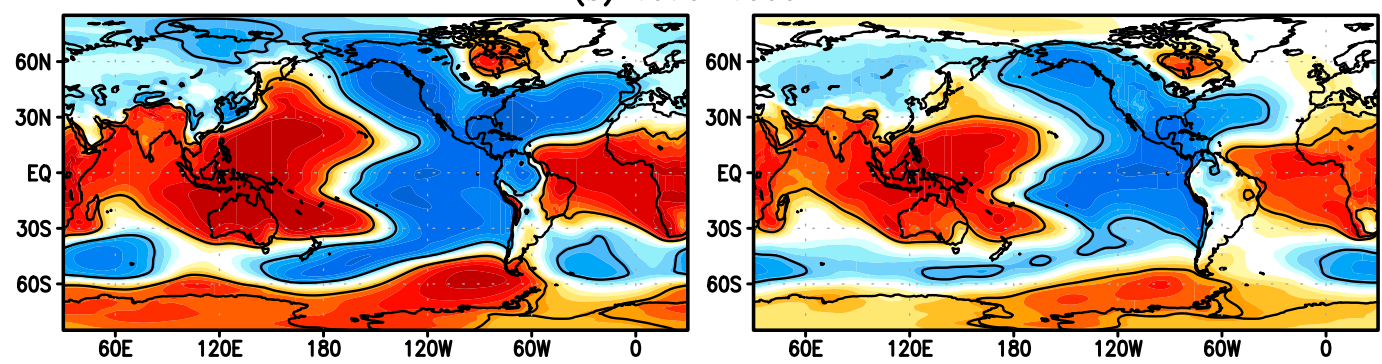

(c) 2000-2016

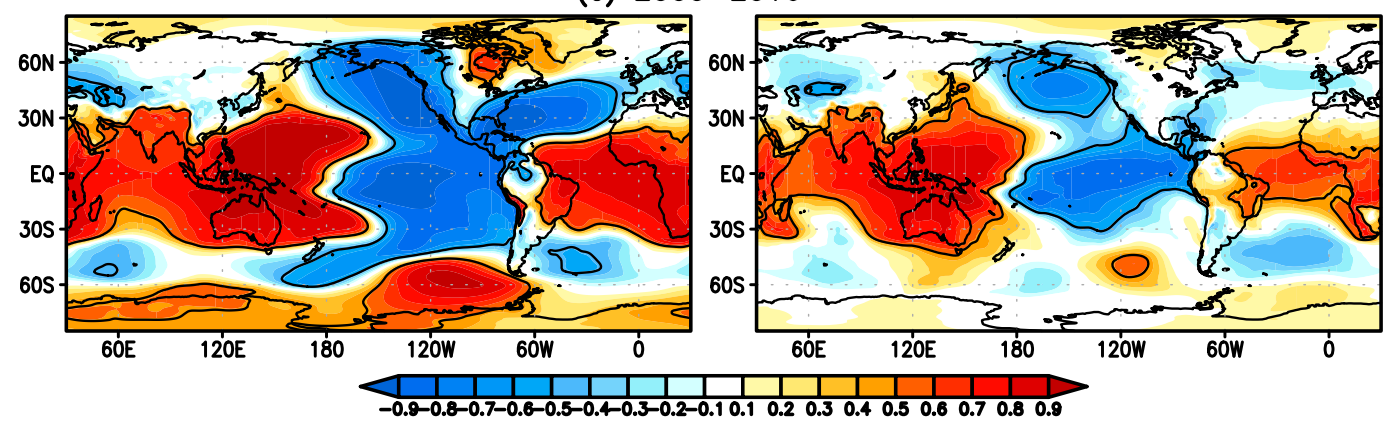

FIG. 18. The spatial distributions of the correlation coefficients of the mean sea level pressure (MSLP) anomalies for DJF with the DJF MSN PC1 for the (left) ensemble mean reforecasts and (right) observations for (a) 1958-78, (b) 1979-99, and (c) 2000-16. The contours correspond to the $95 \%$ statistical significance level. The color bar is shown at the bottom of the figure.

centers of the negative correlations in the western and eastern coast of the North America, as well as in the eastern tropical Pacific. This combination generally causes increased precipitation in the southwest and southeast United States during the winter of an El Niño year. In addition to the seasonal mean anomalies, a corresponding shift of the Pacific-North American storm track can also generate a transient eddy moisture flux divergence in the southern United States (Seager and Hoerling 2014; Feng et al. 2019).

Among the three periods, the reforecasts are very consistent with each other in the Pacific domain (left panels, Fig. 18). However, there are no correlations in the tropical Atlantic and Indian Oceans in 195878 (left panel, Fig. 18a) although the correlations are significant in these areas in the later periods (left panels, Figs. 18b and 18c), as well as in the tropical
Indian Ocean for the observational correlations in 1958-78 (right panel, Fig. 18a). The highest similarity between the reforecasts and the observations occur in 1979-99 (Fig. 18b), when the ENSO cycle was most active.

The correlation patterns of the MAM MSN PC1 with the atmospheric circulations in the lower and upper levels (not shown) are quite similar to those in DJF, as the ENSO-related SST anomalies are quite persistent from boreal winter to spring. However, although the winter-spring ENSO anomalies in the eastern-central tropical Pacific can persist into boreal summer, the teleconnections associated with the planetary wave trains are weakened after boreal spring because the atmospheric mean state is changed (e.g., Kumar and Hoerling 1998). Moreover, as we have discussed before, the SST anomalies in the equatorial Pacific associated with 
Anomaly Correlation between MSLP (JJA) and PC1

CFSv2

(a) 1958-1978

OBS.
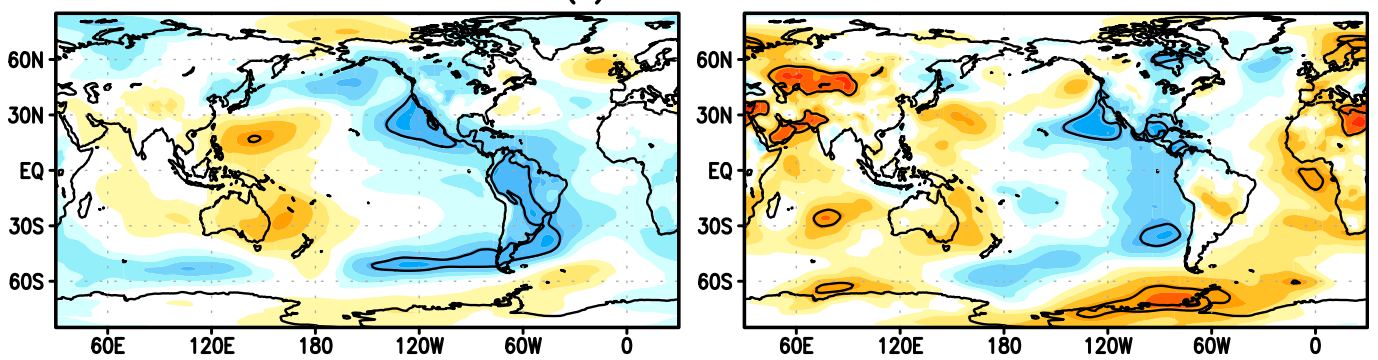

(b) 1979-1999
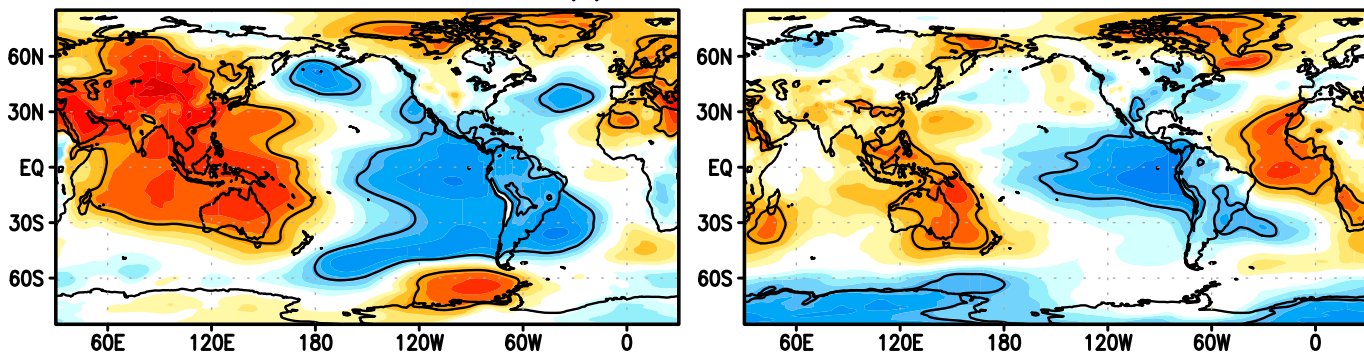

(c) 2000-2016

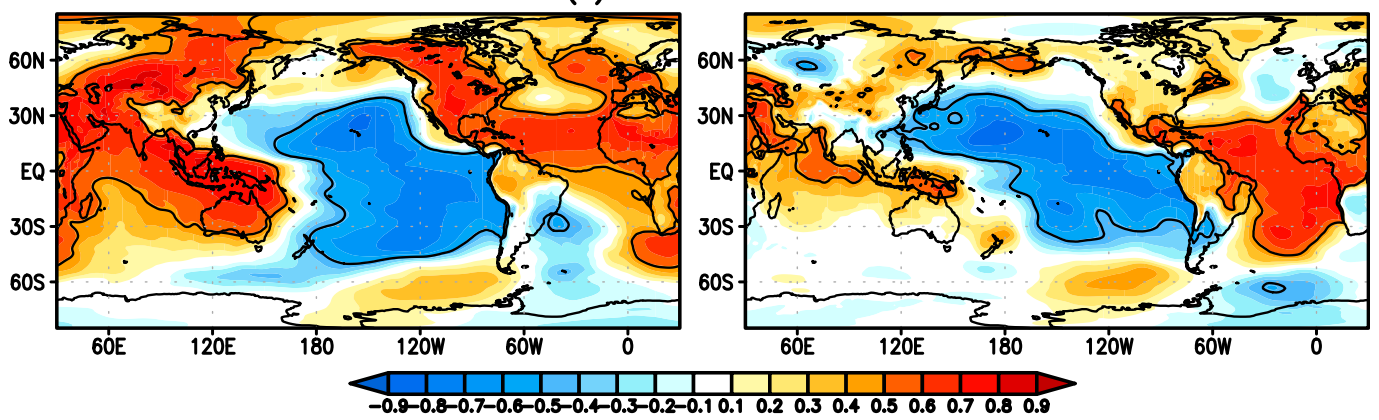

FIG. 19. The spatial distributions of the correlation coefficients of the mean sea level pressure (MSLP) anomalies for JJA with the JJA MSN PC1 for the (left) ensemble mean reforecasts and (right) observations for (a) 1958-78, (b) 1979-99, and (c) 2000-17. The contours correspond to the $95 \%$ statistical significance level. The color bar is shown at the bottom of the figure.

the emerging ENSO events may still be weak and feature different spatial patterns at this stage. As a result, the teleconnections in the extratropical atmosphere are largely statistically insignificant during JJA in the Northern Hemisphere. On the other hand, the patterns of Southern Oscillation are still detectable in the correlation maps of the MSN PC1 with the MSLP anomalies in JJA during 1979-99 (Fig. 19b) and 200017 (Fig. 19c), although the correlations are generally low in 1958-78 (Fig. 19a). More interestingly, statistically significant positive correlations also appear in the tropical North Atlantic in the reforecasts for 2000-17 (left panel, Fig. 19c), roughly consistent with the observations (right panel, Fig. 19c). This correlation pattern is similar to the observational pattern of the SLP anomalies associated with the tropical North Atlantic SST anomalies during the summer seasons
(April-September) of 1979-2007 derived by Kushnir et al. (2010) using a multiple regression analysis (their Fig. 2b). It is interesting to note that the resemblance of our and Kushnir et al.'s (2010) patterns are not confined in the tropical Atlantic and North America but also in the Pacific domain. Similar Atlantic influence is also detectable in SON during this period (not shown), although the ENSO influence becomes more dominant again.

\section{Summary and discussion}

In this paper, we analyzed a set of ensemble seasonal reforecasts for 1958-2017 using CFSv2 to evaluate the predictive skill of the U.S. seasonal precipitation and examine its sources of predictability. Our analysis is conducted for each of the three periods of 1958-78, 
1979-99, and 2000-17, corresponding to three PDO phases during the past 60 years. It is found that the ensemble reforecasts at two-month lead realistically simulate the patterns of the U.S. seasonal precipitation variance. They also reproduce the spatial distribution of the winter precipitation trends throughout the past 60 years and the continental-scale increase of summer precipitation since the 2000s. The correlation skill shows that seasonal precipitation in the United States is better predicted in the winter and spring than in the summer and fall, although the latter still show substantial skillful areas.

The $\mathrm{S} / \mathrm{N}$ ratio of the CFSv2 precipitation also shows strong seasonal dependence that is consistent with other climate models. We further applied the MSN EOF analysis to identify the large-scale patterns of the U.S. predictable precipitation signals. In winter and spring, the most predictable patterns feature a north-south dipole throughout the United States with enhancements in the eastern and western areas. The summer and fall patterns are respectively dominated by the anomalies in the central and southern United States. In verification with observations, the winter-spring patterns are more skillful. The ENSO influences on these predictable patterns are detectable from fall to the subsequent spring but most dominant in winter and spring. The seasonality of the U.S. precipitation predictability and its ENSO dependence confirm the previous AGCM results (e.g., Quan et al. 2006; Seager and Hoerling 2014; among many others), but in a more realistic framework of coupled reforecast, which takes into account the SST seasonal predictability, the coupled ocean-atmosphere feedback and the effects of initialization and model climate drift.

Our results also show other sources of predictability during summer and fall, when the ENSO effect is weaker. Interestingly, these potential sources seem to count for the multidecadal change of the seasonal prediction skill and predictability. Among the three periods, the predictive skill of the U.S. precipitation is highest during 1979-99 while the $\mathrm{S} / \mathrm{N}$ ratio reveals apparent greater predictability in the post-1979 periods than during 1958-78. The phase of PDO can be a dominant factor associated with the enhanced predication skill in 1979-99 and reduced skill in 1958-78. Furthermore, since the 2000s, the forcing from the summer SST anomalies in the tropical North Atlantic has become more significant and shown an opposite sign to those in the tropical Pacific forcing. Although the MSN PC1s are more strongly correlated with the tropical Atlantic SST anomalies during winter and spring than in summer, the correlations generally have the same sign as those in the central and eastern tropical Pacific, implying that the contributing Atlantic SST anomalies are mostly generated by ENSO themselves (e.g., Huang et al. 2002). Since the positive SST anomalies in the tropical North Atlantic tend to reduce the precipitation in the United States for both the winter and summer (e.g., Kushnir et al. 2010), these Atlantic anomalies are most likely to play a moderating role in the ENSO-induced precipitation anomalies in the United States. During summer, on the other hand, the tropical North Atlantic SST anomalies showed weak positive correlations with the U.S. precipitation during 1958-99 but emerged as a more distinctive source of the U.S. rainfall predictability since 2000 . From this perspective, the future contributions of the AMV and PDO to the U.S. precipitation in summer should be further explored.

The multidecadal change of the U.S. precipitation predictability may also be caused by the long-term change of the ENSO predictability. Barnston et al. (2012) found that the real-time ENSO predictions during 2002-11 have lower skills than the ones for the 1980s and 1990s. This multidecadal change has been confirmed by other analyses of the reforecast datasets for the past 30 years or so and generally attributed to the reduced predictability due to weaker ENSO signals after 2000 (e.g., Hu et al. 2019). The same argument may also explain the lower predictability in 1958-78 since the ENSO variability then was weaker than in 1979-99. However, examining our longer CFSv2 reforecasts for 1958-2014, Huang et al. (2017a) found that the ENSO prediction skill in 1958-78 is comparable to that for 1979-2014 for the onset and development of ENSO events but the skill of the earlier predictions declines faster when passing through spring. This is because current models tend to make a prototype of the ENSO events in the 1980s and 1990s and, even initialized with the observation-based states in 1958-78, usually predict more persistent SST anomalies in the ENSO decaying phase than the observed ones during this period. Therefore, the inability of the coupled forecast models in recognizing the multidecadal change of the ENSO characteristics can be another source of the reduced skills of ENSO, and thus, for U.S. precipitation in 195878 and $2000-17$.

Overall, based on a longer reforecast dataset, the study is an attempt to 1) compare estimates and sources of predictability against earlier results and 2) assess the low-frequency variability in skill of U.S. precipitation similar to those done by Weisheimer et al. (2017) for NAO and by Huang et al. (2017a) for ENSO. Even if our results may mainly conform to earlier results of relatively low predictability and the fact that precipitation skill generally has been flatlined for the past two decades, 
our results still contribute toward ultimately resolving the ongoing debate on whether low skill for seasonal precipitation is due to limits of seasonal predictability or is a consequence of errors in seasonal forecast systems (i.e., predictability is higher but it is not being realized because of biases in forecast systems). As we are well aware, the question of the limits of seasonal predictability cannot be resolved from first principles or from the analysis of observational data alone, and convergence toward an answer has to rely on repeated assessments of seasonal predictability in newer generation of models, analysis based on multimodel systems and longer and longer reforecasts. Therefore, we believe that the results of this analysis contribute to the current knowledge base on the assessment of seasonal predictability toward ultimately resolving the question of its limits.

We would also like to offer the following thoughts on how the results from this analysis can be relevant in developing pathways for generating more skillful predictions or informing practitioners of seasonal prediction. Admittedly, based on a long history of research in the sources of seasonal predictability, it is now well established that ENSO is the most dominant source of predictability. It is also very likely (and if progress in seasonal predictions made in the last 20 years is any indication) that improvements in seasonal prediction skill beyond the linear composite signal related to ENSO will charter a path of slow evolution. Further exploring ENSO as a skill source of the U.S. seasonal forecast is likely to focus on the different flavors of ENSO (e.g., Johnson 2013), and the possibility that their influences on U.S. seasonal climate will be materially different from the linear composite signal. If such a diversity in responses to ENSO flavors is established, then incorporating such influences will improve the capability of modern coupled forecast systems in realizing seasonal predictability. Harvesting these additional sources of seasonal prediction skill related to ENSO flavors incrementally, and further, placing our confidence in signals beyond ENSO will once again require repeated analysis using newer generation of models, analysis based on multimodel systems and longer and longer reforecasts. The process of developing confidence in signals beyond canonical ENSO patterns, though slow, is a necessary process because, in its absence, forecast practitioners will continue to fall back on the information contained in ENSO composites and ignore indications of model responses beyond ENSO. To reach a stage where signal inferred based on dynamical models can deliver useful information beyond canonical ENSO patterns, and further, forecast practitioners can place confidence in them (and thereby, make use of the information) is the context that the results from this analysis will eventually have their usefulness.

In this study, we focused on the oceanic forcing factors to the U.S. seasonal prediction. Other sources of predictability, such as land-atmosphere feedbacks arising from the memory in soil moisture and/or snowpack, can also play important roles in additional skill (Roundy and Wood 2015; Dirmeyer and Halder 2016). On the other hand, the influence of internal atmospheric variability (e.g., Coats et al. 2013; Stevenson et al. 2015; Jha et al. 2019) is a major factor that limits the predictability and prediction skill of the U.S. precipitation. In addition to these factors, the limit of global SST prediction skill and the bias in predicted SST patterns (e.g., Kumar et al. 2012; Xue et al. 2013; Shin and Huang 2019) also prevent more accurate precipitation forecasts. These issues will be examined in our further analysis of these datasets.

Beyond the statistical pattern analysis, further progress can be made through more detailed case analysis. For instance, numerous analyses (e.g., Chen and Kumar 2018; Zhang et al. 2018b) have been done to examine the California drought events in the 2015/16 El Niño winter when the regional precipitations did not conform to the expected El Niño response as described in this paper. A preliminary examination of our reforecasts shows that the situation in the 2015/16 winter is not unique. For instance, a typical California drought also occurred in 1963/64 during a major El Niño winter. In both cases, an anomalous anticyclone in the subtropical northeastern Pacific contributed to departure in the observed precipitations over California from the canonical El Niño response pattern. Although the model ensemble mean prediction missed this feature in both cases, we found that some ensemble members of the reforecasts in 2015/16 had better predictions of the regional precipitation with a relatively minor northward shift of the El Niño-induced anomalous center of low sea level pressure off the North America coast. Further case studies are in progress and will be reported in due course.

Acknowledgments. This work is supported by the NOAA MAPP drought project (NA17OAR4310144). We thank Dr. B Jha for providing the CPC GFS ensemble simulations for this study. We thank useful discussions with Dr. P. Dirmeyer and the constructive comments and suggestions from the three anonymous reviewers and the editor. We acknowledge the Extreme Science and Engineering Discovery Environment (XSEDE) for providing the computational resources for the CFSv2 60-yr reforecasts. 


\section{REFERENCES}

Balmaseda, M. A., K. Mogensen, and A. T. Weaver, 2013: Evaluation of the ECMWF ocean reanalysis system ORAS4. Quart. J. Roy. Meteor. Soc., 139, 1132-1161, https://doi.org/10.1002/ qj.2063.

Barlow, M., S. Nigam, and E. H. Berbery, 2001: ENSO, Pacific decadal variability, and U.S. summertime precipitation, drought, and stream flow. J. Climate, 14, 2105-2128, https://doi.org/ 10.1175/1520-0442(2001)014<2105:EPDVAU>2.0.CO;2.

Barnston, A. G., and T. M. Smith, 1996: Specification of prediction of global surface temperature and precipitation from global SST using CCA. J. Climate, 9, 2660-2697, https://doi.org/ 10.1175/1520-0442(1996)009<2660:SAPOGS >2.0.CO;2.

— , and B. Lyon, 2016: Does the NMME capture a recent decadal shift toward increasing drought occurrence in the southwestern United States? J. Climate, 29, 561-581, https://doi.org/ 10.1175/JCLI-D-15-0311.1.

— , and Coauthors, 1994: Long-lead seasonal forecasts-Where do we stand? Bull. Amer. Meteor. Soc., 75, 2097-2114, https:// doi.org/10.1175/1520-0477(1994)075<2097:LLSFDW>2.0.CO;2.

- M. K. Tippett, M. L. L'Heureux, S. Li, and D. G. DeWitt, 2012: Skill of real-time seasonal ENSO model predictions during 2002-11: Is our capability increasing? Bull. Amer. Meteor. Soc., 93, 631-651, https://doi.org/10.1175/BAMS-D11-00111.1.

Becker, E., and H. van den Dool, 2016: Probabilistic seasonal forecasts in the North American multimodel ensemble: A baseline skill assessment. J. Climate, 29, 3015-3026, https:// doi.org/10.1175/JCLI-D-14-00862.1.

Biasutti, M., R. Seager, and D. B. Kirschbaum, 2016: Landslides in West Coast metropolitan areas: The role of extreme weather events. Wea. Climate Extremes, 14, 67-79, https://doi.org/ 10.1016/j.wace.2016.11.004.

Cayan, D. R., K. T. Redmond, and L. G. Riddle, 1999: ENSO and hydrologic extremes in the western United States. J. Climate, 12, 2881-2893, https://doi.org/10.1175/1520-0442(1999)012<2881: EAHEIT $>2.0 . \mathrm{CO} ; 2$.

Chen, L.-C., H. van den Dool, E. Becker, and Q. Zhang, 2017: ENSO precipitation and temperature forecasts in the North American multimodel ensemble: Composite analysis and validation. J. Climate, 30, 1103-1125, https://doi.org/10.1175/ JCLI-D-15-0903.1.

Chen, M., and A. Kumar, 2018: Winter 2015/16 atmosphere and precipitation anomalies over North America: El Niño response and the role of noise. Mon. Wea. Rev., 146, 909-927, https://doi.org/10.1175/MWR-D-17-0116.1.

, W. Shi, P. Xie, V. B. S. Silva, V. E. Kousky, R. Wayne Higgins, and J. E. Janowiak, 2008: Assessing objective techniques for gauge-based analyses of global daily precipitation. J. Geophys. Res., 113, D04110, https://doi.org/10.1029/ 2007JD009132.

Chiodi, A. M., and D. E. Harrison, 2015: Global seasonal precipitation anomalies robustly associated with El Niño and La Niña events-An OLR perspective. J. Climate, 28, 6133-6159, https://doi.org/10.1175/JCLI-D-14-00387.1.

Coats, S., J. E. Smerdon, R. Seager, and J. F. Gonzalez-Rouco, 2013: Megadroughts in southwestern North America in ECHO-g millennial simulations and their comparison to proxy drought reconstructions. J. Climate, 26, 7635-7649, https:// doi.org/10.1175/JCLI-D-12-00603.1.

Cook, B. I., A. P. Williams, J. S. Mankin, R. Seager, J. E. Smerdon, and D. Singh, 2018: Revisiting the leading drivers of Pacific coastal drought variability in the contiguous United States. J. Climate, 31, 25-43, https://doi.org/10.1175/JCLI-D-17-0172.1.

Cook, E. R., R. Seager, M. Cane, and D. Stahle, 2007: North American drought: Reconstructions, causes, and consequences. Earth-Sci. Rev., 81, 93-134, https://doi.org/10.1016/ j.earscirev.2006.12.002.

Crockett, J. L., and A. L. Westerling, 2018: Greater temperature and precipitation extremes intensify western U.S. droughts, wildfire severity, and Sierra Nevada tree mortality. J. Climate, 31, 341-354, https://doi.org/10.1175/JCLI-D-17-0254.1.

Dai, A., 2013: The influence of the inter-decadal Pacific oscillation on US precipitation during 1923-2010. Climate Dyn., 41, 633-646, https://doi.org/10.1007/s00382-012-1446-5.

— , and T. M. L. Wigley, 2000: Global patterns of ENSO induced precipitation. Geophys. Res. Lett., 27, 1283-1286, https:// doi.org/10.1029/1999GL011140.

Deser, C., A. S. Phillips, and J. W. Hurrell, 2004: Pacific interdecadal climate variability: linkages between the tropics and the North Pacific during boreal winter since 1900. J. Climate, 17, 3109-3124, https://doi.org/10.1175/1520-0442(2004)017<3109: PICVLB $>2.0 . \mathrm{CO} ; 2$.

Ding, H., M. Newman, M. A. Alexander, and A. T. Wittenberg, 2019: Diagnosing secular variations in retrospective ENSO seasonal forecast skill using CMIP5 model-analogs. Geophys. Res. Lett., 46, 1721-1730, https://doi.org/10.1029/2018GL080598.

Dirmeyer, P. A., and S. Halder, 2016: Sensitivity of surface fluxes and atmospheric boundary layer properties to initial soil moisture variations in CFSv2. Wea. Forecasting, 31, 19731983, https://doi.org/10.1175/WAF-D-16-0049.1.

Ek, M., K. E. Mitchell, Y. Lin, E. Rogers, P. Grunmann, V. Koren, G. Gayno, and J. D. Tarpley, 2003: Implementation of Noah land-surface model advances in the National Centers for Environmental Prediction operational mesoscale Eta model. J. Geophys. Res., 108, 8851, https://doi.org/10.1029/ 2002JD003296.

Enfield, D. B., and D. A. Mayer, 1997: Tropical Atlantic sea surface temperature variability and its relation to El Niño-Southern Oscillation. J. Geophys. Res., 102, 929-945, https://doi.org/ 10.1029/96JC03296.

_ - A. M. Mestas-Nuñez, and P. J. Trimble, 2001: The Atlantic multidecadal oscillation and its relation to rainfall and river flows in the continental U.S. Geophys. Res. Lett., 28, 2077 2080, https://doi.org/10.1029/2000GL012745.

Feng, S., R. J. Oglesby, C. M. Rowe, D. B. Loope, and Q. Hu, 2008: Atlantic and Pacific SST influences on medieval drought in North America simulated by the Community Atmospheric Model. J. Geophys. Res., 113, D11101, https://doi.org/10.1029/ 2007JD009347.

Feng, X., B. Huang and D. Straus, 2019: Seasonal prediction skill and predictability of the Northern Hemisphere storm track variability in Project Minerva. Climate Dyn., 52, 6427-6440, https://doi.org/10.1007/S00382-018-4520-9.

Findell, K. L., and T. L. Delworth, 2010: Impact of common sea surface temperature anomalies on global drought and pluvial frequency. J. Climate, 23, 485-503, https://doi.org/10.1175/ 2009JCLI3153.1.

Goddard, L., and S. J. Mason, 2002: Sensitivity of seasonal climate forecasts to persisted SST anomalies. Climate Dyn., 19, 619631, https://doi.org/10.1007/s00382-002-0251-y.

Griffies, S. M., M. J. Harrison, R. C. Pacanowski, and A. Rosati, 2004: A technical guide to MOM4. NOAA/GFDL Ocean Group Tech. Rep. 5, 342 pp., https://www.gfdl.noaa.gov/ bibliography/related_files/smg0301.pdf. 
Guan, Y., B. Huang, J. Zhu, Z.-Z. Hu, and J. L. Kinter, 2014: Interannual variability of the South Pacific Ocean in observations and simulated by the NCEP Climate Forecast System, version 2. Climate Dyn., 43, 1141-1157, https://doi.org/10.1007/ s00382-014-2148-y.

Harding, K. J., and P. K. Snyder, 2015: The relationship between the Pacific-North American teleconnection pattern, the Great Plains low-level jet, and north central U.S. heavy rainfall events. J. Climate, 28, 6729-6742, https://doi.org/10.1175/ JCLI-D-14-00657.1.

Hartmann, D. L., 2015: Pacific sea surface temperature and the winter of 2014. Geophys. Res. Lett., 42, 1894-1902, https:// doi.org/10.1002/2015GL063083.

Herweijer, C., R. Seager, and E. R. Cook, 2006: North American droughts of the mid to late nineteenth century: History, simulation and implications for mediaeval drought. Holocene, 16, 159-171, https://doi.org/10.1191/0959683606hl917rp.

Hoerling, M. P., and A. Kumar, 2003: The perfect ocean for drought. Science, 299, 691-694, https://doi.org/10.1126/ science.1079053.

Hu, Z.-Z., and B. Huang, 2007: The predictive skill and the most predictable pattern in the tropical Atlantic: The effect of ENSO. Mon. Wea. Rev., 135, 1786-1806, https://doi.org/ 10.1175/MWR3393.1.

— , and - 2009: Interferential impact of ENSO and PDO on dry and wet conditions in the U.S. Great Plains. J. Climate, 22, 6047-6065, https://doi.org/10.1175/2009JCLI2798.1.

- A. Kumar, B. Jha, J. Zhu, and B. Huang, 2017: Persistence and predictions of the remarkable warm anomaly in the northeastern Pacific Ocean during 2014-16. J. Climate, 30, 689-702, https://doi.org/10.1175/JCLI-D-16-0348.1.

,-- J. Zhu, P. Peng, and B. Huang, 2019: On the challenge for ENSO cycle prediction: An example from NCEP Climate Forecast System, version 2. J. Climate, 32, 183-194, https:// doi.org/10.1175/JCLI-D-18-0285.1.

Huang, B., 2004: Remotely forced variability in the tropical Atlantic Ocean. Climate Dyn., 23, 133-152, https://doi.org/ 10.1007/s00382-004-0443-8.

—_, and J. L. Kinter III, 2002: The interannual variability in the tropical Indian Ocean. J. Geophys. Res., 107, 3199, https:// doi.org/10.1029/2001JC001278.

— P. S. Schopf, and Z. Pan, 2002: The ENSO effect on the tropical Atlantic variability: A regionally coupled model study. Geophys. Res. Lett., 29, 2039, https://doi.org/10.1029/ 2002 GL014872.

- - and Coauthors, 2015: Climate drift of AMOC, North Atlantic salinity and Arctic sea ice in CFSv2 decadal predictions. Climate Dyn., 44, 559-583, https://doi.org/10.1007/ s00382-014-2395-y.

_ , C.-S. Shin, J. Shukla, L. Marx, M. Balmaseda, S. Halder, P. A. Dirmeyer, and J. L. Kinter III, 2017a: Reforecasting the ENSO events in the past 57 years (1958-2014). J. Climate, 30, 7669-7693, https://doi.org/10.1175/JCLI-D-16-0642.1.

— , and Coauthors, 2017b: Extended Reconstructed Sea Surface Temperature version 5 (ERSSTv5): Upgrades, validations, and intercomparisons. J. Climate, 30, 8179-8205, https:// doi.org/10.1175/JCLI-D-16-0836.1.

Jha, B., A. Kumar, and Z.-Z. Hu, 2019: An update on the estimate of predictability of seasonal mean atmospheric variability using North American Multi-Model Ensemble. Climate Dyn., 53, 7397-7409, https://doi.org/10.1007/S00382-016-3217-1.

Ji, M., A. Kumar, and A. Leetmaa, 1994: A multiseason climate forecast system at the National Meteorological Center.
Bull. Amer. Meteor. Soc., 75, 569-578, https://doi.org/10.1175/ 1520-0477(1994)075<0569:AMCFSA > 2.0.CO;2.

Jia, L., and Coauthors, 2015: Improved seasonal prediction of temperature and precipitation over land in a high-resolution GFDL climate model. J. Climate, 28, 2044-2062, https:// doi.org/10.1175/JCLI-D-14-00112.1.

Jin, E. K., and Coauthors, 2008: Current status of ENSO prediction skill in coupled ocean-atmosphere models. Climate Dyn., 31, 647-664, https://doi.org/10.1007/s00382-008-0397-3.

Johnson, N. C., 2013: How many ENSO flavors can we distinguish? J. Climate, 26, 4816-4827, https://doi.org/10.1175/ JCLI-D-12-00649.1.

Kirtman, B., and Coauthors, 2014: The North American multimodel ensemble, Phase-1 seasonal-to-interannual prediction; Phase-2 toward developing intraseasonal prediction. Bull. Amer. Meteor. Soc., 95, 585-601, https://doi.org/10.1175/ BAMS-D-12-00050.1.

Kumar, A., 2009: Finite samples and uncertainty estimates for skill measures for seasonal predictions. Mon. Wea. Rev., 137, 2622-2631, https://doi.org/10.1175/2009MWR2814.1.

, and M. P. Hoerling, 1998: Annual cycle of Pacific-North American seasonal predictability associated with different phases of ENSO. J. Climate, 11, 3295-3308, https://doi.org/ 10.1175/1520-0442(1998)011<3295:ACOPNA > 2.0.CO;2.

, and - 2003: The nature and causes for the delayed atmospheric response to El Niño. J. Climate, 16, 1391-1403, https://doi.org/10.1175/1520-0442-16.9.1391.

—, M. Chen, L. Zhang, W. Wang, Y. Xue, C. Wen, L. Marx, and B. Huang, 2012: An analysis of the nonstationarity in the bias of sea surface temperature forecasts for the NCEP Climate Forecast System (CFS) version 2. Mon. Wea. Rev., 140, 30033016, https://doi.org/10.1175/MWR-D-11-00335.1.

, P. Peng, and M. Chen, 2014a: Is there a relationship between potential and actual skill? Mon. Wea. Rev., 142, 2220-2227, https://doi.org/10.1175/MWR-D-13-00287.1.

— B. Bha, and H. Wang, 2014b: Attribution of SST variability in global oceans and the role of ENSO. Climate Dyn., 43, 209220, https://doi.org/10.1007/s00382-013-1865-y.

Kushnir, Y., R. Seager, M. Ting, N. Naik, and J. Nakamura, 2010: Mechanisms of tropical Atlantic SST influence on North American hydroclimate variability. J. Climate, 23, 5610-5628, https://doi.org/10.1175/2010JCLI3172.1.

Lee, S.-K., B. E. Mapes, C. Wang, D. B. Enfield, and S. J. Weaver, 2014: Springtime ENSO phase evolution and its relation to rainfall in the continental U.S. Geophys. Res. Lett., 41, 16731680, https://doi.org/10.1002/2013GL059137.

- H. Lopez, E.-S. Chung, P. N. DiNezio, S.-W. Yeh, and A. T. Wittenberg, 2018: On the fragile relationship between El Niño and California rainfall. Geophys. Res. Lett., 45, 907915, https://doi.org/10.1002/2017GL076197.

L'Heureux, M. L., M. K. Tippett, and A. G. Barnston, 2015: Characterizing ENSO coupled variability and its impact on North American seasonal precipitation and temperature. J. Climate, 28, 4231-4245, https://doi.org/10.1175/JCLI-D-1400508.1.

_ —_, and —_, 2017: Reply to "Comment on 'Characterizing ENSO coupled variability and its impact on North American seasonal precipitation and temperature'." J. Climate, 30, 437441, https://doi.org/10.1175/JCLI-D-16-0080.1.

Li, L., R. W. Schmitt, and C. C. Ummenhofer, 2018: The role of the subtropical North Atlantic water cycle in recent US extreme precipitation events. Climate Dyn., 50, 1291-1305, https:// doi.org/10.1007/s00382-017-3685-y. 
Liang, J., S. Yang, Z.-Z. Hu, B. Huang, A. Kumar, and Z. Zhang, 2009: Predictable patterns of the Asian and Indo-Pacific summer precipitation in NCEP CFS. Climate Dyn., 32, 9891001, https://doi.org/10.1007/s00382-008-0420-8.

Lopez, H., and B. P. Kirtman, 2019: ENSO influence over the Pacific North American sector: Uncertainty due to atmospheric internal variability. Climate Dyn., 52, 6149-6172, https://doi.org/ 10.1007/s00382-018-4500-0.

Madec, G., 2008: NEMO reference manual, ocean dynamics component: NEMO-OPA. Preliminary version, Institut PierreSimon Laplace Note du Pôle de Modélisation 27, 209 pp.

Mason, S., and L. Goddard, 2001: Probabilistic precipitation anomalies associated with ENSO. Bull. Amer. Meteor. Soc., 82, 619-638, https://doi.org/10.1175/1520-0477(2001) 082<0619:PPAAWE $>2.3$.CO;2.

Mo, K. C., and D. P. Lettenmaier, 2018: Drought variability and trends over the central United States in the instrumental record. J. Climate, 19, 1149-1166, https://doi.org/10.1175/ JHM-D-17-0225.1.

— J. E. Schemm, and S.-H. Yoo, 2009: Influence of ENSO and the Atlantic multidecadal oscillation on drought over the United States. J. Climate, 22, 5962-5982, https://doi.org/ 10.1175/2009JCLI2966.1.

Nigam, S., B. Guan, and A. Ruiz-Barradas, 2011: Key role of the Atlantic multidecadal oscillation in 20th century drought and wet periods over the Great Plains. Geophys. Res. Lett., 38, L16713, https://doi.org/10.1029/2011GL048650.

Oswald, E. M., 2018: An analysis of the prevalence of heat waves in the United States between 1948 and 2015. J. Climate, 37, 15351549, https://doi.org/10.1175/JAMC-D-17-0274.1.

Perry, C. A., 2000: Significant floods in the United States during the 20th century-USGS measures a century of floods. USGS Fact Sheet 024-00, 4 pp., http://pubs.usgs.gov/fs/2000/0024/ report.pdf.

Peterson, T. C., and Coauthors, 2013: Monitoring and understanding changes in heat waves, cold waves, floods, and droughts in the United States. Bull. Amer. Meteor. Soc., 94, 821-824, https:// doi.org/10.1175/BAMS-D-12-00066.1.

Quan, X., M. Hoerling, J. Whitaker, G. Bates, and T. Xu, 2006: Diagnosing sources of U.S. seasonal forecast skill. J. Climate, 19, 3279-3293, https://doi.org/10.1175/JCLI3789.1.

Ropelewski, C. F., and M. S. Halpert, 1986: North American precipitation and temperature patterns associated with the El Niño/Southern Oscillation (ENSO). Mon. Wea. Rev., 114, 2352-2362, https://doi.org/10.1175/1520-0493(1986)114<2352: NAPATP $>2.0 . \mathrm{CO} ; 2$.

Roundy, J. K., and E. F. Wood, 2015: The attribution of landatmosphere interactions on the seasonal predictability of drought. J. Hydrometeor., 16, 793-810, https://doi.org/10.1175/ JHM-D-14-0121.1.

Rui, H., and H. Beaudoing, 2015: README document for Global Land Data Assimilation System version 2 (GLDAS-2) products. NASA Goddard Earth Sciences Data and Information Services Center Tech. Doc., 23 pp.

Saha, S., and Coauthors, 2006: The NCEP Climate Forecast System. J. Climate, 19, 3483-3517, https://doi.org/10.1175/ JCLI3812.1.

- and Coauthors, 2010: The NCEP Climate Forecast System Reanalysis. Bull. Amer. Meteor. Soc., 91, 1015-1057, https:// doi.org/10.1175/2010BAMS3001.1.

, and Coauthors, 2014: The NCEP Coupled Forecast System, version 2. J. Climate, 27, 2185-2203, https://doi.org/10.1175/ JCLI-D-12-00823.1.
Saji, N. H., B. N. Goswami, P. N. Vinayachandran, and T. Yamagata, 1999: A dipole mode in the tropical Indian Ocean. Nature, 401, 360-363, https://doi.org/10.1038/43854.

Schubert, S. D., M. J. Suarez, P. J. Pegion, R. D. Koster, and J. T. Bacmeister, 2004: On the cause of the 1930s Dust Bowl. Science, 303, 1855-1859, https://doi.org/10.1126/science.1095048.

,,,---- , and,- 2008 : Potential predictability of longterm drought and pluvial conditions in the U.S. Great Plains. J. Climate, 21, 802-816, https://doi.org/10.1175/2007JCLI1741.1.

—, and Coauthors, 2009: A U.S. CLIVAR project to assess and compare the responses of global climate models to droughtrelated SST forcing patterns: Overview and results. J. Climate, 22, 5251-5272, https://doi.org/10.1175/2009JCLI3060.1.

_ , and Coauthors, 2016: Global meteorological drought: A synthesis of current understanding with a focus on SST drivers of precipitation deficits. J. Climate, 29, 3989-4019, https:// doi.org/10.1175/JCLI-D-15-0452.1.

Seager, R., and M. Hoerling, 2014: Atmosphere and ocean origins of North American drought. J. Climate, 27, 4581-4606, https:// doi.org/10.1175/JCLI-D-13-00329.1.

— , L. Goddard, J. Nakamura, N. Naik, and D. Lee, 2014: Dynamical causes of the 2010/11 Texas-northern Mexico drought. J. Hydrometeor., 15, 39-68, https://doi.org/10.1175/ JHM-D-13-024.1.

- M. Hoerling, S. Schubert, H. Wang, B. Lyon, A. Kumar, J. Nakamura, and N. Henderson, 2015: Causes of the 2011-14 California drought. J. Climate, 28, 6997-7024, https://doi.org/ 10.1175/JCLI-D-14-00860.1.

Shin, C.-S. and B. Huang, 2019: A spurious warming trend in the NMME equatorial Pacific SST hindcasts. Climate Dyn., 53, 7287-7303, https://doi.org/10.1007/S00382-017-3777-8.

—, - J. Zhu, L. Marx, and J. L. Kinter, 2019: Improved seasonal predictive skill and enhanced predictability of the Asian summer monsoon rainfall following ENSO events in NCEP CFSv2 hindcasts. Climate Dyn., 52, 3079-3098, https:// doi.org/10.1007/s00382-018-4316-y.

Shukla, R. P., B. Huang, L. Marx, J. L. Kinter, and C.-S. Shin, 2018: Predictability and prediction of Indian summer monsoon by CFSv2: Implication of the initial shock effect. Climate Dyn., 50, 159-178, https://doi.org/10.1007/s00382-017-3594-0.

Stevenson, S., A. Timmerman, Y. Chikamoto, S. Langford, and P. DiNezio, 2015: Stochastically generated North American megadroughts. J. Climate, 28, 1865-1880, https://doi.org/10.1175/ JCLI-D-13-00689.1.

Stockdale, T. N., D. L. T. Anderson, J. O. Alves, and M. A. Balmaseda, 1998: Global seasonal rainfall forecasts with a coupled ocean-atmosphere model. Nature, 392, 370-373, https:// doi.org/10.1038/32861.

— and its prediction of sea surface temperature. Climate Dyn., 37, 455-471, https://doi.org/10.1007/s00382-010-0947-3.

Straus, D. M., and J. Shukla, 2002: Does ENSO force the PNA? J. Climate, 15, 2340-2358, https://doi.org/10.1175/1520-0442(2002) 015<2340:DEFTP $>2.0 . \mathrm{CO} ; 2$.

Strazzo, S., D. C. Collins, A. Schepen, Q. J. Wang, E. Becker, and L. Jia, 2019: Application of a hybrid statistical-dynamical system to seasonal prediction of North American temperature and precipitation. Mon. Wea. Rev., 147, 607-625, https:// doi.org/10.1175/MWR-D-18-0156.1.

Ting, M., and H. Wang, 1997: Summertime U.S. precipitation variability and its relation to Pacific sea surface temperature. J. Climate, 10, 1853-1873, https://doi.org/10.1175/ 1520-0442(1997)010<1853:SUSPVA $>2.0$. CO 2 . 
Trenberth, K. E., and J. W. Hurrell, 1994: Decadal atmosphereocean variations in the Pacific. Climate Dyn., 9, 303-319, https://doi.org/10.1007/BF00204745.

Uppala, S. M., and Coauthors, 2005: The ERA-40 Re-Analysis. Quart. J. Roy. Meteor. Soc., 131, 2961-3012, https://doi.org/ 10.1256/qj.04.176.

Venzke, S., M. R. Allen, R. T. Sutton, and D. P. Rowell, 1999: The atmospheric response over the North Atlantic to decadal changes in sea surface temperature. J. Climate, 12, 2562-2584, https://doi.org/10.1175/1520-0442(1999)012<2562: TAROTN $>2.0 . \mathrm{CO} ; 2$.

Wang, C., S.-K. Lee, and D. B. Enfield, 2008: Climate response to anomalously large and small Atlantic warm pools during the summer. J. Climate, 21, 2437-2450, https://doi.org/10.1175/ 2007JCLI2029.1.

Wang, H., S. Schubert, R. Koster, Y.-G. Ham, and M. Suarez, 2014: On the role of SST forcing in the 2011 and 2012 extreme U.S. heat and drought: A study in contrasts. J. Hydrometeor., 15, 1255-1273, https://doi.org/10.1175/JHM-D-13-069.1.

Weaver, S. J., S. Schubert, and H. Wang, 2009: Warm season variations in the low-level circulation and precipitation over the central United States in observations, AMIP simulations, and idealized SST experiments. J. Climate, 22, 5401-5420, https:// doi.org/10.1175/2009JCLI2984.1.

Weisheimer, A., N. Schaller, C. O'Reilly, D. A. Macleod, and T. Oalmer, 2017: Atmospheric seasonal forecasts of the twentieth century: Multi-decadal variability in predictive skill of the winter North Atlantic Oscillation (NAO) and their potential value for extreme event attribution. Quart. J. Roy. Meteor. Soc., 143, 917-926, https://doi.org/10.1002/qj.2976.

Winton, M., 2000: A reformulated three-layer sea ice model. J. Atmos. Oceanic Technol., 17, 525-531, https://doi.org/10.1175/ 1520-0426(2000)017<0525:ARTLSI >2.0.CO;2.
Xue, Y., M. Chen, A. Kumar, Z.-Z. Hu, and W. Wang, 2013: Prediction skill and bias of tropical Pacific sea surface temperature in the NCEP Climate Forecast System version 2. J. Climate, 26, 5358-5378, https://doi.org/10.1175/JCLI-D12-00600.1.

Yulaeva, E., and J. M. Wallace, 1994: The signature of ENSO in global temperature and precipitation fields derived from the microwave sounding unit. J. Climate, 7, 1719-1736, https:// doi.org/10.1175/1520-0442(1994)007<1719:TSOEIG>2.0.CO;2.

Zhang, T., B. Huang, S. Yang, and J. L. Kinter, 2018a: Predictable patterns of the atmospheric low-level circulation over the Indo-Pacific region in Project Minerva: Seasonal dependence and intra-ensemble variability. J. Climate, 31, 83518379, https://doi.org/10.1175/JCLI-D-17-0577.1.

_ , and Coauthors, 2018b: Predictability and prediction of Southern California rains during strong El Niño events: A focus on the failed 2016 winter rain. J. Climate, 31, 555-574, https://doi.org/10.1175/JCLI-D-17-0396.1.

Zhang, Y., J. M. Wallace, and D. S. Battisti, 1997: ENSO-like decade-to-century scale variability: 1900-93. J. Climate, 10, 1004-1020, https://doi.org/10.1175/1520-0442(1997)010<1004: ELIV $>2.0 . \mathrm{CO} ; 2$

Zhu, J., and J. Shukla, 2013: The role of air-sea coupling in seasonal prediction of Asian-Pacific summer monsoon rainfall. J. Climate, 26, 5689-5697, https://doi.org/10.1175/JCLI-D-13-00190.1.

_, B. Huang, L. Marx, J. L. Kinter III, M. A. Balmaseda, R.-H. Zhang, and Z.-Z. Hu, 2012: Ensemble ENSO hindcasts initialized from multiple ocean analyses. Geophys. Res. Lett., 39, L09602, https://doi.org/10.1029/2012GL051503.

, J. L. Kinter, and A. Kumar, 2015: Seasonality in predictive skill and predictable pattern of the tropical Indian Ocean SST. J. Climate, 28, 7962-7984, https://doi.org/10.1175/ JCLI-D-15-0067.1. 